\title{
Proceeding for Recent Trends in Biomedical Sciences-2018 (RTBS-2018)
}

16th March 2018

(Friday)

\section{ABSTRACT BOOK}

Organized by

Organised by Department of Medical Laboratory Sciences, Lovely Professional University Punjab

At

Smt. Shanti Devi Mittal Auditorium, Lovely Professional University

Punjab

Published by

Asian Journal of Pharmaceutical \& Clinical Research

www.ajpcr.com

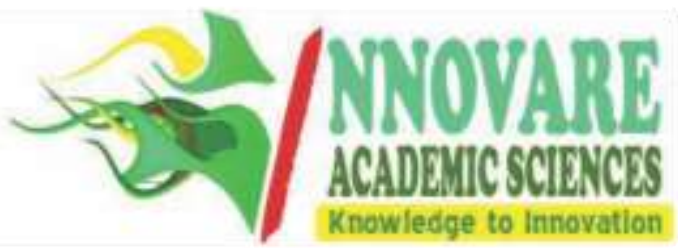




\section{RTBS-2018 ORGANIZING COMMITTEE}

\begin{tabular}{|c|c|}
\hline \multicolumn{2}{|c|}{$\begin{array}{c}\text { Chief Patron } \\
\text { Shri Ashok Mittal } \\
\text { Honourable Chancellor, Lovely Professional University }\end{array}$} \\
\hline \multicolumn{2}{|c|}{$\begin{array}{c}\text { Patrons } \\
\text { Smt. Rashmi Mittal } \\
\text { Pro -Chancellor, Lovely Professional University } \\
\text { Dr. Ramesh Kanwar } \\
\text { Vice Chancellor, Lovely Professional University }\end{array}$} \\
\hline \multicolumn{2}{|c|}{$\begin{array}{c}\text { Chairperson } \\
\text { Dr. Monica Gulati } \\
\text { Sr. Dean, LFAMS, Lovely Professional University }\end{array}$} \\
\hline \multicolumn{2}{|c|}{$\begin{array}{c}\text { Ioint Secretary } \\
\text { Mr. Gurinder Singh } \\
\text { COD, Medical Laboratory Sciences, Lovely Professional University }\end{array}$} \\
\hline \multicolumn{2}{|c|}{$\begin{array}{c}\text { Organizing Secretory } \\
\text { Dr. Pranav Kumar Prabhakar }\end{array}$} \\
\hline $\begin{array}{l}\text { Finance \& Sponsorship Committee } \\
\text { Mr. Naresh Kumar* } \\
\text { Dr. Saurabh Saxena } \\
\text { Mr. Dinobandhu Nandi } \\
\text { Dr. Pranav Kumar Prabhakar } \\
\text { Ms. Hem Lata }\end{array}$ & $\begin{array}{l}\text { Scientific Committee } \\
\text { Dr. Saurabh Saxena* } \\
\text { Dr. Manish Vya** } \\
\text { Dr. Gopal Lal Khatik } \\
\text { Mr. Suresh Mani } \\
\text { Dr. Anania Arjuna } \\
\text { Dr. Pranav Kumar Prabhakar }\end{array}$ \\
\hline $\begin{array}{l}\text { Souvenir and Publication Committee } \\
\text { Mr. Thomson Soni* } \\
\text { Mr. Naresh Kumar }\end{array}$ & $\begin{array}{l}\text { Registration \& Reception Committee } \\
\text { Ms. Savita Devi* } \\
\text { Mrs. Anujot Kaur* } \\
\text { Mr. Naresh Kumar } \\
\text { Ms. Manju } \\
\text { Ms. Ravina Taak } \\
\text { Ms. Hem Lata } \\
\end{array}$ \\
\hline $\begin{array}{l}\text { Hospitality \& Accommodation } \\
\text { Ms. Jyoti Lakhanpal } \\
\text { Mr. Narendra Pandey* } \\
\text { Mr. Ammar Sohail }\end{array}$ & $\begin{array}{l}\text { Catering \& Transport } \\
\text { Mr. Dinobandhu Nandi* } \\
\text { Mr. Dileep Singh Baghel* } \\
\text { Mr. Thomson Soni } \\
\text { Ms. Savita Devi } \\
\text { Ms. Ravina Taak }\end{array}$ \\
\hline $\begin{array}{l}\text { Venue \& Cultural Event Management } \\
\text { Dr. Anania Arjuna* } \\
\text { Dr. SurajPal* } \\
\text { Ms. Mani Wadhba } \\
\text { Mrs. Anujot Kaur }\end{array}$ & $\begin{array}{l}\text { Website Management \& Media } \\
\text { Publicity } \\
\text { Mr. Pradeep Sharma* } \\
\text { Mr. Harpreet Singh* } \\
\text { Ms. Manju } \\
\text { Dr. Pranav Kumar Prabhakar }\end{array}$ \\
\hline
\end{tabular}




\section{INDEX}

\begin{tabular}{|c|c|c|}
\hline Abstract No. & Title & Page No. \\
\hline \multicolumn{3}{|c|}{ Oral Presentations } \\
\hline RTBS-0-01 & Improved Technique of Tissue Processing for Histopathology Analysis & 1 \\
\hline RTBS-0-02 & Structural Characterisation of 5-HT2A receptor in Homo sapiens by in silico method & 2 \\
\hline RTBS-0-03 & $\begin{array}{l}\text { Effect of Releasing the Superficial Front Fascial Line on Improving Shoulder Pain and } \\
\text { Dysfunction }\end{array}$ & 3 \\
\hline RTBS-0-04 & $\begin{array}{l}\text { Prevalence and drug resistance in Acinetobacter sp. isolated from ICU patients in } \\
\text { Punjab, India }\end{array}$ & 4 \\
\hline RTBS-0-05 & $\begin{array}{l}\text { Structural Comparison of Prokaryotic and Eukaryotic Folate transporters by } \\
\text { Computational Approach }\end{array}$ & 5 \\
\hline RTBS-0-06 & $\begin{array}{l}\text { Web Plot Digitizer Software: Can it be Used to Measure Neck Posture in Clinical } \\
\text { Practice? }\end{array}$ & 6 \\
\hline RTBS-0-07 & $\begin{array}{l}\text { A Comparative Study of Stereo-Chemical Effect of Anti-Prostate Agents By Molecular } \\
\text { Docking }\end{array}$ & 7 \\
\hline RTBS-0-08 & Cytokines: An approachable key player in rheumatoid arthritis & 8 \\
\hline RTBS-0-09 & $\begin{array}{l}\text { Safe and Effective Topical Delivery of Betamethasone Nano-colloidal Carrier: } \\
\text { Dermatological and Histological Evaluation }\end{array}$ & 9 \\
\hline RTBS-0-10 & Effects of selected vitamins on growth and heart rate modulation in Daphnia & 10 \\
\hline RTBS-0-11 & Mechanism of MERS-CoV and human host cell interaction, an in-silico analysis & 11 \\
\hline RTBS-0-12 & $\begin{array}{l}\text { Design and Performance Verification of Newly Developed Disposable Static Diffusion } \\
\text { Cell for Drug Diffusion/Permeability Studies }\end{array}$ & 12 \\
\hline RTBS-0-13 & $\begin{array}{l}\text { Antibiotic Resistance Pattern and Prevalence of Beta-lactamases among Clinical } \\
\text { Isolates of Enterobacteriaceae in a Tertiary Care Hospital in Western U.P. (India) }\end{array}$ & 13 \\
\hline RTBS-0-14 & $\begin{array}{l}\text { Physico-chemical, Qualitative and HPTLC Profile of Leaves and Root of Tylophora } \\
\text { indica (Burm. f) Merr. }\end{array}$ & 14 \\
\hline RTBS-0-15 & $\begin{array}{l}\text { Computer Assisted Drug Designing of Triazole Derivative of Noscapine as Tubuline } \\
\text { Binding Anti-Cancer Drug }\end{array}$ & 15 \\
\hline RTBS-0-16 & $\begin{array}{l}\text { Comparative Analysis of the Effect of Hypoxia Mimetic on Red and White } \\
\text { Gastrocnemius Muscle }\end{array}$ & 16 \\
\hline RTBS-0-17 & $\begin{array}{l}\text { Changes in the Heart rate and Cranio Sacral Rhythm in the Stressed and non - } \\
\text { Stressed Population: An experimental study }\end{array}$ & 17 \\
\hline RTBS-0-18 & $\begin{array}{l}\text { Evaluation of Antibacterial Activity of Leaf Extract of Limnophila conferta and Sida } \\
\text { acuta }\end{array}$ & 18 \\
\hline RTBS-0-19 & $\begin{array}{l}\text { Pharmaceutical Development, Standardization and In-vitro Antioxidant Evaluation of } \\
\text { Eladi Gutika }\end{array}$ & 19 \\
\hline RTBS-0-20 & $\begin{array}{l}\text { Development and validation of UV spectroscopic method of analysis for Curcumin in } \\
\text { Self nanoemulsifying drug delivery system }\end{array}$ & 20 \\
\hline RTBS-0-21 & Anti diabetic potential of different parts of calotropis procera (Aiton) & 21 \\
\hline RTBS-0-22 & The Dark Genome: Regulators of mammalian gene expression & 22 \\
\hline RTBS-0-23 & Nanomaterials Used in Cancer Therapy & 23 \\
\hline RTBS-0-24 & Application of QbD approach for the optimization of orodispersible film formulation & 24 \\
\hline RTBS-0-25 & Preservation of microbial spoilage of food by biosurfactant based coating & 25 \\
\hline RTBS-0-26 & Screening of In-vitro and In-vivo studies based on the antidiabetic activity of Louqat & 26 \\
\hline RTBS-0-27 & A Comparison of Drug Release: Microparticles Vs Nanoparticles & 27 \\
\hline RTBS-0-28 & Fact or Myth: Is Croton tiglium L. Poisonous? & 28 \\
\hline RTBS-0-29 & Anti Diabetic potential of different parts of Calotropis Procera (Aiton) & 29 \\
\hline RTBS-0-30 & Mycobacterium tuberculosis: Havoc to Human Health & 30 \\
\hline \multicolumn{3}{|c|}{ Poster Presentation (Morning Session) } \\
\hline RTBS-P-01 & Therapeutic potential of PDE5 inhibitors (PDE5i): Promising Perspectives & 31 \\
\hline RTBS-P-02 & Relationship of TSH with BMI in Subclinical Hypothyroid patients & 32 \\
\hline RTBS-P-03 & Mechanism and models of neuropathic pain: Recent updates & 33 \\
\hline RTBS-P-04 & $\begin{array}{l}\text { Mechanism of Abscisic Acid Signalling in Response to Abiotic Stresses in Plants with } \\
\text { Special Reference to Cadmium Toxicity }\end{array}$ & 34 \\
\hline RTBS-P-05 & $\begin{array}{l}\text { Neurotransmitters and chemical mediators of inflammation: The therapeutic targets } \\
\text { in neuropathic pain }\end{array}$ & 35 \\
\hline
\end{tabular}


RTBS-P-06

RTBS-P-07

RTBS-P-08

RTBS-P-09

RTBS-P-10

RTBS-P-11

RTBS-P-12

RTBS-P-13

RTBS-P-14

RTBS-P-15

RTBS-P-16

RTBS-P-17

RTBS-P-18

RTBS-P-19

RTBS-P-20

RTBS-P-21

RTBS-P-22

RTBS-P-23

RTBS-P-24

RTBS-P-25

RTBS-P-26

RTBS-P-27

RTBS-P-28

RTBS-P-29

RTBS-P-30

RTBS-P-31

RTBS-P-32

RTBS-P-33

RTBS-P-34

RTBS-P-35

RTBS-P-36

RTBS-P-37

RTBS-P-38

RTBS-P-39

RTBS-P-40

RTBS-P-41

RTBS-P-42

RTBS-P-43

RTBS-P-44

RTBS-P-45

RTBS-P-46

RTBS-P-47

RTBS-P-48

RTBS-P-49

RTBS-P-50
Co-administration of curcumin and sildenafil ameliorates behavioral and biochemical alterations in the rat model of alcoholic neuropathy

Formulation, systematic optimization, in-vitro, ex-vivo and stability assessment of transethosome based gel of curcumin

Clinical Evaluation and Comparison of Infectious Biomarkers in Sepsis Patients

Admitted to Super-Speciality Hospital in Punjab

Finite Element Analysis of porous bone scaffold

Different Roles of miRNA in the Hepatitis C Infection

Recreational Activity and Yoga: An Avenue to Prevent Criminal Propensity among Drug Addicts

Phytochemical Screening, In-vitro Antibacterial Activity and Antioxidant Activity of essential oil from leaves of Ajuga parviflora Benth

Assessment of in vitro antibacterial and antifungal activity of Curcuma caesia Roxb

Role of Gold nanoparticles in theranostic: An Update

An Overview of various techniques used to prepare gold nanoparticles

Clinical Significance of Carica papaya Leave Extract in Thrombocytopenia Induced by Dengue

Modified Apple Polysaccharide: Role in Treatment of Colonic Diseases

Surface Engineered PPI Dendrimers in Cancer Treatment: Formulation Development and Characterization

Protein based nanocarriers for drug delivery: An Overview

Lecithin Based Ultradeformable Carriers - A Unique Vesicle for Transdermal Delivery through Stratum Corneum

Pharmaceutical Approach for Treatment of Chronic Disease: Hypertension by Chronotherapy

ECG signal based characterization of Coronary Artery Disease

Relationship of Seminal fructose and Serum prolactin levels in infertile men

Strategies to Overcome the Solubility Issue of Drug

In - Vitro Anti - Cancer Studies of Ethanolic extract of peel of Allium cepa on

Colorectal Cancer Cell Line (Caco-2)

Nitofurantoin resistance in urinary tract infections

Potential preclinical and clinical toxicity of metallic nanoparticles

Historical Perspective, Prevalence, Risk Factors and Special Reference on

Pathophysiology of Gestational Diabetes Mellitus

Prevalence of Dyslipidemia in Diabetes mellitus type2, Obesity and Hypertension

Isolation and characterization of microorganism from hand and utensil samples of

food vendors and their resistance to common used antimicrobials

Significance of Cryopreservation in the Field of Assisted Reproductive Technology

Co-crystals: Role in drug development

Prediction of Anti-Parkinson Potential of Phytoconstiuents Using PASS Online

Program

Structure activity relationship study of Sodium-dependent Glucose Co-transporter-2

(SGLT-2) inhibitors as antidiabetic agent

Stem cell Therapy: A Potential boon for Metastatic Breast Cancer

Musculoskeletal Disorders among University Student Using Long -Term and Short-

Term Personal Computer

Formulation, characterization and in vitro antioxidant evaluation of polyherbal based lozenges for treatment of stress

Design, formulation, and pharmacokinetic evaluation of bilayer tablet of Fexofenadine $\mathrm{HCl}$ and Montelukast sodium

Microneedle: A Novel Platform for Transdermal Drug Delivery System

Investigation and optimization of formulation parameters for self-nanoemulsifying

delivery system of Curcumin-Duloxetine using Box-Benken Design

Study of electrolytes and liver function tests in chronic alcoholism

A novel multiplex PCR for simultaneous detection of Dengue and 
antibacterial agents

RTBS-P-51

RTBS-P-52

RTBS-P-53

RTBS-P-54

RTBS-P-55

RTBS-P-56

RTBS-P-57

RTBS-P-58

RTBS-P-59

RTBS-P-60
Quest of Immunosuppressive Anti-Cancer Drugs In SOTR: A Systematic Review

Rheumatoid Arthritis: An Autoimmune Disease

Pharmaceutical co-crystal: An emerging trend in pharmaceutics

Preliminary studies on generation of glimepiride cocrystals

dentification of possible molecular targets of potential antiparkinson drugs by

predicting their binding affinities using molecular docking technique

An overview of system designing of latest infusion system, sealant and hemostasis used for biomedical application

\section{Poster Presentation (Evening Session)}

\section{RTBS-P-61}

RTBS-P-62

RTBS-P-63

RTBS-P-64

RTBS-P-65

RTBS-P-66

RTBS-P-67

RTBS-P-68

RTBS-P-69

RTBS-P-70

RTBS-P-71

RTBS-P-72

RTBS-P-73

RTBS-P-74

RTBS-P-75

RTBS-P-76

RTBS-P-77

RTBS-P-78

RTBS-P-79

RTBS-P-80

RTBS-P-81

RTBS-P-82

RTBS-P-83

RTBS-P-84

RTBS-P-85

RTBS-P-86

RTBS-P-87

RTBS-P-88

RTBS-P-89

RTBS-P-90

RTBS-P-91

RTBS-P-92

RTBS-P-93

RTBS-P-94

RTBS-P-95

Ileo-colonic targeted granules of Berberine for Chronotherapeutic treatment of Rheumatoid Arthritis

Role of Data Integrity in Quality Assurance: An overview

Characterisation Evaluation of Dendrimers

93

Stem Cell Therapy: Working for Joint Pain, Alzheimer's disease, Heart Disease and Diabetes

Extraction methods of Natural Polymers used as Pharmaceutical

Superdisintegrants

Synthesis of copper nanoparticles using ascorbic acid and cetyl trimethyl

ammonium bromide

Development and Evaluation of Emulgels for Treatment of Viral Born Skin Disease Wart

A Review of Medical Plants with Potential Antidiabetic Activity

Assessment of Dengue Fever: Natural and Herbal Remedies

A Survey on Metabolic Syndrome in Jammu \& Kashmir

95

96

97

98

99

100

Comparative study of an immunochromatographic Assay with Enzyme-Linked

Immunosorbent assay for the Detection of HBSAg in NMCH Bihar

Vitamin D deficiency - A risk factor for type 2 diabetes mellitus

Co-relation between obesity and hypertension

104

105

Potential preclinical and clinical toxicity of metallic nanoparticles

106

An over view of pharmaceutical uses of Allicin and its method of isolation

treatment of Rheumatoid arthritis: A review

Subdermal buprenorphine implant: Suitable alternative in the management of opioid addiction

Comparative evaluation of marketing approval process for the pharmaceutical products in regulated and semi regulated countries

Artificial Intelligence: Machine Intelligence Contrast to Natural Intelligence and

Future in Pharmacy

Circadian rhythm: endogenous and zeitgebers

Iontophoresis: current and novel approach to skin penetration

Development and application of recombinant DNA technology in pharmaceuticals

Implications of sigma receptors ligands in cardiovascular diseases

Gene Therapy: New possibilities and future expectations

Screening Of In-vitro Antioxidant and Anti-inflammatory Activities of

Hinguleshwara rasa

Prevalence of psychological distress and its associated factors in hypertensive patients: A survey at SPS Hospitals, Ludhiana

Novel medium designing for the cultivation of some economically important fungal species 


\begin{tabular}{|c|c|c|}
\hline RTBS-P-96 & Gene Therapy & 126 \\
\hline RTBS-P-97 & Development and Evaluation of Levocetrizine dihydrochloride Microsphere & 127 \\
\hline RTBS-P-98 & Orodispersible Tablets: A new trend in Fast Dissolving Tablet system & 128 \\
\hline RTBS-P-99 & $\begin{array}{l}\text { Formulation Development and Evaluation of Antihypertensive Drug Loaded Multi- } \\
\text { walled Carbon Nanotubes }\end{array}$ & 129 \\
\hline RTBS-P-100 & SNEDDS: An Approach to Enhance Bioavailability & 130 \\
\hline RTBS-P-101 & Biomarkers for Alzheimer's Disease & 131 \\
\hline RTBS-P-102 & Role of Vein Finder Device in Medical Sciences As Well As in Forensic Sciences & 132 \\
\hline RTBS-P-103 & Ledebouria ovatifolia (Baker) Jessop used in the Healing of Peptic Ulcer & 133 \\
\hline RTBS-P-104 & Nanosuspension: - A Loom for the Improving the Bioavailability of Drugs & 134 \\
\hline RTBS-P-105 & Stem Cell Therapy: Advanced Approaches in Medical Treatment & 135 \\
\hline RTBS-P-106 & Relation between air pollution and cardiovascular disease & 136 \\
\hline RTBS-P-107 & Cosmetovigilence in Ayurveda & 137 \\
\hline RTBS-P-108 & Biosensors: Effective tool in diagnostic evaluation in health sciences & 138 \\
\hline RTBS-P-109 & Recent advancements in the detection of type 2 diabetes mellitus: A review & 139 \\
\hline RTBS-P-110 & $\begin{array}{l}\text { Combination therapy: Synergistic effect of synthetic drug and natural } \\
\text { phytochemicals for the treatment of diabetes mellitus }\end{array}$ & 140 \\
\hline RTBS-P-111 & $\begin{array}{l}\text { Comparison of removal of crystal violet on processed and unprocessed, cost } \\
\text { effective agro-waste, wheat bran }\end{array}$ & 141 \\
\hline RTBS-P-112 & $\begin{array}{l}\text { Food Packaging Formulation Using Chitosan in Conjugation with a Biological } \\
\text { Antimicrobial Agent }\end{array}$ & 142 \\
\hline RTBS-P-113 & A review: Genetic engineering and its medical applications & 143 \\
\hline RTBS-P-114 & $\begin{array}{l}\text { Colon specific drug delivery system (CSDDS) for the treatment of Rheumatoid } \\
\text { Arthritis (RA) }\end{array}$ & 144 \\
\hline RTBS-P-115 & Advancement in nanotechnology and its role in drug delivery: A Review & 145 \\
\hline RTBS-P-116 & $\begin{array}{l}\text { Allied Health Professionals in Health Sector: An Overview with emphasis on Need of } \\
\text { redefining India's health service paradigm }\end{array}$ & 146 \\
\hline RTBS-P-117 & Circulation of Contaminated Currency Notes & 147 \\
\hline RTBS-P-118 & $\begin{array}{l}\text { Influence of formulation parameters on dissolution rate enhancement of Acyclovir } \\
\text { using liquisolid formulation }\end{array}$ & 148 \\
\hline RTBS-P-119 & $\begin{array}{l}\text { Potential of Plant growth-promoting rhizobacteria (PGPR): As antagonists and } \\
\text { biocontrol agents }\end{array}$ & 149 \\
\hline RTBS-P-120 & $\begin{array}{l}\text { Evaluation of Antagonistic Potential of Soil Bacteria against Pathogenic Fungus: } \\
\text { Candida albicans }\end{array}$ & 150 \\
\hline RTBS-P-121 & $\begin{array}{l}\text { Design of Microparticulated Salbutamol Sulphate pH Sensitive Pulsatile Delivery } \\
\text { System for Chronotherapy of Nocturnal Asthma }\end{array}$ & 151 \\
\hline
\end{tabular}




\title{
IMPROVED TECHNIQUE OF TISSUE PROCESSING FOR HISTOPATHOLOGY ANALYSIS HARPREET SINGH*, NARESH KUMAR, PRANAV KUMAR PRABHAKAR
}

Department of Medical Laboratory Sciences, Lovely Professional University, Punjab, India.Email: harpreet1.singh@lpu.co.in;

\begin{abstract}
The main aim of the tissue processing is to make the tissue hard by removing the water contents and replace it with a hard material, so that, it can be cut into thin section for histopathological examination after staining. The steps involved in tissue processing includes, dehydration, clearing, infiltration/impregnation and finally embed in hard material to give internal and external support to tissue during section cutting. The purpose of the study is to look for the fasten the processing time so that tissue remains in the chemicals for shortest possible time, so that, the tissue architecture should not affected. Earlier the study was conducted on two types of animal tissue fixed in $10 \%$ formalin and without formalin kept in deep freezer. At present time study was conducted using human tissue. About 20-40 samples of human tissue has been processed and the timing of processing has been reduced to near about 3.5hours using acetone, chloroform and paraffin wax as dehydrating, clearing and embedding agents. The routine and most widely method of tissue processing takes about 11-12 hours of using alcohol, xylene and paraffin wax. After processing sections were cut more easily as compare to the routine method. The sections are stained with Haematoxylin and Eosin stain.
\end{abstract}

Keywords: Tissue processing; dehydration; clearing, infiltration; haematoxylin and eosin stain. 


\title{
STRUCTURAL CHARACTERISATION OF 5-HT2A RECEPTOR IN HOMO SAPIENS BY IN SILICO METHOD
}

\author{
SONI SINGH, ALOK JHA*
}

Department of Biotechnology and Life Sciences, Mangalayatan University, Extended NCR 33rd Milestone, Aligarh-Mathura Highway, Beswan, Aligarh-202145, India. Email: alok.jha@managalayatan.edu.in

\begin{abstract}
5-HT2A receptor is primarily involved in uptake and transport of serotonin molecule from nerve cell to extracellular fluid. In the present study we characterise 5-HT2A receptor by using different in silico methods. The study involved 5-HT2A homology Model prediction by: Modeller 9.14, Swiss Model server, Phyre2 and Geno3D. The homology models of 5-HT2A were evaluated by Procheck, ERRAT, Qmean score and Ramachandran Plot analysis. We compared all different models. Further structural analysis suggested that the structure of 5HT2A is a monomer with 18 alpha helices, 7 beta sheets and 1 disulphide bridge. There is no signal peptide region in the protein sequence.The structure contains mostly polar and aromatic amino acid as suggested by hydropathy plot. However, in both the partioning system bilayer to water and water to bilayer, there are some hydropathy predicted segments, which are also transmembrane segments. Finally the pore features including diameter profile, size, and shape were determined by porewalker and the shape of the pore was found to be UDSD.The study suggested that 5-HT2A receptor interaction with its natural ligand serotonin and other inhibitor compounds would further add information about GPCRs. 5-HT2A receptor could be an important target for therapeutics development.
\end{abstract}

Keywords: 5-HT2A receptor, Homology Modelling, Ramachandran Plot, Profunc, Hydropathy Plot 


\title{
EFFECT OF RELEASING THE SUPERFICIAL FRONT FASCIAL LINE ON IMPROVING SHOULDER PAIN AND DYSFUNCTION
}

\author{
MINAL RAJEN SHAH
}

Hindusabha hospital, Ghatkopar West, Mumbai 40086, Maharashtra. Email: officialminals@gmail.com

\begin{abstract}
Shoulder pain is the third most common musculoskeletal condition having a lifetime prevalence of up to $70 \%$ and this seems to be increasing in incidence, rotator cuff strain caused by overuse and stressful triggers in common middle age population, and the objective of this study is to find out the efficacy of myofascial meridians in which superficial front line helps improve shoulder pain and dysfunction. Purpose of the study is to reduce shoulder dysfunction through the release of myofascial meridian SFL an experimental study design was adapted for this work. convenient sampling, pre and post-test, study population is between 20 to 50 years of age, 10 samples were taken, statistical analysis was done by an independent't' test, outcome measures used were SPADI scale, VAS, WONG BAKER FACES pain scale.10 patients who participated in the study, all are reported shoulder pain and functional impairment, out of that 30\% of the patients reported delayed recovery who were chronic patients, $70 \%$ patients who are all obese. The mean score of shoulder pain and disability index for the respondents with shoulder pain is $40.43 \pm 21.83$. This study concluded that the Manual concept of myofascial release of SFL plays a major role in improving the patients with shoulder pain \& dysfunction and further study can be done in large samples.
\end{abstract}

Key words: Shoulder pain ,SFL, MFR, SPADI scale, Faces scale, fascia. 


\author{
PREVALENCE AND DRUG RESISTANCE IN ACINETOBACTER SP. ISOLATED FROM ICU \\ PATIENTS IN PUNJAB, INDIA \\ TANVIR KAUR $^{1 *}{ }^{*}$ CHAYANIKA PUTATUNDA ${ }^{2}$, AROMA OBEROI ${ }^{3}$, ASHISH VYAS ${ }^{1}$, GAURAV KUMAR ${ }^{1}$
}

1Department of Microbiology, School of Bioengineering and Biosciences, Lovely Professional University, Phagwara 144402, Punjab, India. ${ }^{2}$ Department of Microbiology, DAV University, Jalandhar 144012, Punjab, India. ${ }^{3}$ Department of Microbiology, Christian Medical College and Hospital, Ludhiana 141008, Punjab, India.E. mail: tanvir.nanaksar1313@gmail.com

\begin{abstract}
Acinetobacter sp. is an important nosocomial, opportunistic pathogen quite prevalent in patients admitted to intensive care unit (ICU). Various species of Acinetobacter (A. baumanii, A. iwoffii and A. haemolyticus) have been reported to cause iatrogenic meningitis, septicemia, and pneumonia, wound infections, urinary and genital infections. The Acinetobacter sp. has gained recent impetus on account of its innate ability to display resistance against commonly used antibiotics. Therefore, the aim of present study was to estimate the prevalence and determine antibiotic susceptibility of the Acinetobacter sp. isolated from the ICU patients of a tertiary care hospital, Ludhiana, Punjab. During this study, a total of 298 clinical samples were collected and subjected to isolation and characterization of microorganisms by the classical culture methods. Amongst 298 samples, 69 samples (23.15\%) were found to be positive in routine culture while 29 (9.73\%) of them were found to be positive for Acinetobacter sp. Antimicrobial susceptibility testing (AST) suggested that isolated Acinetobacter sp. were resistant towards various first, second and third line antibiotics while colistin and polymyxin-B were found to be the most effective drugs. The above results represent Acinetobacter sp. as a highly prevalent microorganism among the hospitalized patients while its potential to acquire resistance toward commonly used antibiotics represent it as a serious threat to the healthcare industry, therefore signifying the need for its regular monitoring in the healthcare setups.
\end{abstract}

Keywords: Acinetobacter sp.; Intensive care unit (ICU); Nosocomial or hospital acquired infections (HAIs); Drug resistance 


\title{
STRUCTURAL COMPARISON OF PROKARYOTIC AND EUKARYOTIC FOLATE TRANSPORTERS BY COMPUTATIONAL APPROACH
}

\author{
DEEPA AGARWAL, ALOK JHA*
}

Department of Biotechnology and Life Sciences, Mangalayatan University, Extended NCR 33rd Milestone, Aligarh-Mathura Highway, Beswan, Aligarh-202145, India. Email: alok.jha@managalayatan.edu.in

\begin{abstract}
Computational modelling technique has become an integral part of modern molecular research. In silico approach has particularly drawn attention in providing a realistic representation needed to understand the fundamental molecular structure of a transporter. Folate is one of the vitamin $\mathrm{B} 9$ essential for DNA synthesis whose absorption is mediated by the membrane transporters of various family in different parts of human body. Taken into consideration the importance of folate metabolism and role in internalization of antifolates in prokaryotes and eukaryotes; the structural study of folate transporters in Homo sapiens, Plasmodium falciparum and Streptococcus sp. has been accomplished and verified using different software. The structure has been generated using Modeller and Swiss model and visualised using PyMol. The models were valid ated by Procheck and ERRAT analysis along with the values of different secondary structures mapping to diverse sections of the Ramachandran plot. The structural comparison was performed by TM Score indicating 2.90, 2.65 and 3.19 RMSD values in Humans, Plasmodium and Streptococcus. The structural comparison analysis included secondary structure and topology analysis which was carried out by PDBsum. The evaluation of transmembrane helices and hydrophobicity was done using TMHMM and Protscale resulting into the presence of 1, 4 and 12 membrane spanning segments in Plasmodium, Streptococcus and Humans. Pore features including diameter profiles, pore lining residues, size, shape and regularity of pore was calculated using Pore Walker showing pore shape as UDS, US and UDUD in Humans, Plasmodium and Streptococcus. Such folate receptors are the main targets for specific conveyance of antifolates or its conjugates which may be developed as submeningeal haemorrhage, impaired thrombopoiesis and cancer therapeutics.
\end{abstract}

Key Words: Folate Transporters, antifolates, structural study, software 


\title{
WEB PLOT DIGITIZER SOFTWARE: CAN IT BE USED TO MEASURE NECK POSTURE IN CLINICAL PRACTICE?

\author{
SURESH MANI ${ }^{1}$, SHOBHA SHARMA ${ }^{2}$, DEVINDER KAUR AJIT SINGH ${ }^{2}$
}

${ }^{1}$ School of Physiotherapy, Lovely Professional University, Phagwara-144411, Punjab, India. ${ }^{2}$ School of Rehabilitation Sciences, Faculty of Health Sciences, Universiti Kebangsaan Malaysia, Kuala Lumpur, Malaysia. Email: shobha.sharma@ukm.edu.my

\begin{abstract}
The software is an integral part of quantitative forward head posture (FHP) evaluation in clinical practice. Most software reported in the literature are paid versions, require special skills for usage or are in languages other than English and thus may impede adoption in regular clinical practice.

The aim of this study was to evaluate Web Plot Digitizer (WPD) software in assessing forward head posture in a clinical setting. A total of 15 normal subjects were recruited. Using digital photogrammetry, sagittal head tilt, craniocervical, and shoulder angles were measured using web plot digitizer, an open resource of web or window based software. Sagittal head tilt and craniocervical angles were $16.35 \pm 8.33^{\circ}$ and $47.43 \pm 7.97{ }^{\circ}$ respectively. The shoulder angle was $52.28 \pm 12.46^{\circ}$. The cranio-cervical angles indicate the presence of mild FHP posture even among the healthy subjects. This preliminary result using WPD software suggests that it may be adopted in the current clinical practice to evaluate quantitative FHP using digital photogrammetry method. However, future research should determine the validity and reliability of WPD among patients with neck related musculoskeletal disorders with a larger sample.
\end{abstract}

Key words: Forward head posture, quantitative, photogrammetry, software, web plot digitizer 


\title{
A COMPARATIVE STUDY OF STEREO-CHEMICAL EFFECT OF ANTI-PROSTATE AGENTS BY MOLECULAR DOCKING
}

\author{
OLUWASEUN S. OSANYINPEIU*, ROQIA BASHARY, AMIT MITTAL, MANISH VYAS, SURENDRA KUMAR NAYAK, \\ GOPAL L. KHATIK
}

School of Pharmaceutical Sciences, Lovely Professional University, Punjab.Email: sseun17@gmail.com

\begin{abstract}
Prostate cancer is the leading cause of deaths in men. There are various factors which may lead to prostate cancer. Among these factors, overexpression of androgen or induction of its activity is proposed to be the main cause. The androgen receptors which are present in the prostate gland are responsible for androgen activity. Anti-prostate agents used in the treatment of prostate cancer are classified as steroidal and nonsteroidal. Non-steroidal shows better activity and fewer side effects as compared to steroidal agents. They show better affinity to the protein i.e. androgen receptor proteins present in the prostate gland. Recently reported anti-prostate cancer agents have shown the stereo-chemical effect as it is well known that stereochemistry plays critical role in the bioactivity. In the present research work, we studied the various anti-prostate cancer agents which were having one or two stereocentre and studied the effect of stereochemistry on binding affinity to androgen receptor through molecular docking. Autodock Vina molecular docking software was used to determine the binding affinity at $1 \mathrm{z} 95$ protein. All studied molecules have shown the stereo-chemical implication on binding affinity. The molecules with $R$-stereochemistry showed better binding affinity at $1 z 95$ protein compare to $S$ - stereoisomers and this trend was well supported by the standard drug Bicalutamide also. Thus while designing the antiprostate cancer agents we must look upon the stereochemistry of ligand.
\end{abstract}

Keyword: Stereochemistry, Prostate cancer, Molecular docking, Autodock Vina 


\title{
CYTOKINES: AN APPROACHABLE KEY PLAYER IN RHEUMATOID ARTHRITIS DINOBANDHU NANDI
}

Department of Medical Laboratory Sciences, Lovely Professional University, -144411, Punjab.Email: dinobandhu.22003@lpu.co.in

\begin{abstract}
Rheumatoid arthritis (RA) is a chronic progressive autoimmune disease which affects the body systematically and has the characterizations of inflammation that is associated with articular and extra-articular damages and has 1\% prevalence in the industrialized world. RA is called a syndrome which comprises pain, stiffness and synovitis of diarthrodial joints which comorbid with cardiovascular, neurologic, and metabolic involvement. The immune system is strongly associated with the disease progression and its onset. Pathogenetic and genetic studies have been suggested that impairment in innate as well as the adaptive immune system is the reason for autoimmunity in RA, and these events can predate the clinical onset by up to one decade. The autoimmune aspect of RA is proven by recognition of HLA-DR subtypes which indicate the involvement of the APCs in RA. Upon activation of cells, they release a variety of cytokines and chemokines. Cytokines are the most potent biomarker that is associated with RA pathogenesis. They are small proteins involved in cell signalling and possess autocrine and paracrine effects. The event of RA pathogenesis is initiated with the activation of innate immune response where antigen-presenting cells (APCs) are activated by antigens. APCs process the antigen by specific pathway and present it to T-cells which results in liberation of cytokines (commonly pro-inflammatory cytokines). The major cytokines released as a result of cell-cell interaction are implicated in the pathogenesis of RA. Pro-inflammatory cytokines like TNF- $\alpha$, IL1, IL-6, IL-12, IL-15, IL- 17, IL-18, IL-22, and IL-32 are the major identified cytokine that is predominantly found in patients with RA and they play a significant role in pathogenesis. Regulatory cytokines are also associated with the pathogenesis, their dysregulation leads to the more severe form of the disease. The blocking of these biomarkers is suggestive for the inhibition of progression of the active disease. The therapeutic use of Etanercept, Adalimumab, Anakira, Infliximab targets the biomarkers and efficiently manage the disease progression. Some drugs are in phase II clinical trials which target the cytokines and associated biomarkers to prevent the degree of severity of RA pathogenesis.
\end{abstract}

Keywords: Biomarker, pannus, pro- inflammatory cytokine, chemokine, antigen presenting cell. 


\title{
SAFE AND EFFECTIVE TOPICAL DELIVERY OF BETAMETHASONE NANO-COLLOIDAL CARRIER: DERMATOLOGICAL AND HISTOLOGICAL EVALUATION
}

\author{
SHEETU WADHWA ${ }^{1}$, BHUPINDER SINGH ${ }^{2}$, SACHIN SINGH ${ }^{1}$, DEEP SHIKHA SHARMA ${ }^{1}$, AND OM PRAKASH \\ KATARE $^{2}$
}

1School of Pharmaceutical Sciences, Lovely Professional University, Phagwara - 144411, Punjab, India.2 Drug Delivery Research Group, University Institute of Pharmaceutical Sciences, Panjab University, Chandigarh 160 014, India.Email: sheetu.21001@lpu.co.in

\begin{abstract}
Topical steroidal anti-inflammatory drugs like Betamethasone (BTM) are highly prevalent in a number of skin disorders and diseases, because of their proven efficacy. But they simultaneously suffer from serious limitations such as skin atrophy, irritation and improper absorption. Hence forth, this piece of work aims to evolve a formulation strategy based on the principles of novel drug delivery and exploitation of unique biomaterials like phospholipids to circumvent the problems while improving the overall performance. Various nano-lipoidal carriers loaded with BTM were prepared by thin-film hydration (liposomes and transfersomes). The developed carriers were characterized for micromeritics, morphology and drug loading potential. Topical delivery attributes were evaluated by skin permeation and skin retention studies employing mice skin. Developed systems were evaluated for bio-safety studies on shaved Laca mice. Anti-psoriatic activity was also performed on mouse-tail model and evaluated histopathologically. The formulations were assessed for stability as per ICH guidelines. All the colloidal carriers were found to lie in the optimum size with almost regular geometry. The topical drug transport characteristics of colloidal carriers were found to be significantly better than the marketed product. These carriers were better tolerated as no histopathological changes were observed in the mice skin samples. These offered better skin retention in the form of micro-reservoirs for prolonged stay. A significant enhancement in the anti-psoriatic activity was observed vis- $a$ vis the commercial one. The developed carriers were found to stabilize the entrapped drug. These delivery benefits may scientifically be attributed to the changes brought forth in the drug molecules at the level of physicochemical characteristics which would modify the kinetics leady to improved pharmacodynamic efficacy. Nano-colloidal carriers based on biocompatible lipids were able to increase the safety and efficacy of BTM.
\end{abstract}




\title{
EFFECTS OF SELECTED VITAMINS ON GROWTH AND HEART RATE MODULATION IN DAPHNIA

\author{
KHAIDEM DEVIKA CHANU ${ }^{1}$, GYANESH SINGH $^{2 *}$
}

1 Zoological Survey of India, Kolkata, West Bengal, India.2School of Bioengineering and Biosciences, Lovely Professional University, Phagwara, Punjab 144411, India. Email: gyanesh.15278@lpu.co.in

\begin{abstract}
Daphnia is a water crustacean that is commonly present in freshwater bodies all over the world. These organisms can be cultured in the lab, and are used as a model organism for different types of research. Because of their aquatic habitat, and sensitivity towards water pollution, Daphnia is often used for monitoring the water quality. The size of these zooplanktons ranges from $0.5 \mathrm{~mm}$ to $5 \mathrm{~mm}$. Their chitin body cover is transparent, therefore, it is possible to visualize and monitor their internal organs as well as heart beat using a live cell imaging microscope. Haemoglobin of these organisms is extracellular, and, when haemoglobin production increases during stressed conditions, they might appear reddish in colour. We evaluated the effect of selected vitamins including biotin, Pyridoxine, Vitamin A,Vitamin C, Vitamin D3, Vitamin E on the growth and/or the heart rate of Daphnia. Our results indicate that these vitamins not only affect the heart rate, but also synergize in certain cases to modulate the heart rates of Daphnia. Although, the effect of these vitamins on the growth of Daphnia was not drastic at lower concentrations, higher concentrations of these vitamins were observed to be very toxic. Literature survey indicate that such heart rate modulations have not reported in humans. Therefore, this study can have important implications. Such studies, when replicated in humans, can have important therapeutic and diagnostic significance. Because of higher incidence of cardiac disorders in humans, detailed investigation of such cardiomodulatory effects is required.
\end{abstract}

Keywords: Daphnia, heart rate modulation, vitamins, Pyridoxine, hemoglobin 


\title{
MECHANISM OF MERS-COV AND HUMAN HOST CELL INTERACTION, AN IN-SILICO ANALYSIS SUKRIT SRIVASTAVA, MOHIT KAMTHANIA, NISHI SHARMA*
}

Mangalayatan University, Extended NCR 33rd Milestone, Aligarh-Mathura Highway, Beswan, Aligarh-202145, India.

\begin{abstract}
Middle East Respiratory Syndrome (MERS) is the recently know most alarming corona virus disease. MERS is caused by Middle East Respiratory Syndrome Coronavirus (MERS-CoV). So far MERS has caused three outbreaks in Saudi Arabia $(2013,2014)$ and in South Korea (2015). No successful and specific vaccine for MERS has yet been reported. In our present study we decipher the interaction mechanism of MERS-CoV with human host cell. In our study we have included Spike (S) glycoprotein and Envelope (E) proteins, which are directly involved in the host cell interaction. Interaction of these proteins with different human host cell proteins has been thoroughly studied by molecular docking. Molecular dynamics simulation analysis was performed to confirm the stable interaction of the viral and human host cell proteins. Overall we confirm by insilico analysis methods about S and E proteins being involved in human host cell interaction. Moreover, we have also performed structural characterization and conservancy analysis of eleven other MERS-CoV proteins, which are involved in viral proliferation in human host cell. Since these proteins are crucially involved in infection to human cells, they could also be used as vaccine to prevent MERS-CoV infection.
\end{abstract}

Key words: Middle East Respiratory Syndrome (MERS), Coronavirus, Molecular Docking, Molecular Dynamics (MD) simulation, Vaccine 


\title{
DESIGN AND PERFORMANCE VERIFICATION OF NEWLY DEVELOPED DISPOSABLE STATIC DIFFUSION CELL FOR DRUG DIFFUSION/PERMEABILITY STUDIES
}

\author{
ANKIT KUMAR YADAV ${ }^{1}$, VARUN GARG ${ }^{1}$, MONICA GULATI ${ }^{1}$, PARIKSHIT BANSAL ${ }^{2}$, KOMPAL BANSAL ${ }^{2}$, SACHIN \\ KUMAR SINGH $^{1,}{ }^{*}$, AMIT MITTAL ${ }^{1}$, RAKESH NARANG ${ }^{1}$, BIMLESH KUMAR ${ }^{1}$, NARENDRA KUMAR PANDEY ${ }^{1}$ \\ SHEETU WADHWA ${ }^{1}$, GOPAL LAL KHATIK ${ }^{1}$, MAYUKH BANERJEE ${ }^{1}$, SOUVIK MOHANTA1, SHUBHAM SINHA ${ }^{1}$, JIVAN \\ JYOTI ${ }^{1}$, SANANDA SOM 1
}

\footnotetext{
1School of Pharmaceutical Sciences, Lovely Professional University, Phagwara - 144411, Punjab, India. ${ }^{2}$ Excellion Innovations and Inventions Pvt Ltd.(EXII) Pvt. Limited, 5568, Sector 38-West, Chandigarh-160014, India.Email: singhsachin23@gmail.com; sachin_pharma06@yahoo.co.in
}

\begin{abstract}
The present study describes a disposable static diffusion cell for in vitro diffusion studies in order to achieve better results as compared to well existing Franz diffusion cell in terms of absence of bubbles, variable receptor compartment, ease of handling and faster results. The cell consists of a cup shaped donor compartment made of semi permeable that could be either cellophane membrane or, animal skin fitted to a rigid frame which is supported on a plastic plate that contains a hole for the sample withdrawal. The receptor compartment is a separate unit and it could be any container up to $500 \mathrm{ml}$ volume capacity. The most preferred receptor compartment is glass beaker. In the present study goat skin was used as semi permeable membrane and verification of its performance was carried out through diffusion studies using gel formulations of one each of the fourselected biopharmaceutical classification system (BCS) class drugs. Metronidazole, diclofenac sodium, fluconazole and sulfadiazine were used as model drugs for BCS class I, II, III and IV, respectively. The newly developed diffusion cell (NDDC) was found to provide faster and more reproducible results as compared to Franz diffusion cell (FDC). At the time interval of $24 \mathrm{~h}$, the cell was found to exhibit a higher diffusion of metronidazole, diclofenac sodium, fluconazole and sulfadiazine by $0.65,0.65,0.32$ and 0.81 folds, respectively. The faster release obtained with NDDC was attributed to a larger surface area of skin as compared to that in FDC. It was concluded that better reproducibility of results could be achieved with NDDC.
\end{abstract}

Keywords: Newly developed diffusion cell; Franz diffusion cell; BCS; Metronidazole; Diclofenac sodium; Fluconazole; Sulfadiazine 
Abstract No. RTBS-0-13

\title{
ANTIBIOTIC RESISTANCE PATTERN AND PREVALENCE OF BETA-LACTAMASES AMONG CLINICAL ISOLATES OF ENTEROBACTERIACEAE IN A TERTIARY CARE HOSPITAL IN WESTERN U.P. (INDIA)
}

\author{
RATAN DEEP, VIVEK AGWAN, ANITA PANDEY
}

Department of Microbiology, Subharti Medical College, Swami Vivekanand Subharti University, Meerut . Email: rattandeep.pandit@gmail.com

\begin{abstract}
The worldwide dissemintion of Enterobacteriaceae, producing beta lactamases for the enzymatic mechanisms for antimicrobial drug resistance, necessitates the measures to improve quantitative risk assessment and the surveillance of resistant gene distribution. It is necessary to know the prevalence of beta lactamase producing strains in a hospital in order to formulate a policy of empirical therapy. The present study was performed to assess the drug resistance patterns in general and to demonstrate the occurrence of extended spectrum beta lactamases along with coexistence of additional beta lactam resistance mechanisms among Enterobacteriaceae in particular. The study was performed on a total of 957 consecutive no duplicate clinical samples received in the microbiological laboratory of the hospital for investigation. Samples were cultured in the respective culture media for the isolation of causative organism and bacteria were identified using standard bacteriological techniques. Antimicrobial Sensitivity Testing was performed by Kirby Bauer method and antiprograms were used as per CLSI guidelines. Out of a total of 957 samples, 282 isolates were grown in the culture. Among them, 58.1\% $(n=164)$ bacteria belonged to family Enterobacteriaceae. $54.3 \%$ (n=89) of the family were ESBL producers. $40.9 \%$ were coproducers of ESBL and Carbapenemase both. There is need to timely detect ESBLs in Enterobacteriaceae along with possible coexistence of additional mechanisms of resistance to beta lactams, in order to effectively treat patients, check the increasing trend of antimicrobial resistance and formulate new treatment alternatives.
\end{abstract}

Key Words: Antimicrobial Resistance, Enterobacteriaceae, ESBL, Carbapenemase. 
Abstract No. RTBS-0-14

\title{
PHYSICO-CHEMICAL, QUALITATIVE AND HPTLC PROFILE OF LEAVES AND ROOT OF TYLOPHORA INDICA (BURM. F) MERR. CHARU KHANNA $^{1,2}{ }^{*}$, SHALINI SINGH ${ }^{1}$, MANISH VYAS ${ }^{2}$
}

${ }^{1}$ Department of Microbiology, School of Bioengineering and Biosciences, Lovely Professional University, Phagwara, Punjab, India. ${ }^{2}$ Department of Ayurvedic Pharmaceutical Sciences, School of Pharmaceutical Sciences, Lovely Professional University, Phagwara, Punjab, India.*Email: info.charukhanna@gmail.com

\begin{abstract}
Ethno medicinal studies of various medicinal plants have presented multiple therapeutic applications of different parts and for some of which, standards are still not available. A number of parameters assist in enlisting the crude drug as authentic and standard for being used in product manufacturing. In the present study, Tylophora indica (T. indica) root and leaves has been studied for physico-chemical, phytochemical, chromatographic and XRD analysis. The root and leaf powder has been analysed for physico-chemical evaluation and phytochemical screening as per standard protocols. High Performance Thin Layer Chromatography (HPTLC) has been conducted with two different solvent systems and observed at two wavelengths (254 nm and $366 \mathrm{~nm}$ ). XRD of T. indica roots has been assessed for elemental analysis. The results for T. indica leaf and root physico-chemical analysis are assessed by loss on drying (4.5 \pm $0.5 \%, 11.3 \pm 0.6 \%)$, total ash (11.08 $0.9 \%, 6.8 \pm 1.32 \%)$, water soluble ash $(6.6 \pm 0.4 \%, 4.16 \pm 0.98 \%)$, acid insoluble ash (12.8 $\pm 1.16 \%, 1 \pm 1.0 \%)$,

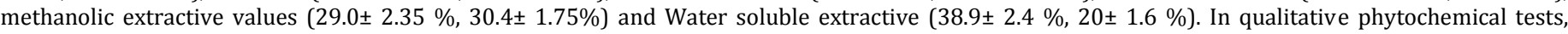
alkaloids, carbohydrates, tannins, glycosides and flavonoids were found in all extracts except for saponin and amino acids which were observed only in aqueous extracts and root extract respectively. The number of Rf values for root and leaf extracts in solvent system 1 at 254 nm are 6 and 9 respectively and at $366 \mathrm{~nm}$ are 6 and 6 respectively. In solvent system 2, the number of Rf values for root and leaf extracts at $254 \mathrm{~nm}$ are 7 and 11 respectively and at $366 \mathrm{~nm}$ are 5 and 6 respectively. XRD studies indicate the absence of heavy metals such as mercury, lead and arsenic. The results of this study presents that the T. indica leaf samples comply with the standards. The results of roots may be considered as standard and can be helpful in forming the monograph which is still an area of investigation.
\end{abstract}

Key words: Tylophora indica, Physico chemical, Phytochemical, HPTLC, XRD 


\title{
COMPUTER ASSISTED DRUG DESIGNING OF TRIAZOLE DERIVATIVE OF NOSCAPINE AS TUBULINE BINDING ANTI-CANCER DRUG
}

\author{
PUJA KUMARI ${ }^{1 \#, ~ V I N E E T A ~ D I X I T 2 \# ~}{ }^{2}$, ATUL KUMAR TIWARI ${ }^{2}$, SAURABH SAXENA ${ }^{3}$, NAVEEN KUMAR \\ VISHVAKARMA ${ }^{1}$, PRADEEP KUMAR NAIK ${ }^{4}$, DHANANJAY SHUKLA ${ }^{1, *}$
}

\begin{abstract}
${ }^{1}$ Department of Biotechnology, Guru Ghasidas Vishwavidyalaya, Bilaspur, Chhattisgarh. ${ }^{2}$ Government Science College, Ambikapur, Chhattisgarh. ${ }^{3}$ Department of Medical laboratory sciences, Lovely Professional University, Punjab. ${ }^{4}$ Department of Life Science, Sambalpur University, Odisha- 768019." Both authors contributed equally to this work.Email: sdhannu@gmail.com
\end{abstract}

\begin{abstract}
Microtubule-interfering drugs are commonly used to treat malignant disorders owing to indispensable role of this cytoskeletal element. These drugs include paclitaxel, docetaxel and the vinca alkaloids. However, due to their non-selective action and over-polymerization effect, these chemotherapeutic drugs have demonstrated complications with serious toxicity (mainly peripheral neuropathies, gastrointestinal toxicity, and myelo- \& immuno-suppresion) (by taxanes) or depolymerizing effects (by vincas) on microtubules. Therefore, there is urgent requirement of exploring new tubulin-binding agents that would be significantly effective and lesser toxic as compared to presently available drugs for human cancer therapy. Current study focuses fusion of two novel anti-cancer compound with low toxicity i.e. Noscapine and Triazole to generate a new ligand derivatives. Using CADD approach and molecular docking, molecular interaction of these derivatives with $\alpha \beta$-tubulin heterodimer was confirmed and investigated by Molecular docking along with dynamics simulation. A greater affinity of the newly designed ligands for binding to tubulin was predicted. The predictive binding free energy (Gbind,pred) of these derivatives (ranging from -10.5178 to $-16.8473 \mathrm{kcal} / \mathrm{mol}$ ) based on linear interaction energy (LIE) method with a Surface Generalized Born (SGB) continuum salvation model demonstrated enhanced binding affinity with tubulin as compared to the lead compound Natural $\alpha$-Noscapine $(-5.505 \mathrm{kcal} / \mathrm{mol})$. The binding energy of ligand, determined by using LigX i.e. MM/GBVI was found to be $-23.208 \mathrm{kcal} / \mathrm{mol}$. This indicate better efficacy of designed derivative compound as compared nascopine and Triazole.
\end{abstract}

Keywords: Noscapine, Triazole, Tubulin heterodimer, Molecular Docking 


\title{
COMPARATIVE ANALYSIS OF THE EFFECT OF HYPOXIA MIMETIC ON RED AND WHITE GASTROCNEMIUS MUSCLE
}

\author{
DHANANJAY SHUKLA ${ }^{1}$, SAURABH SAXENA ${ }^{2 *}$
}

${ }^{1}$ Department of Biotechnology, Guru Ghasidas Vishwavidyalaya, Bilaspur, Chhattisgarh.'ㄹepartment of Medical Laboratory Sciences, Lovely Professional University, Phagwara, Punjab - 144411.Email: drsaurabh.bio@gmail.com

\begin{abstract}
Hypoxia induces specific responses in skeletal muscles. Several studies have shown that exercise under hypoxia can stimulate muscular and systemic adaptation, which give a better performance over training under normal oxygen conditions. Moreover, the use of hypoxia mimetic has also shown molecular adaptations similar to that under hypoxia. In our previous work, we have already demonstrated that supplementation of cobalt chloride (a hypoxia mimetic) increases endurance performance in rats and protect red gastrocnemius muscle from oxidative damage. In the current study, we compared the effect of cobalt supplementation on white gastrocnemius (fast glycolytic) muscle in exercising and sedentary male SpragueDawley rats. We found that hypoxia mimetic treatment improves antioxidant status of both red and white gastrocnemius muscle as evident by increased reduced glutathione (GSH)/oxidized glutathione (GSSG) ratio and superoxide dismutase (SOD) and glutathione peroxida se (GPx) activity. The muscle reactive oxygen species (ROS) level increased but lipid peroxidation was found to be decreased in both types of muscle after cobalt supplementation. Endurance training reduced ROS level and lipid peroxidation in both types of muscle. However, the LDH activity and lactate level in white muscle were found to be more as compared to red muscle that was further enhanced with cobalt supplementation. In conclusion, our study indicates that cobalt supplementation protects both types of muscle from deleterious effects of ROS.
\end{abstract}

Keywords: Cobalt chloride, antioxidant, exercise, oxidative stress 


\title{
CHANGES IN THE HEART RATE AND CRANIO SACRAL RHYTHM IN THE STRESSED AND NON - STRESSED POPULATION: AN EXPERIMENTAL STUDY
}

\section{S. MICHEAL RAJ, SATISH KUMAR ANUMULA*, CHAITANYA BEKU}

Department of Physiotherapy, Lovely School of Physiotherapy and Paramedical Sciences, Lovely Professional University, Phagwara144411, Punjab (India).Email: satish.19885@lpu.co.in

\begin{abstract}
In the present society stress has become a major health problem which impacts negatively on the physical and psychological health of an individual. This study uses the cranio sacral rhythm (CSR) to evaluate the stress level and enabling for the intervention with the cranio sacral therapy. In this experimental design study, the age groups of between 18-34 years were recruited. At three different levels (Feet, sacrum and occiput) cranio sacral rhythm was recorded for 05 minutes along with the heart rate by using pulse oxymeter. Results reveled that, the CSR ranging between $4.07-4.41$ and 5.08-6.0 in stressed and non- stressed population respectively. In healthy population $\mathrm{C} / \mathrm{E}$ quotient is $<1$, if $\mathrm{C} / \mathrm{E}$ ratio $>1$ that revels flexion phase (expansion) less than the extension phase (contraction) results in poor tone of the postural muscles leading to depression. In the conclusion it can be stated that CSR will fluctuates with stress as the stress increases, the CSR decreases In the stressed individuals sacrum proved to be more reliable site to record the CSR. The data also suggested CSR will not have any gender identical changes in stressed and non - stressed population.
\end{abstract}

Key words: Cranio sacral rhythm, Hear rate, pulse oxymeter, depression, anxiety. 
Abstract No. RTBS-0-18

\title{
EVALUATION OF ANTIBACTERIAL ACTIVITY OF LEAF EXTRACT OF LIMNOPHILA CONFERTA AND SIDA ACUTA
}

\section{VINEETA DIXIT ${ }^{1 \#}{ }^{\text {SAURABH SAXENA }}{ }^{2 \#}$, HIM SHWETA KHAKA ${ }^{1}$, ATUL TIWARI ${ }^{3}$, NAVEEN VISHWAKARMA ${ }^{1}$, DHANANJAY SHUKLA ${ }^{1}$}

\begin{abstract}
1 Department of Biotechnology, Guru Ghasidas Vishwavidyalaya, Bilaspur, Chhattisgarh. ${ }^{2}$ Department of Medical Laboratory Sciences, Lovely Professional University, Punjab. ${ }^{3}$ Government Science College, Ambikapur, Chhattisgarh\# Both authors contributed equally to this work.Email: sdhannu@gmail.com
\end{abstract}

\begin{abstract}
Two important medicinal plants Sida acuta and Limnophila conferta were investigated for their phytochemical constituents and antibacterial activity. Sida acuta (Malvaceae) has been used traditionally in many diseases such as fever, chronic migraine, dysentery, elephantiasis and diarrhea. Limnophila conferta (Scrophulariaceae) has been used to treat different types of skin disorders and conditions of inflammation in the ancient system of medicine. Ethanol, acetone and water were taken as solvents to investigate the phytoconstituents and antibacterial activity of the leaf extracts of Sida acuta and Limnophila conferta on E.coli (MTCC 739) and S.aureus (MTCC 737). Phytochemical studies showed the presence of flavonoids, alkaloids, phytosterols in aqueous and ethanolic extracts of both Sida acuta and Limnophila conferta, however, Limnophila conferta was also confirmed with phenols. It was observed that the ethanolic extracts of Sida acuta had a relatively higher antibacterial activity against E.coli and S.aureus. The zone of inhibition for the ethanolic extract varied from $6 \mathrm{~mm}$ to $12 \mathrm{~mm}$ against E.coli and from $3.66 \mathrm{~mm}$ to $7 \mathrm{~mm}$ against S.aureus. Acetone extracts of Limnophila conferta showed a greater antibacterial activity against E.coli and S.aureus. The zone of inhibition for the acetone extract varied from $5.33 \mathrm{~mm}$ to $10.66 \mathrm{~mm}$ against E.coli and from $2.6 \mathrm{~mm}$ to $7.33 \mathrm{~mm}$ against S.aureus.
\end{abstract}

Keywords: Antibacterial activity, Plant extracts, Sida acuta, Limnophila conferta 


\title{
PHARMACEUTICAL DEVELOPMENT, STANDARDIZATION AND IN-VITRO ANTIOXIDANT EVALUATION OF ELADI GUTIKA
}

HARPREET KAUR, NEHA BHATIA, GOPAL L KHATIK, ANIL K SAH, MANISH VYAS*

School of Pharmaceutical Sciences, Lovely Professional University, Phagwara. Email: p141293@gmail.com

\begin{abstract}
WHO (World Health Organization) and Ministry of AYUSH, India collaboratively establishing protocols or monographs for the global acceptance of traditional medicines. Standardization confirms the identity, quality, purity and efficacy of drugs and formulations. Therefore, continuous efforts of APC (Ayurvedic Pharmacopeia Committee) \& PLIM (Pharmacopoeial Laboratory for Indian Medicines) have resulted in the publication of several monographs for the standardization of Ayurvedic drugs and formulations. But, yet standards of many ayurvedic formulations are not available. One such formulation is Eladi gutika. It is a polyherbal formulation with wide array of therapeutic activities including hiccup, vertigo, intoxication, fever, rheumatism. Present study was designed to formulate eladi gutika and standardized according to the protocol. The analysis of formulation was based on organoleptic, physiochemical, qualitative parameters, and HPTLC. Furthermore, the formulation was also evaluated for its in-vitro antioxidant activity. The results revealed that the prepared formulation complying with all standards of the vati and gutika. In addition to this formulation also possess antioxidant activity.
\end{abstract}

Keyword: Eladi gutika, standardization, antioxidant activity, HPTLC. 


\title{
DEVELOPMENT AND VALIDATION OF UV SPECTROSCOPIC METHOD OF ANALYSIS FOR CURCUMIN IN SELF NANOEMULSIFYING DRUG DELIVERY SYSTEM
}

\author{
VARUN GARG ${ }^{1}$, BIMLESH KUMAR ${ }^{1}$, ANKIT KUMAR YADAV ${ }^{1}$, MONICA GULATI ${ }^{1}$, NARENDRA KUMAR PANDEY ${ }^{1}$, \\ SACHIN KUMAR SINGH ${ }^{*}$
}

School of Pharmaceutical Sciences, Lovely Professional University, Phagwara - 144411, Punjab, India

\begin{abstract}
The purpose of the present investigation was to develop a suitable, simple, precise, accurate, robust, and reproducible UV method for estimation of curcumin (CRM) per se and in tablet and emulsion dosage forms. Methods: Spectrum of curcumin was scanned in the range of $200-500$ nm on a UVVisible double beam spectrophotometer (UV-1800, Shimadzu, Japan) using stock solution of curcumin (100 $\mu \mathrm{g} / \mathrm{mL})$ as reference solution and methanol as blank. Linearity was assessed from the calibration curve prepared using solutions of concentrations $2,4,6$, 8 and $10 \mu \mathrm{g} / \mathrm{ml}$ in quintuplicate. The method was validated by determining linearity, range, specificity, LOD, LOQ inter-day and intra-day precision, accuracy, and robustness as per ICH Q2 (R1) guidelines. Results and Discussion: The absorbance maxima ( $\lambda$ max) was found to be 420 nm with range of $2-10$ $\mu \mathrm{g} / \mathrm{ml}$. The regression coefficient $\left(\mathrm{r}^{2}\right)$ value was found to be 0.999 . Percentage relative standard deviation (RSD) for all parameters was found to be within limits. The validated method was successfully implemented in the estimation of CRM in tablet and self-nanoemulsifying drug delivery systems (SNEDDS) in terms of percentage drug loading/assay. Conclusion: The developed method was successfully used to quantify the drugs released from dissolution and diffusion samples of prepared tablets, solid SNEDDS and raw curcumin.
\end{abstract}




\title{
ANTI DIABETIC POTENTIAL OF DIFFERENT PARTS OF CALOTROPIS PROCERA (AITON) PRITI VERMA, PRIYANKA JOSHI, AMRIT PAL SINGH, GOPAL L.KHATIK, MANISH VYAS*
}

School of Pharmaceutical Sciences, Lovely Professional University, Phagwara,Punjab, India. Email: pritiv741@gmail.com

\begin{abstract}
Diabetes mellitus is a group of metabolic diseases characterized by hyperglycemia resulting from defects in insulin secretion, action, or both. It is the most common endocrine disorder and many people worldwide suffering from it. According to WHO in 2015, an estimated 1.6 million deaths were directly caused by diabetes despite great advances have been made in treatment and control of diabetes. Oral medication and insulin are the most preferred therapies for the treatment of diabetes. However, prolonged administration of such treatments leads to many side effects whereas alternative or complementary medicines and therapies are relatively safe. Antidiabetic activity of many phytoconstituents including the alkaloids, glycosides, flavonoids, terpenoids, steroids and polysaccharides are already reported. Therefore, phytomedicines are being screened to establish a safe and effective medicine for the treatment of diabetes. C.procera [Calotropis procera (Aiton) W. T. Aiton] is one of such medicinal plants, of which, various parts like flowers, leaves, latex, and fruits have been reported for their antidiabetic activity. Furthermore, the plant has also been reported for the activity against diabetic neuropathy. Cardenolides, lignans, tannins, saponins and flavanol glycoside are main constituents for the antidiabetic activity of $C$. Procera. Hence, present review describes the various in-vitro and in-vivo antidiabetic studies for the C.procera.
\end{abstract}

Keywords: Calotropis procera, antidiabetic, C. procera different parts, phytoconstiuents 
Abstract No. RTBS-0-22

\title{
THE DARK GENOME: REGULATORS OF MAMMALIAN GENE EXPRESSION RAVINA TAAK
}

Department of Medical Laboratory Sciences, Lovely Professional University, Phagwara- 144411, Punjab (India). Email: ravina.22439@lpu.co.in

\begin{abstract}
Every cell function differently, the function of cell determine by proteins and proteins are encoded by genes. Since couple of decades, we probably knows the complexity of eukaryotic genome as it consist huge amount of genome which do not synthesize protein although they took part in gene expression, known non-coding genome. Human genome sequencing consortium revealed that there are only 20,000 genes which having protein coding capacity in human genome, which means only $2 \%$ of transcriptome encodes for proteins rest $98 \%$ do not synthesize protein which is commonly consider as 'JUNK' DNA. But recent studies revealed that these sequence is not consider junk at all. This portion of DNA play major role in regulation of gene expression. These sequence are transcribed by generally RNA polymerase II enzyme and called as non-coding RNA which means RNA that do not code for any protein. Non coding RNA are categorized into infrastructural RNA (tRNA, rRNA, snRNA, snoRNA) and newly identified regulatory RNA that is lncRNA having more than 200 nucleotides (long non coding RNA) and small ncRNA (small non coding RNA). They are mRNA like transcript but lack of an apparent open reading frame (ORF), evolved from intronic and intergenic region of gene. Here we summarize the characteristics and functions of regulatory lncRNAs. Non-coding RNA have potential roles in chromatin remodelling, several mechanism for regulation of gene expression at transcription or post transcription level and in mediating epigenetic modification. As a regulatory molecule lncRNA function as signalling, decoy, guides and as a scaffolds. Enhancer RNA (eRNA) facilitate loop formation between promoter and enhancer region induce interaction between transcription factors and promoter. In the milieu eRNA recruit the important transcription factor binding over the DNA, IncRNA like HOTAIR and XIST as chromatin regulator recruit the epigenetic modifier to target loci as a guide which induce gene silencing. Recently lncRNAs also designated as a molecule that make great effects in many pathological processes such as neurogenesis, oncogenesis etc. Transcriptional gene silencing of tumor suppressors triggered by lncRNAs, and developmentally regulated genome-wide programming by the Polycomb group of proteins has been identified. The silencing of entire set genes by ncRNAs in various tumor tissues will prove to be a highly valuable prognostic biomarker for the emergence of cancer has been studied recently.
\end{abstract}

Key words: Gene expression; scaffolds; decoy; regulation 
Abstract No. RTBS-0-23

\title{
NANOMATERIALS USED IN CANCER THERAPY RUPAL DUBEY
}

Department of Medical Laboratory Sciences, Lovely Professional University, Phagwara-144411, Punjab (India). Email: rupal.22667@lpu.co.in

\begin{abstract}
Cancer Nano therapeutics are rapidly progressing and are being implemented to solve several limitations of the conventional drug delivery systems. In conventional drug delivery systems, the drugs are distributed throughout the body. Hence, majority of drugs do not reach the target sites. The major drawbacks of conventional drug delivery system are nonspecific biodistribution, lack of water solubility and drug resistance. To improve the biodistribution of the cancer drugs, nanoparticles have been designed for optimal size and surface characteristics so that their circulation time increases in the bloodstream. The size of nanoparticles used in a drug delivery system should be large eno ugh to prevent their rapid leakage into the blood capillaries but small enough to escape capture by the fixed macrophages. Size of nanoparticle is upto $100 \mathrm{~nm}$. The nanoparticles have enhanced permeability and retention effect due to which they carry the active drugs specifically to the target cells. This is the passive targeting mechanism i.e. the fast growing cancer cells demand recruitment of new vessels for oxygen and nutrients, this imbalance creates tumor vessels dilated with numerous pores showing gap junctions which is then referred to as enhanced permeability and since intracellular concentration of ions is increased this feature is referred to as increased retention time. In addition to this, active strategies are also used. In active targeting mechanism, ligands or antibodies specific for the tumor are used which amplify the specificity of the nanoparticles. Liposomes and polymers increase the potential number of drugs that can be conjugated to the targeted nanoparticles. Nanoparticles accumulate in the cells without being recognized by P-glycoprotein, which is one of the main mediator of multidrug resistance. Due to this the intracellular concentration of the drug increases. With the use of nanoparticles the pharmacokinetics has improved and the side effects of cancer drugs have been reduced. Multifunctional nanoparticles are facilitating the effective and tailored cancer treatment.
\end{abstract}




\title{
APPLICATION OF QBD APPROACH FOR THE OPTIMIZATION OF ORODISPERSIBLE FILM FORMULATION
}

\author{
ASHUTOSH GUPTA ${ }^{1 *}$, JATIN KUMAR ${ }^{1}$, SURAJPAL VERMA ${ }^{2}$, HARMANPREET SINGH ${ }^{2}$
}

${ }^{1}$ School of Pharmaceutical Sciences, Lovely Professional University, Phagwara, Punjab, India. ${ }^{2}$ Associate Professor, School of Pharmaceutical Sciences, Lovely Professional University, Phagwara, Punjab, India.Email: ashugupta1812@gmail.com

\begin{abstract}
The present study was done to understand the effect of formulation variables on the quality of fast dissolving films using Quality by Design (QbD) approach as mentioned in ICH Q8 (R2) guideline. A Definitive Screening Design of Experiments (DoE) was used to identify and classify the critical formulation variables affecting critical quality attributes (CQA) using $2 \times 2$ factorial design. Based upon prescreening study, the critical formulation variables i.e. concentration of film forming polymer and plasticizers were kept in range of $1.5 \% \mathrm{w} / \mathrm{w}-2.5 \% \mathrm{w} / \mathrm{w}$ and $0.5 \% \mathrm{v} / \mathrm{v}-1 \% \mathrm{v} / \mathrm{v}$ respectively. A total of 8 laboratory-scale DoE formulations were prepared and evaluated for CQA's i.e. mechanical properties (folding endurance) and disintegration time. Data were analyzed for elucidating interactions between two variables and for providing a predictive model for the process. The main factors impacting mechanical property was found to be concentration of film forming polymer and plasticizers. Results suggested that the concentration of film forming polymer and plasticizer were critical to manufacture fast dissolving film with desired mechanical property i.e. folding endurance ( $>150$ folds) and CQA i.e. disintegration time $(<1$ minute). Optimized batches obtained from the QbD approach will be used for incorporation of drug (Naratriptan) so as to prepare drug loaded films which will be used for management of migraine.
\end{abstract}

Keywords: Quality by design, film, Design of Experiments, Critical Quality Attributes. 


\title{
PRESERVATION OF MICROBIAL SPOILAGE OF FOOD BY BIOSURFACTANT BASED COATING

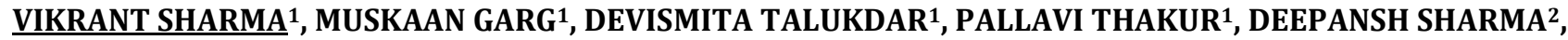 GAURAV KUMAR ${ }^{1}$
}

Department of Microbiology, School of Bioengineering and Biosciences, Lovely Professional University, Phagwara 144402, Punjab, India.Amity Institute of Microbial Technology, Amity University, Jaipur 303002, Rajasthan, India.Email: vikrants2096@gmail.com

\begin{abstract}
Microbial spoilage of food is one of the leading causes of food scarcity worldwide, which could have devastating effect on the socioeconomic of any country. Along with classical food preservation methods, various innovative approaches can significantly increase the food safety. Biosurfactants are the amphiphilic microbial metabolites, while many of them have potential antimicrobial properties and therefore can be used for food preservation. During this study, three biosurfactants including Bacillus subtilis 10T, Bacillus subtilis 3258 and Rhamnolipid exhibited good antifungal activity against Aspergillus oryzae, Curvularia sp., and two unknown food spoiling fungi, while rhamnolipid was found to be most potent fungicide. Further the ramanolipid coating $(1 \mathrm{mg} / \mathrm{ml})$ on potato and tomato protected them from fugal spoilage up to 20 days at room temperature in contrast to untreated samples which started spoiling in 6-7 days. Above findings emphasis on the potential use of biosurfactants for the preservation of food items, however a detailed study to ensure the safety of biosurfactant is of prerequisite.
\end{abstract}




\title{
SCREENING OF IN-VITRO AND IN-VIVO STUDIES BASED ON THE ANTIDIABETIC ACTIVITY OF LOUQAT
}

\author{
AMRIT PAL SINGH, PRIYANKA JOSHI, PRITI VERMA, GOPAL L.KHATIK, HARPREET KAUR, MANISH VYAS*
}

School of Pharmaceutical Sciences, Lovely Professional University, Phagwara (Punjab).Email: amritnandra1@gmail.com

\begin{abstract}
International Diabetes Federation (IDF) reported, approximately 425 million adults (20-79 years) were diabetic till 2017 and expecting rise in population up to 629 million by 2045 despite having a range of conventional medicines and treatments. However, these treatments lead to serious adverse effects due to the prolonged administration. Therefore, ethnomedicines are being explored for the search of safe and effective alternate for the management of diabetes. Loquat (Eriobotrya japonica Lindl.) is used as an ethnomedicine in the north India for the treatment of many disorders including diabetes. Mainly leaves, fruits and seeds of Loquat are used for the medicinal purposes. However, leaves have been reported for the antidiabetic activity may be due to the presence of phenolics and triterpenes. Hence, present review will explore the antidiabetic potential of Loquat to establish it as antidiabetic drug.
\end{abstract}

Keywords: Loquat, diabetes, ethnomedicine, 


\title{
A COMPARISON OF DRUG RELEASE: MICROPARTICLES VS NANOPARTICLES NISHAT ANIUM, SHARAD VISHT
}

Smt. Tarawati Institute of Bio-Medical \& Allied Sciences, Roorkee. Email: nishatanjum.1610@gmail.com

\begin{abstract}
The purpose of this research was to study and compare the efficiency of microparticels or nanoparticles as drug delivery. The microparticles or nanoparticles were prepared using single phase emulsification method followed by chemical stabilization method. The glycyrrhetinic acid ammonium was used as drug, bovine serum albumin was used as polymer and carbopol 934P was used for mucoadhesion. Microparticels and nanoparticles were evaluated and the kinetics of drug release was studied using BIT software. The line equation for glycyrrhetinic acid ammonium was found to be $y=0.0012 x+0.0003$. The FTIR showed no drug excipient interaction. The yield was found to be $97.95 \pm 0.34 \%$ and $95.79 \pm 0.61 \%$, particle size by scanning electron microscopy was $3.5 \pm 1.46 \mu \mathrm{m}$ and $250 \pm 1.32 \mathrm{~nm}$, drug entrapment was found to be $44.86 \pm 023$ and $36.85 \pm 0.27$ drug loading was found to be $52.74 \pm 0.73$ and $42.74 \pm 0.12$, swelling index was found to be $81.73 \pm 0.12$ and $92.63 \pm 0.53 \%$ mucoadhesion testing by in vitro wash-off test (after $10 \mathrm{~h}$ ) was found to be $86.34 \pm 0.63$ and $93.43 \pm 0.25$ for microparticels or nanoparticles respectively. The percentage cumulative drug release was $88.45 \pm 0.12$ and $97.16 \pm 0.11$ for microparticels and nanoparticles. The kinetics of drug release was studied using BIT software which showed that the drug release follows Korsmeyer-Peppas Equation model as best fit with $\mathrm{R}^{2}$ value 0.9820 and $0.9896, \mathrm{~K}$ value 3.0067 and $3.5237, \mathrm{n}$ value 0.7657 and $0.6305, \mathrm{k}$ value 3.0067 and 3.5237 for microparticels or nanoparticles respectively which indicate Anomalous transport as drug release. It was concluded that nanoparticles maintains the plasma drug concentration better than microspheres on the basis of in-vivo drug release.
\end{abstract}

Keywords: Microparticels, nanoparticles, glycyrrhetinic acid, emulsion, drug release. 
Abstract No. RTBS-0-28

FACT OR MYTH: IS CROTON TIGLIUM L. POISONOUS? PRIYANKA IOSHI, PRITI VERMA, AMRIT PAL SINGH, GOPAL L. KHATIK, MANISH VYAS*

School of Pharmaceutical Sciences, Lovely Professional University, Phagwara, Punjab, India.Email: priyanka.joshi00001@gmail.com

\begin{abstract}
The indigenous systems of medicines, specifically, Ayurved have been practiced since centuries. These systems have been using drugs originated from the various natural sources including the plant, animal, minerals and metals. Plant based drugs are being used frequently due to their relatively safe and effective nature. Some of these drugs are classified as visha and upvisha varga due to their toxic nature and special treatments required to safe use. Though, these drugs are being overlooked and not the part of main course of treatments. However, recent studies based on the poisonous plants have been reported their multidimensional therapeutic potential and also comparatively effective and rapid onset of action. One of such drug is seeds of Croton tiglium L. known for its purgative nature are rich in various secondary metabolites including alkaloids, saponins, flavonoids, and terpenoids. These metabolites may responsible for its anti-dermatophytic, anti-oxidant, anti-tumour, anti-HIV, anti-molluscidal, anti-convulsant, larvicidal activity, antitermitic activity, genotoxic activity, analgesic activity, haem-agglutinating \& haemolytic activity, and antinociceptive effect. Moreover, other parts of the Croton tiglium L. also possess different activities. The present review describes the various studies on different in-vitro and in-vivo studies based on the different activities of Croton tiglium L. to deal with the myth related of its toxicity.
\end{abstract}

Keywords: Croton tiglium L., Poison, Myth, Visha 


\title{
ANTI DIABETIC POTENTIAL OF DIFFERENT PARTS OF CALOTROPIS PROCERA (AITON) PRITI VERMA, PRIYANKA JOSHI", AMRIT PAL SINGH *GOPAL L.KHATIK*, MANISH VYAS*
}

School of Pharmaceutical Sciences, Lovely Professional University, Phagwara,Punjab, India.Email: pritiv741@gmail.com

\begin{abstract}
Diabetes mellitus is a group of metabolic diseases characterized by hyperglycemia resulting from defects in insulin secretion, action, or both. It is the most common endocrine disorder and many people worldwide suffering from it. According to WHO in 2015, an estimated 1.6 million deaths were directly caused by diabetes despite great advances have been made in treatment and control of diabetes. Oral medication and insulin are the most preferred therapies for the treatment of diabetes. However, prolonged administration of such treatments leads to many side effects whereas alternative or complementary medicines and therapies are relatively safe. Antidiabetic activity of many phytoconstituents including the alkaloids, glycosides, flavonoids, terpenoids, steroids and polysaccharides are already reported. Therefore, phytomedicines are being screened to establish a safe and effective medicine for the treatment of diabetes. C.procera [Calotropis procera (Aiton) W. T. Aiton] is one of such medicinal plants, of which, various parts like flowers, leaves, latex, and fruits have been reported for their antidiabetic activity. Furthermore, the plant has also been reported for the activity against diabetic neuropathy. Cardenolides, lignans, tannins, saponins and flavanol glycoside are main constituents for the antidiabetic activity of $C$. Procera. Hence, present review describes the various in-vitro and in-vivo antidiabetic studies based on the C.procera.
\end{abstract}

Keywords: Calotropis procera, antidiabetic activity, C. procera different parts, phytoconstituents 
Abstract No. RTBS-0-30

\title{
MYCOBACTERIUM TUBERCULOSIS: HAVOC TO HUMAN HEALTH VIJAYETA JOSHI
}

PG Dept of Biotechnology, Lyallpur Khalsa College, Jalandhar City.Email: vijayetajoshi@yahoo.com

\begin{abstract}
Tuberculosis (TB) remains a threat to the health of people worldwide. India has the highest TB burden with 0.37 million causalities and 1.9 million new cases annually. Primarily a pathogen of the respiratory system, aerobic Mycobacterium tuberculosis complex (MTBC) infects the lungs via the inhalation of infected aerosol droplets generated by people with pulmonary disease through coughing. Infection with Mycobacterium tuberculosis can result in active TB or, more commonly, latent infection. Latently infected persons, of which there are estimated to be $\sim 2$ billion in the world, represent an enormous reservoir of potential reactivation $\mathrm{TB}$, which can spread to other people. The bacilli travel to the alveoli, where they begin to organize the early granuloma. Conventional diagnostic tests including X-Ray, microscopic examination, mycobacterial culture and biochemical tests have played a potent role in diagnosing this deadly disease to some extent. Nucleic acid amplification tests (NAATs) such as PCR reliably confirm the presence of $M$. tuberculosis in microscopically positive cases but results revealed are infirm in case of paucibacillary clinical specimens. In fact, a variable spectrum of latent infection likely exists just as active TB has varying degrees of severity. The changing paradigm of latent infection in TB is still one of the key global health concern. It is anticipated that the discovery of biological pathways of tuberculosis pathogenesis will provide novel targets for future approaches to the treatment and prevention of tuberculosis.
\end{abstract}

Keywords: Mycobacterium tuberculosis, granuloma, diagnostic tests, paucibacillary, pathogenesis. 
Abstract No. RTBS-P-01

\title{
THERAPEUTIC POTENTIAL OF PDE5 INHIBITORS (PDE5I): PROMISING PERSPECTIVES INDU MELKANI, SAKSHI PANCHAL, BIMLESH KUMAR*, SACHIN KUMAR SINGH, MONICA GULATI, NARENDRA KUMAR PANDEY, SAURABH SINGH
}

School of Pharmaceutical Sciences, Lovely Professional University, Jalandhar, Punjab, India.Email: bimlesh1pharm@gmail.com, bimlesh.12474@lpu.co.in

\begin{abstract}
Phosphodiesterase (PDEs) include at least 11 different isozymes (PDE1-PDE11). Albeit redundancy has been observed towards hydrolyzation of cAMP and cGMP, selective inhibition has been investigated due to differences in structure. cGMP cleavage is accomplished by PDE5, 6 and 9, whereas PDE4, 7 and 8 are cAMP specific; subtypes 1, 2, 3, 10 and 11 are enzymatically active on both cyclic isotypes. PDE5 inhibitors (PDE5i) are known to exert benefits in conditions like heart failure, infarct, cardiomyopathy. It is widely reported as treatment for erectile dysfunction (ED). Facilitation of neuroprotection by PDE5 inhibition occurs through the enhancement of the NO-cGMP pathway. Sildenafil (SD), tadalafil (TD), and vardenafil (VD) are selective PDE5i. SD, reverses the cholinergic-muscarinic antagonism-induced memory and learning deficit, inhibited scopolamine-induced cognitive impairments and also treated neuropathic pain. PDE5i antagonizes age-associated memory deficits, such as dementia. Enhancement of cerebral blood flow, mitigating ischemic damage as well as improving open-field locomotor function evident by Selective PDE5 inhibition. SD also reduced apoptosis, astrocytosis, and microgliosis. SD and VD have shown neuroprotective properties in a Huntington's disease (HD). On the other hand, TD and SD have exhibited a decrease in the phosphorylation of Tau proteins in the mouse hippocampus. These proteins are known to be defective and fail to stabilize microtubules in AD. Moreover, PDE5i also demonstrated the potential benefit in an experimental paradigm of PD. This presentation reviews potential of PDE5 inhibitors on therapeutic power in various diseases.
\end{abstract}

Keywords: PDE5, PDE5 inhibitors, Cardioprotection, Neuroprotection 


\title{
RELATIONSHIP OF TSH WITH BMI IN SUBCLINICAL HYPOTHYROID PATIENTS ANUPAM SHARMA ${ }^{1}$, SAVITA DEVI ${ }^{2}$, KAMALDEEP SINGH ${ }^{3}$, PRANAV KUMAR PRABHAKAR ${ }^{*} *$
}

Department of Medical Laboratory Sciences, Lovely Professional University, Phagwara- 144411, Punjab (India).Email: pranav.16113@lpu.co.in

\begin{abstract}
Thyroid hormones (T3 and T4) synthesized by thyroid gland and play essential role in normal body development and tissue metab olism. Iodine is essential factor that is required for synthesis of thyroid hormones. The secretion of thyroid hormones is regulated by Negative feedback mechanism. After reached in blood circulation the majority of T4 and T3 bound with carrier proteins -: thyroxine - binding proteins (TBG) having higher affinity for T4, thyroxine - binding prealbumin (transthyretin) and albumin for purpose of transportation. The common diseases related to thyroid hormones includes -: Hypothyroidism, Hyperthyroidism, Thyroiditis, Goiter, Nodes, and Tumors of thyroid glands (Benign and Malignant). Subclinical hypothyroidism also called mild thyroid failure is defined as normal thyroid hormones but mildly elevated TSH ( $5-10 \mathrm{uIU} / \mathrm{ml})$ with no or mild sign and symptoms. The Prevalence of thyroid disorders commonly observes in females then males. Obesity is defined by body mass index which is a reasonable indicator of body fat. Hypothyroidism is associated with obesity and various studies conducted to find out the relationship between TSH and BMI observed different finding in the particular study. In present study, a poor positive correlation between TSH and BMI was observed in total euthyroid subjects. A poor negative association between TSH and BMI in euthyroid Males and poor positive ( $\mathrm{r}$ value - 0.21) relationship was observed in euthyroid females. In Subclinical hypothyroid patients (Total, Male and female), Poor negative correlation was observed between TSH and BMI. The conclusion of this study is, as TSH increased the BMI will also increase in (mostly females) euthyroid subjects. The Inverse or poor negative correlation was observed within TSH and BMI among euthyroid males and inverse correlation was noticed in patients with subclinical hypothyroidism.
\end{abstract}

Key words: TSH; Basal Metabolic Rate; r value; Hypothyroid ; Goiter 


\title{
MECHANISM AND MODELS OF NEUROPATHIC PAIN: RECENT UPDATES
}

\section{RAII, SAKSHI PANCHAL, INDU MELKANI, BIMLESH KUMAR*, SACHIN KUMAR SINGH, MONICA GULATI, NARENDRA KUMAR PANDEY, SAURABH SINGH}

School of Pharmaceutical Sciences, Lovely Professional University, Jalandhar, Punjab, India.Email: bimlesh1pharm@gmail.com, bimlesh.12474@lpu.co.in

\begin{abstract}
Lesions of somatosensory nervous system (arising in the skin, muscles, joints, fascia and including thermoreceptors, mechanoreceptors, chemoreceptors, proprioceptors and nociceptors that send signals to the spinal cord and eventually to brain) leads to neuropathic pain (NP). NP results in spontaneous painful response against noxious and innocuous stimuli. NP is reported to affect 7-10\% of the general population. Peripheral neuropathic pain is more common because of the ageing global population, increased incidence of diabetes mellitus and the increasing rates of cancer and the consequence of chemotherapy, which affect all sensory fibres (A $\beta, A \delta$ and $C$ fibres). Cerebrovascular disease affecting the central somatosensory pathways (poststroke pain) and neurodegenerative diseases (notably Parkinson disease) are brain disorders that often cause central neuropathic pain. To understand the mechanism of neuropathic pain and therapeutic targets for its treatment, there is requirement of suitable animal models which mimic the neuropathic pain as it happens in humans. The developed models so far have immensely contributed to understand the nature of pain with its underlying mechanism that may be central or peripheral. These models and preclinical data available have successfully helped in finding out new therapeutic targets and agents, leading to management at clinical level. This presentation reviews on diverse animal models of NP and their mechanisms.
\end{abstract}

Keywords: neuropathic pain, peripheral neuropathy, sensitization, animal models 
Abstract No. RTBS-P-04

\title{
MECHANISM OF ABSCISIC ACID SIGNALLING IN RESPONSE TO ABIOTIC STRESSES IN PLANTS WITH SPECIAL REFERENCE TO CADMIUM TOXICITY
}

\section{PRASANN KUMAR}

Department of Agronomy, School of Agriculture, Lovely Professional University, Jalandhar, 144411, Punjab (India). Email: prasann0659@gmail.com

\begin{abstract}
The plant hormone abscisic acid (ABA) is a sesquiterpenoid synthesized from xanthophylls and appears to influence several physiological and developmental events. The level of ABA in plants increases upon their exposure to environmental stress, such as drought, high temperature, low temperature, salinity and flooding. It appears that ABA is a general endogenous inducer of tolerance to environmental stresses. Changes in $\mathrm{ABA}$

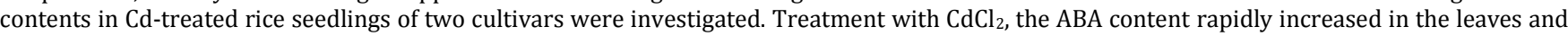
roots of Cd-tolerant cultivar (cv. Tainung 67, TNG 67) but not in the Cd-sensitive cultivar (cv. Taichung Native 1, TN1). The reduction of transpiration rate of TN1 caused Cd was less than that of TNG67. Exogenous application of ABA reduced transpiration rate decreased Cd content and enhanced Cd tolerance of TN1 seedlings. Exogenous application of the ABA biosynthesis inhibitor, fluridone, reduced ABA accumulation, increased transpiration rate and Cd content and decreased Cd tolerance of TNG67 seedlings was reversed by the application of ABA.
\end{abstract}

Keywords: ABA, Biotic, Cadmium, Density, Energy, Forage, Gap, India 
Abstract No. RTBS-P-05

\title{
NEUROTRANSMITTERS AND CHEMICAL MEDIATORS OF INFLAMMATION: THE THERAPEUTIC TARGETS IN NEUROPATHIC PAIN
}

\section{AXEL MANZI,SAKSHI PANCHAL, INDU MELKANI, BIMLESH KUMAR*, SACHIN KUMAR SINGH, MONICA GULATI, NARENDRA KUMAR PANDEY, SAURABH SINGH}

School of Pharmaceutical Sciences, Lovely Professional University, Jalandhar, Punjab, India Email: bimlesh1pharm@gmail.com, bimlesh.12474@lpu.co.in

\begin{abstract}
Primary lesion, dysfunction and/or transitory perturbation in the peripheral or central nervous system (CNS) lead to neuropathic pain. Somatosensory pathway responsible for the conscious perception of touch, pain, pressure, heat, movement and vibration originate from muscles, joints, skin and ears. Accumulating evidences shows that inflammatory mediators (TNF- $\alpha$, Bradykinin, PGE2, IFN- $\gamma$, Histamine, Fractaline and BDNF) and neurotransmitters (Glutamate, Substance P, CGRP, ATP and Serotonin) contribute to develop neuropathic pain. Nerve injury produces an inflammatory component, both at the site of injury and at the level of cell body in dorsal root ganglion. Local enrichment of (pro-)inflammatory mediators provide stimulation for nerve fiber sensitization and modulation of transient receptor potential channels (TRPV1), these have been shown to be directly activated by reactive oxygen/nitrogen species, leading to increased nerve fiber excitation and manifestation of mechanical and cold hypersensitivity behaviors. On the other hand, in the development of neuropathic pain, peripheral neurons transmit signals to spinal dorsal horn neurons to release calcitonin gene-related protein, substance P, glutamate, and ATP like neurotransmitters. Locally in the dorsal horn, there are also neurotransmitters such as GABA, glycine, serotonin are involved, they may initiate microglial activation in association with neuropathic pain. This presentation reviews the role of inflammatory mediators and neurotransmitters as one of the key targets for treatm ent in neuropathic pain.
\end{abstract}

Keywords: Adenosine triphosphate, Chemical mediators, Inflammation, Neuropathic pain, Neurotransmitters 


\title{
CO-ADMINISTRATION OF CURCUMIN AND SILDENAFIL AMELIORATES BEHAVIORAL AND BIOCHEMICAL ALTERATIONS IN THE RAT MODEL OF ALCOHOLIC NEUROPATHY

\author{
SAKSHI PANCHAL, INDU MELKANI, MANINDER KAUR, BIMLESH KUMAR*, SACHIN KUMAR SINGH, MONICA \\ GULATI, NARENDRA KUMAR PANDEY, SAURABH SINGH
}

School of Pharmaceutical Sciences, Lovely Professional University, Jalandhar, Punjab, India

Email: bimlesh1pharm@gmail.com, bimlesh.12474@lpu.co.in

\begin{abstract}
Neuropathic pain (NP) is associated with chronic alcohol consumption which affects both central and peripheral nervous system and there is no reliable satisfactory treatment available till date. The present study describes the attenuation of co-administration of curcumin and sildenafil on alcohol induced neuropathy. Neuropathy was induced using ethanol (35\% v/v, $10 \mathrm{~g} / \mathrm{kg}$, p.o.) for 10 weeks to the animals. Curcumin (30 and 60 $\mathrm{mg} / \mathrm{kg}$, i.p.) and Sildenafil ( 5 and $10 \mathrm{mg} / \mathrm{kg}$, i.p.) were given alone and in combination $30 \mathrm{mg} / \mathrm{kg}$ curcumin and $5 \mathrm{mg} / \mathrm{kg}$, sildenafil, i.p. to investigate the changes in thermal and mechanical hyperalgesia, allodynia and histopathological parameters. Role of oxidative stress was investigated using thiobarbituric acid reactive species and glutathione. Chronic consumption of alcohol for 10 weeks resulted in the development of significant thermal and mechanical hyperalgesia, allodynia and increased oxidative stress. Administration of curcumin and sildenafil alone, at their low as well as well as high doses significantly attenuated the symptoms of neuropathic pain induced by alcohol. However, concomitant administration of curcumin and sildenafil at their lower doses was found to significantly improve nerve functions, biochemical and histopathological parameters as compared to their individual administration. Hence co-administration of curcumin and sildenafil may bring new dimension towards attenuation of alcohol induced neuropathic pain.
\end{abstract}

Keywords: curcumin, sildenafil, alcohol neuropathy, oxidative stress 


\title{
FORMULATION, SYSTEMATIC OPTIMIZATION, IN-VITRO, EX-VIVO AND STABILITY ASSESSMENT OF TRANSETHOSOME BASED GEL OF CURCUMIN
PRABHIOT KAUR, VARUN GARG, PALAK BAWA, ROOPESH SHARMA, SACHIN KUMAR SINGH*, BIMLESH KUMAR, MONICA GULATI, NARENDRA KUMAR PANDEY, SOUVIK MOHANTA, JIVAN JYOTI, SANANDA SOM

School of Pharmaceutical Sciences, Lovely Professional University, Phagwara -144411, Punjab, India

Email : singhsachin23@gmail.com; sachin_pharma06@yahoo.co.in

\begin{abstract}
The current work presents formulation of curcumin-loaded transethosome (CRM-TE) in the form of a gel and its characterization. Thirteen formulations were prepared by varying the concentration of PL90G as lipid, ethanol and ratio of lipid: span using Box Behnken Design. The optimized formulation was characterized for vesicle size, entrapment efficiency, drug retention, drug permeation through skin, and morphology. Parameters of CRM-TE were compared to other vesicular systems that includes, liposomes, ethosomes, and transfersomes. Optimized CRM-TE was incorporated into gels and comparative evaluation was done. CRM-TE gel was kept at $5 \pm 3^{\circ} \mathrm{C}, 25 \pm 3^{\circ} \mathrm{C}$ and $40 \pm 3^{\circ} \mathrm{C}$ for 180 days and evaluated for entrapment efficacy and vesicle size. CRM-TE showed $286.4 \mathrm{~nm}$ vesicle size, $61.2 \%$ entrapment efficiency, $19.8 \%$ drug retention in the skin, and $71.3 \%$ drug permeation at $24 \mathrm{~h}$. It was found superior in terms of all the parameters as compared to other vesicular formulations. CRM-TE gel also exhibited best characteristics in terms of entrapment efficiency, drug retention and drug permeation. CRM-TE gel exhibited better stability at 5 $\pm 3^{\circ} \mathrm{C}$ in terms of vesicle size and entrapment efficiency as compared to other storage conditions. CRM-TE gel could offer efficient delivery of curcumin through topical route.
\end{abstract}

Keywords: Curcumin; Transethosome; CRM-TE gel; Box Behnken Design; Stability studies 


\title{
CLINICAL EVALUATION AND COMPARISON OF INFECTIOUS BIOMARKERS IN SEPSIS PATIENTS ADMITTED TO SUPER-SPECIALITY HOSPITAL IN PUNJAB
} NURAKANT NEUPANE, JYOTI LAKHANPAL*

Department of Paramedical Sciences, Lovely Professional University, Phagwara-144411, Punjab (India) Email: jyoti.22005@lpu.co.in

\begin{abstract}
Sepsis, a systemic inflammation, mainly originated due to various infections. Despite the use of latest treatments and increased experience, mortality rates in sepsis remain high. No long-term data, comparing the PCT and CRP levels and differentiating the PCT levels in males and females were available. The main objectives of this study were to evaluate PCT and compare different parameters for diagnosis of sepsis and related conditions. The samples of 74 patients were taken, admitted to ICU at Max Hospital, Mohali. The parameters used for diagnosis and differentiating were PCT, CRP, and TLC levels. Out of 74, 44 patients were diagnosed with sepsis condition while remaining had higher PCT values due to different conditions. For comparison, the different variables including Chi-square test, percentage were used. PCT values were analyzed and represented in terms of Mean and Standard Deviation. A total number of 74 patients were grouped on basis of gender, age, and $p$-value. The main cause of sepsis comes out be Gram-negative bacteria (54.3\%) while gram-positive bacteria, fungi, and yeast were $45.7 \%$. The prevalence of sepsis condition was more prominent in males as compared to females. The severity of sepsis increases with increasing serum procalcitonin values resulting in higher death rate. From the study, sepsis is mainly caused by gram-negative bacteria. In comparison with CRP and TLC levels, serum PCT is considered to be a cost-effective biomarker for accurate diagnosis as well as early treatment of sepsis condition.
\end{abstract}

Keywords: Procalcitonin, Sepsis, biomarker, Bacterial infection, Mortality 


\title{
FINITE ELEMENT ANALYSIS OF POROUS BONE SCAFFOLD \\ GULSHANDEEP SINGH ${ }^{*}$, SUNNY ZAFAR ${ }^{2}$, MOHAMMAD TALHA ${ }^{2}$
}

${ }^{1}$ Department of Mechanical Engineering, Lovely Professional University, Phagwara- 144411, Punjab (India).²Department of Engineering, Indian Institute of Technology Mandi, Kamand-175005, Himachal Pradesh (India)

Email: singh.gulshandeep11396@gmail.com

\begin{abstract}
Design and development of bone scaffolds using biopolymers is one of the current trends in bone tissue engineering. The artificially fabricated bone scaffolds should be made with biopolymers to resemble the properties as that of natural bone. The study presents the Stress-Strain Analysis of different models of bone scaffold, by the method of Finite Element Analysis using COMSOL Multiphysics software. The behavior of different models is observed under compression and shear forces. The study compares the results with two different materials, a biopolymer PLA (polylactic acid) and a biopolymer composite of PLA/HA (polylactic acid and hydroxyapatite). Four lattice models of 10X10X10mm3 volume with same length to diameter ratio and same porosity, but with different unit cells. The unit cells which varies in dimensions of individual cell and no. of cells in a model.
\end{abstract}

Key-words: Bone scaffolds, biopolymers, Finite Element Analysis, COMSOL Multiphysics, compression, shear, polylactic acid, hydroxyapatite, and porosity. 
Abstract No. RTBS-P-10

\title{
DIFFERENT ROLES OF MIRNA IN THE HEPATITIS C INFECTION THOMSON SONI
}

Department of Medical laboratory Sciences, Lovely Professional University,Phagwara- 144411, Punjab (India) Email: thomson22263@lpu.co.in

\begin{abstract}
Hepatitis $\mathrm{C}$ virus (HCV) is a +ve sense single stranded RNA virus whose size is near about 55-65nm and belongs to the family Flaviviridae which causes acute viral infection. Every year approximately 399000 people die worldwide because of this infection mostly from cirrhosis and hepatocellular carcinoma (HCC). Till date there is no therapeutic vaccines develop against HCV which can prevent HCV patient from this chronic infection. There are some direct acting antiviral (DAA) drugs developed against the HCV RNA which shows promising results against this virus but their long term consequences are yet unknown. After DAA there are number of patients who still suffering from liver failure. For the prevention of this liver disease there is need for the early diagnosis of this chronic infection. Micro RNA is small non coding RNA molecule whose size is approximately 22 nucleotides. Micro RNA play crucial role for early diagnosis of pathogenesis. It plays important role in the detection of hepatitis $\mathrm{C}$ through as a biomarker in the progression of disease working as a diagnostic tool and treatment of the hepatitis C. Miravirsen, a drug complementary to miRNA-122 is a promising HCV treatment drug which is under clinical trial. The long lasting effect of antiviral activity on the HCV infected patient is showed by the silencing of miRNA 122. MiRNA also regulates the replication of the viral genome by targeting interferon signalling pathway and plays a important function in the pathogenesis of infection. MiRNA plays a vital role in the pathogenesis of the HCV infection by controlling the signalling pathways like apoptosis, immune response and proliferation of the liver cells. The main aim of this review is to focus on the different roles of the microRNA in hepatitis infection and treatment by miRNA on molecular level against hepatitis $\mathrm{C}$ liver progression.
\end{abstract}

Keywords: Hepatitis C, MicroRNA, liver progression, Biomarker, Direct acting antiviral, cirrhosis, Interferon signaling. 


\title{
Recreational Activity and Yoga: An Avenue to Prevent Criminal Propensity among Drug Addicts
}

\author{
NEELAM K SHARMA, ARIUN SINGH*
}

Department of Physical Education, Lovely Professional University, Phagwara- 144411, Punjab (India)

Email: dr.arjun89@gmail.com

\begin{abstract}
The aim of the study was to assess the impact of selected training programme in yoga and recreational activity for managing criminal propensity among drug addicts. The sample consisted of 30 male drug addicts distributed randomly equally into three groups recreational activity, yoga and control group. A treatment program of ten weeks was implemented to two experiment groups, while as no sort of treatment was given to control group. The data was analysed through ANCOVA and post hoc test. The results showed that p-value for the F-statistic was .000 which was significant at 0.05 level of significance. Since F-statistic was significant a post hoc comparison of differences between the adjusted post-tests paired means was applied among different treatment groups. The findings revealed that there was a significant difference of all the treatment groups with the control group as the $\mathrm{p}<.05$. However adjusted mean value of recreational activity group was found to be least 76.67 , thus recreational activity group was considered as the most effective treatment group and control group was the least effective treatment group in reducing criminal propensity among the drug addicts. This study suggests that recreational activity plays an important role in prevention and management of criminal propensity.
\end{abstract}

Keywords: Recreational activity, Yoga; Criminal propensity; Drug addicts. 


\title{
PHYTOCHEMICAL SCREENING, IN-VITRO ANTIBACTERIAL ACTIVITY AND ANTIOXIDANT ACTIVITY OF ESSENTIAL OIL FROM LEAVES OF AJUGA PARVIFLORA BENTH.
}

\author{
SANIAY KUMAR ${ }^{1}$, PAWAN KUMAR ${ }^{1}$ SACHIN GUPTA2 ${ }^{2}$ MOHD. SUHAIL JAVED ${ }^{1 *}$
}

${ }^{1}$ Department of Chemistry, D.S.B. Campus Kumaun University, Nainital, 263002, Uttarakhand (India).'2Division of Plant Pathology, FOAChatha, Sher-e-Kashmir University of Agricaltural Sciences and Technology -Jammu (J\&K) -180009 (India)

Email: msuhail12003@yahoo.co.in

\begin{abstract}
The aim of our study was to evaluate the phytogenic chemical compounds and assess their antibacterial and antioxidant activity of essential oil of Ajuga parviflora Benth. growing in Himalayan region. In the present study the phytochemical constituents screened from Ajuga parviflora is rich in oxygenated monoterpenoids and sesqueterpenoids which includes Cadinol < $\alpha->(21.36 \%)$, Muurolol < $\alpha->(14.2 \%)$, Cubebol-10-epi- $(12 \%)$, Germacrene D-4-ol (9.6\%), Germacrene D (4.32\%), Phytol acetate (3.58\%) and Humulene epoxide I (1.26\%) are the major constituents. The Zone of Inhibition (ZOI) shown by essential oil against test bacterial strains at concentration of $500 \mu \mathrm{g} / \mathrm{ml}$ to Gram negative bacteria Pseudomonas aeruginosa (5.6mm), Escherichia coli $(5 \mathrm{~mm})$, Salmonella typhimurium $(8.6 \mathrm{~mm})$ and Gram positive bacteria Bacillus subtilis $(8.3 \mathrm{~mm})$. At the same time, ZOI of standard antibiotic ciprofloxacin against test bacterial strains was Pseudomonas aeruginosa (9.6mm), Escherichia coli (14.3mm), Salmonella typhimurium $(19.3 \mathrm{~mm})$ and Bacillus subtilis $(20.6 \mathrm{~mm})$, respectively. The free radical scavenging property of Ajuga parviflora employed by in-vitro assay methods like scavenging activity of DPPH and FRAP was 81\% for DPPH and 74\% for FRAP, respectively.
\end{abstract}

Key words: Ajuga, oil, DPPH, FRAP, phytoconstituents, antibacterial, antioxidant. 


\title{
ASSESSMENT OF IN VITRO ANTIBACTERIAL AND ANTIFUNGAL ACTIVITY OF CURCUMA CAESIA ROXB.
}

VANDNA KALSI*, RANDEEP KAUR, BARINDERJIT KAUR, ASHISH SUTTEE

School of Pharmaceutical Sciences, Lovely Professional University, Phagwara, Punjab, India. Email: vandana.kalsi@lpu.co.in

\begin{abstract}
The present study was carried out with an objective to investigate the antibacterial and antifungal potentials of extracts prepared from dried rhizomes of Curcuma caesia Roxb. family Zingiberaceae. The plant is commonly known as Kali haldi and possesses a number of ethnomedicinal uses. The antibacterial activity of the extracts was tested against two gram positive (Staphylococcus aureus, Streptococcus pyogenes), and two gram negative bacteria (Escherichia coli, Pseudomonas aeruginosa) using cup-plate method. The standard drug used was Ofloxacin (0.2 ml) at a concentration of $5 \mathrm{mg} / \mathrm{ml}$. The antifungal activity was tested against Aspergilus fumigatus and Candida albicans using cup-plate method and Clotrimazole $(10 \mathrm{mg} / \mathrm{ml})$ was taken as standard reference. Both the extracts were investigated for antibacterial and antifungal activity at three doses $(100 \mathrm{mg} / \mathrm{ml}, 150 \mathrm{mg} / \mathrm{ml}$, and $200 \mathrm{mg} / \mathrm{ml})$. The extracts of the plant exhibited dose dependant activity. The ethanolic and DCM extracts of Curcuma caesia at a dose of $200 \mathrm{mg} / \mathrm{ml}$ exhibited significant antibacterial activity with maximum zones of inhibition. Curcuma caesia ethanol extract at a dose of $200 \mathrm{mg} / \mathrm{ml}$ exhibited significant antifungal activity against Candida albicans and Aspergilus fumigatus. The phytochemical analysis of dichloromethane (DCM), and ethanol extracts of the plant have shown the presence of various phytoconstituents like glycosides, carbohydrates, saponins, phytosterol, flavonoids, resins, tannins, and diterpenes. The results of the present investigations suggest that the plant is an important candidate for further investigations on isolation and characterization of the bioactive principles responsible for antimicrobial activity. The antimicrobial activity of Curcuma caesia was due to the presence of various secondary metabolites. The plant can be used to discover bioactive natural products that may serve as leads in the development of new pharmaceutical compounds.
\end{abstract}

Keywords: Curcuma caesia, Zingiberaceae, Staphylococcus aureus, Streptococcus pyogenes 


\title{
ROLE OF GOLD NANOPARTICLES IN THERANOSTIC: AN UPDATE
}

\section{GURMANDEEP KAUR* ${ }^{*}$ YOGITA KUMARI, CLARISSE AYINKAMIYE, SACHIN KUMAR SINGH, SURAJPAL VERMA, MONICA GULATI, GOPAL LAL KHATIK, RAKESH NARANG, BIMLESH KUMAR}

School of Pharmaceutical Sciences, Lovely Professional University, Phagwara -144411, Punjab, India Email: gurmandeep095@gmail.com.

\begin{abstract}
Gold Nanoparticles (AuNPs) have several biomedical applications in diagnosis and treatment of diseases such as targeted chemotherapy and in water remediation. Due to their enormous properties such as large surface to volume ratio, small size and functionalized surface which make gold nanoparticles a suitable carrier system. It can be conjugated with various ligands and drugs for targeted delivery system. Gold nanoparticles cause the necrosis of only cancer cells therefore these can be utilized as a delivery vehicle as well as anticancer agents. In water remediation, AuNPs can utilize for the removal of contaminants from the water due to its high absorption capacity. As a diagnostic agent there are several applications of gold nanoparticles in imaging. AuNPs are utilized in the detection of various metal ions, organic molecules, proteins, microorganisms and toxic chemicals. The current study is focused on the latest updates of gold nanoparticles as targeted drug delivery, as a nano carrier and in diagnostic as well as therapeutics.
\end{abstract}

Keywords: AuNPs; Targeted drug delivery; water remediation; imaging. 


\title{
AN OVERVIEW OF VARIOUS TECHNIQUES USED TO PREPARE GOLD NANOPARTICLES YOGITA KUMARI*, GURMANDEEP KAUR, CLARISSE AYINKAMIYE, SACHIN KUMAR SINGH, SURAJPAL VERMA, MONICA GULATI, GOPAL LAL KHATIK, RAKESH NARANG, BIMLESH KUMAR
}

School of Pharmaceutical Sciences, Lovely Professional University, Phagwara -144411, Punjab, India

Email: kyogita72@gmail.com

\begin{abstract}
The journey of gold has been started from Ayurveda in which gold was used in the form of bhasma and churna for treating various diseases. The release of various therapeutic drugs to a particular target is a consistent challenge for formulation scientists as well as regulatory agencies, hence gold nano-particles (AuNPs) are now a day's being used as a promising carrier system for transporting the drugs to a particular site without affecting the other parts of body. For producing gold nanoparticles of suitable size range and of good stability, various methods are being developed. The two main approaches that are involved in synthesis of AuNPs are "top down" and "bottom up" approach. Top down technique involves successive attrition of gold to get nano sized particles of sub-micron range. Bottom up techniques involves assembly of atoms from bottom into desired nanostructure. Top down method includes Turkish method, Burst method, Photolithography, martin and miscellaneous method, whereas bottom up method includes chemical, sonochemical and thermal reduction methods. All these methods are used to produce gold nanoparticles in nano-range. Till date, despite having enormous unique techniques, generation / synthesis of stable nanoparticles are still a challenge. The current paper focuses on the various preparation techniques of AuNPs and their limitations.
\end{abstract}

Keywords: AuNPS; top down; Turkish; miscellaneous; bottom up. 


\title{
CLINICAL SIGNIFICANCE OF CARICA PAPAYA LEAVE EXTRACT IN THROMBOCYTOPENIA INDUCED BY DENGUE
}

\section{BASHIR USMAN, NAVNEET KHURANA*}

School of Pharmaceutical Sciences, Lovely Professional University, Jalandhar, Punjab, India

Email: bashirusman94@gmail.com,navi.pharmacist@gmail.com

\begin{abstract}
Dengue is the most rapidly spreading mosquito-borne viral disease in the world. In the last 50 years, incidence has increased 30 -fold with increasing geographic expansion to new countries and, in the present decade, from urban to rural settings. It is caused by single stranded RNA, one of the four serotypes (DEN1-4). Its infection is manifested by increased vascular permeability, hypovolemia, hypotension, shock, encephalopathy, encephalitis, liver failure, myocarditis, thrombocytopenia, and peripheral destruction of platelets. Thrombocytopenia may be associated with alterations in megakaryocytopoiesis by the infection of human haematopoietic cells and impaired progenitor cell growth, resulting in platelet dysfunction (platelet activation and aggregation), increased destruction or consumption (peripheral sequestration and consumption). Haemorrhage may be a consequence of the thrombocytopenia and associated platelet dysfunction or disseminated intravascular coagulation. A transient and reversible imbalance of inflammatory mediators, cytokines and chemokines occurs during severe dengue, probably driven by a high early viral burden, leading to dysfunction of vascular endothelial cells, derangement of the haemocoagulation system followed by plasma leakage, shock and bleeding. Carica papaya, belonging to the family- Caricaceae, is proved to be effective in attenuation of thrombocytopenia caused by dengue. Several clinical and preclinical studies have shown that the extract is efficacious and safe in thrombocytopenia. However, in vitro studies have shown that Methanolic extracts, containing triterpenoids and flavonoids has cytotoxic effect against LLC-MK2 cell lines while chloroform extract, rich in alkaloids, tannin and saponin, was found to have less inhibitory action. Carica papaya contains many pharmacologically important phyto constituents. Among them, active moiety responsible for thrombocytopenia is yet to be investigated.
\end{abstract}

Keywords: Dengue, Thrombocytopenia, Carica papaya, Haemorrhage 
Abstract No. RTBS-P-17

\title{
MODIFIED APPLE POLYSACCHARIDE: ROLE IN TREATMENT OF COLONIC DISEASES SOUVIK MOHANTA*, JIVAN JYOTI, SANANDA SOM, VISHU VERMA, SACHIN KUMAR SINGH, MONICA GULATI, BIMLESH KUMAR
}

Department of Pharmaceutical Sciences, Lovely Professional University, Phagwara-144411, Punjab (India) Email: souvikmohanta@gmail.com

\begin{abstract}
Apple is always considered as the healthiest fruit of all. It has the second highest level of anti-oxidative power among all other fruits and its consumption is directly related with controlling the risks of colon specific diseases. Colorectal diseases are increasing in the society at an alarming rate. Regular intake of one or more apple reduces the risk of colon diseases to a significant level. Study confirmed that cloudy apple juice can decrease hyper proliferation, DNA damage and crypt-foci development in the colon of dimethyl hydrazine initiated rats. Many ingredients of apple, such as procyanidins and triterpenoids have beneficial effects for colorectal cancer prevention. Polysaccharide from apple known as the modified apple polysaccharide (MAP) has proven its potential for treatment of various colorectal diseases. It is reported that MAP could induce caspasedependent apoptosis in human colorectal cancer (CRC) cells via both the intrinsic mitochondrial pathway and extrinsic death-receptor pathway. In colitis-associated carcinogenesis, there is activation of nuclear factor-jB (NF-jB) via lipopolysaccharide (LPS) binding to the toll-like receptor 4 (TLR4). The LPS/TLR4/NF-кB pathway contributes to the development and metastasis of colitis-associated colon cancer. Modified apple polysaccharide (MAP) have the ability to alter the LPS/TLR4/NF- $\kappa B$ pathway and stop the metastasis which finally leads to the prevention of colon cancer. This presentation aims in proving the worth of MAP by focusing mainly on its mechanisms of action.
\end{abstract}

Keywords: Modified apple polysaccharide, colorectal diseases, nuclear factor-jB, lipopolysaccharide, toll like receptor 4 
Abstract No. RTBS-P-18

\title{
SURFACE ENGINEERED PPI DENDRIMERS IN CANCER TREATMENT: FORMULATION DEVELOPMENT AND CHARACTERIZATION
}

\section{AKSHAY PATIL ${ }^{*}$ VIJAY MISHRA}

Lovely Institute of technology (Pharmacy), Lovely Professional University, Phagwara, Punjab, 144411

Email: akshayspatil95@gmail.com

\begin{abstract}
Cancer disease depicts the uncontrolled growth of the cells. Treatment alternatives for cancer incorporate surgery, chemotherapy hormone treatment, immunotherapy and radiotherapy. Among them, chemotherapy is the most normally utilized alternative for the treatment of involves. Poor intracellular endorsement of anti-cancer drugs is one offer problem in the cancer chemotherapy, which prompts the failure of cancer chemotherapy. To achieve every viable cell in a tumour, anticancer drugs must be conveyed proficiently through the tumour vasculature, cross the vessel partition and transverse the tumour tissue. Dendrimers are biocompatible, highly reactive, mono dispersed, hyper branched macromolecules having three dimensional structure and unique physicochemical properties which make dendrimer a star in field of biomedical and pharmaceutical research. Poly-(propyleneimine) PPI dendrimers are hyper-branched macromolecules, mostly fabricated by divergent approach in an arrangement of replication of double Micheal addition of acrylonitrile to primary amines tailed by heterogeneously catalyzed hydrogenation of nitriles. Present study was aimed for developing and exploring the use of thiamine (Tm) conjugated 5.0G PPI dendrimers for improved delivery of paclitaxel (PTX). The developed dendrimeric formulations were characterized for size, drug loading efficiency, drug release and in vitro hemolytic toxicity. The surface morphology of dendrimer based formulation was studied by TEM. The PTX-loaded thiamine conjugated PPI dendrimers (PTX-Tm-5.0G PPI) demonstrated reduced in vitro hemolytic toxicity. The maximum drug loading and drug entrapment efficiency was found to be $81.62 \%$ and $97.95 \%$, respectively in methanol: phosphate buffer saline (pH 7.4) (3:7). In vitro drug release data showed sustained release of PTX from PTX-Tm-5.0G PPI as compared to plain PTX and PTX-5.0G PPI dendrimers. The results depicted the promising features of Tm conjugated PPI dendrimer and can be used in cancer treatment.
\end{abstract}




\title{
PROTEIN BASED NANOCARRIERS FOR DRUG DELIVERY: AN OVERVIEW
}

\section{ANSHUL ATTRI*, GURMANDEEP KAUR, YOGITA KUMARI, RINKU ROZERA, M. HIMAJA, SUDHAKAR CK, SACHIN KUMAR SINGH, SURENDRA NAYAK}

School of Pharmaceutical Sciences, Lovely Professional University, Phagwara- 144411, Punjab, India

Email: anshul.attri@live.com

\begin{abstract}
The growth of nanotechnology has created various new opportunities in medical sciences to grab especially in drug delivery. Nanoparticles (NPs) are in a great concern now from the past decade. Most notable use of the NPs is the targeted drug delivery of the therapeutic and diagnostic agents. These NPs include Gold NPs; Silver NPs. Despite their multiple benefits, NPs suffer from clinical level toxicities. Proteins which are natura biomolecules are such an attractive alternative to synthetic polymers or metallic NPs as they are safe because these are natural. Proteins which can be used as nanocarriers for drug delivery are albumin, casein, soy proteins, whey proteins, zein, elastin, gliadin and legumin. These possess various properties like size, surface modification, biocompatibility to the biological fluids, reduced toxicities, etc. These properties result in the targeted delivery of the drug without producing any toxicity to the neighbouring cells. Another advantage is that these protein NPs can be prepared under mild conditions without using toxic chemicals or organic solvents. In this study we review various proteins that have been used in various drug delivery systems.
\end{abstract}

Keywords: Proteins, Nanocarriers, Nanoparticles, Drug delivery 


\title{
LECITHIN BASED ULTRADEFORMABLE CARRIERS - A UNIQUE VESICLE FOR TRANSDERMAL DELIVERY THROUGH STRATUM CORNEUM MANINDERIEET KAUR, SWATI CHAURASIYA, KALVATALA SUDHAKAR* \\ LIT (Pharmacy), School of Pharmaceutical Sciences, LPU, Jalandhar, Punjab 144411 \\ Email: sudhakar.20477@lpu.co.in, manindermani267@gmail.com
}

\begin{abstract}
The conventional treatment of different skin infections is by topical dosage forms such as gels, creams or lotions. These dosage forms exhibit low impact in treatment because of poor permeation across the superficial layer of human skin, stratum corneum. To achieve drug delivery in deeper layers or in blood stream, numerous novel carriers have been fabricated with nanotechnology such as; liposomes, niosomes, transfersomes, ethosomes and many more. These carriers possess ability to give a controlled and expanded release of drugs systemically to increase the bioavailability. Ultradeformable vesicles are one of the second-generation carriers that can also be called as modified form of liposomes comprised of phospholipids, cholesterol, and edge activators. The phospholipids and cholesterol formulate the vesicles whereas edge activators provide deformable and adaptable nature to vesicles that aid to capture amphiphillic drug moieties. These novel carriers are metastable bodies that are non-occlusive in nature. After application, it get permeate across minute pores of stratum corneum due to the generation of driving force and water gradient on the skin layer, which dehydrate the vesicles. The dried vesicles show affinity toward aqueous content of corneocytes and assist to penetrate into deeper layers of skin. Then reform into original shape after penetration across dermis region and blood, which treats various skin diseases such as pimples, cellulitis, acne, ringworm etc.
\end{abstract}

Keywords: Ultradeformable vesicles, Permeation, Skin diseases, Transfersomes, Edge activator, Liposomes. 


\title{
PHARMACEUTICAL APPROACH FOR TREATMENT OF CHRONIC DISEASE: HYPERTENSION BY CHRONOTHERAPY
}

\author{
SWATI CHAURASIYA, MANINDERJEET KAUR, KALVATALA SUDHAKAR*
}

LIT (Pharmacy), School of Pharmaceutical Sciences, LPU, Jalandhar, Punjab 144411

Email: sudhakar.20477@lpu.co.in, swatichaurasiya21@gmail.com

\begin{abstract}
The biological function of the body is controlled by circadian rhythm which is composed by Suprachiasmatic nucleus (SCN) where brain circulates the information to different cells/tissue of the body that make easier for living being to adjust in environment at any time. Hypertension is one of the most common diseases for high rate of morbidity all over the world. The change in blood pressure (BP) and heart rate (HR) is due to 24-hrs circadian rhythm. Chronotherapy plays a vital role in the management of hypertension where patients have to take medication once a day i.e. either in morning or in bedtime. The change in pharmacokinetic and pharmacodynamic of drug had observed due to different time of administration. Administration of antihypertension drugs such as valsartan given during nighttime decreases both diurnal as well as nocturnal BP and reduces excretion of albumin from urine. Various chronopharmaceutical approaches develop to achieve chronotherapy such as pulsatile system, floating system, tablet-in-tablet. Tablet-in-Tablet is a new technique in which multiple drugs can be incorporated which will improve patient compliances, separate two incompatible drugs, modulate different release profile, mask bitter taste drug, and prevent from environmental degradation. A biological clock based dosage form is more effective than same dosage form prescribed by its dose. Chronotherapy is also applicable in other diseases like cancer, rheumatoid arthritis, stroke, asthma, obesity, diabetes.
\end{abstract}

Keywords: Circadian rhythm, Hypertension, Chronotherapy, Chronopharmaceutical approach, Tablet-in-Tablet 


\title{
ECG SIGNAL BASED CHARACTERIZATION OF CORONARY ARTERY DISEASE VINEET KUMAR
}

Department of Electronics and communication Engineering, Lovely Professional University,Phagwara- 144411, Punjab (India) Email: vineet.15921@lpu.co.in

\begin{abstract}
Coronary Artery Disease (CAD) is the main chain of catastrophic heart diseases such as Heart Attack (HA), Ischemic Heart Disea se (IHD) and Heart Failure (HF). Early recognition and handling for CAD state is vital and may help in prevent it from progressing further. For accurate identification of CAD from Electrocardiogram (ECG) signals using manual interpretations is not an easy task to achieve. With the help of computer-aided techniques necessary step should be taken for detection of CAD condition. In this propose work a novel nonlinear methodology, CAD Index (CADI) and HigherOrder Statistics is implemented on ECG signals for accurate identification of CAD. In this work 146793 ECG beats are used. HOS bispectrum and cumulant features are extracted from each ECG beat. The extracted features are subjected to Principal Component Analysis (PCA) dimension reduction technique. Then PCA coefficients are ranked using Bhattacharyya, entropy, fuzzy Max-Relevancy and Min-Redundancy (mRMR), Receiver Operating Characteristics (ROC), t-test, Wilcoxon ranking methods. All ranked features are fed into Support Vector Machines (SVM) classifiers one by one to obtain the highest classification performance by using minimum number of features. The proposed methodology has achieved an average accuracy of $97.65 \%$, sensitivity of $93.58 \%$, and specificity of $98.76 \%$, using SVM classifier using 13 bispectrum features.
\end{abstract}

Keywords: Coronary Artery Disease; ECG; CADI; PCA; Support Vector Machines (SVM) 


\title{
RELATIONSHIP OF SEMINAL FRUCTOSE AND SERUM PROLACTIN LEVELS IN INFERTILE MEN
}

\author{
IUHI KATARIA ${ }^{*}$ GURPREET KAUR $^{1}$, LALIT THAKUR ${ }^{2}$, GAGANDEEP SINGH ${ }^{3}$
}

1Department of Medical Lab Sciences, Khalsa College of Pharmacy \& Technology,Amritsar -143001 Punjab, (India) 2Department of Medical Lab Sciences, Punjab College of Technical Education, Badhowal Ludhiana -142021 Punjab, (India) ${ }^{3}$ Department of Medical Lab Sciences, Baba Isher Singh Institute of Sciences \& Technology Gagra, Moga -142001 Punjab, (India) Email: kataria_juhi@yahoo.in

\begin{abstract}
Male infertility refers to a male's inability to cause pregnancy in a fertile female. Infertility is a wide spread problem for about one in five infertile couples, the problem lies in the male partner. Male infertility is usually caused by problem that affects either sperm production or sperm transport. Male infertility is generally characterized by dysfunctions in the processes of penetration, adhesion, and fusion of sperm with the oocyte. There is a positive association between the abnormal semen parameters and sperm count on which clinical diagnosis depends. The present study was carried out in Jalandhar region of Punjab. The objective of the study aims at evaluating erythrocyte sedimentation rate (ESR) in the blood, prolactin levels in the serum and comparing the levels of fructose in the semen of infertile males and normal healthy controls of reproductive age of $20-45$ years respectively. Morphology and motility of sperm and their counts were determined by microscopy. The semen fructose levels were evaluated by fructose drop test, ESR was evaluated by Westergren's method and Serum prolactin levels were determined by Electrochemiluminescence immunoassay. Seminal analysis revealed low fructose levels and low sperm count with decreased motility. Levels dropped as the age increased in the sample population under study. ESR was found significantly high in infertile men whereas prolactin levels did not show any significant differences as compared to control group. Various factors viz environment, therapeutic agents, occupational factors are responsible for infertility in males. Low fructose levels and less semen volume indicate obstructive azoospermia.
\end{abstract}

Keywords: Infertility; motility; semen analysis; fructose; oocyte; erythrocyte sedimentation rate. 


\title{
STRATEGIES TO OVERCOME THE SOLUBILITY ISSUE OF DRUG AZIMULLAH STANEKZAI, KALVATALA SUDHAKAR*
}

LIT (Pharmacy), School of Pharmaceutical Sciences, LPU, Jalandhar, Punjab 144411

Email: sudhakar.20477@lpu.co.in

\begin{abstract}
Solubility is the spectacle of dissolution of solid in liquid segment to offer a homogenous system. Solubility of drug is important parameter for drug to show its pharmacological and therapeutic action. Absorption of a drug is at once depending on its solubility as only a soluble drug may be absorbed into the cells. A fulfilment of method depends on how correctly it makes the drug available at the site of action. Therapeutic effectiveness of a drug relies upon the bioavailability and eventually upon the solubility of drug especially in oral dosage form. An anticipated $40 \%$ of approved drugs and nearly $90 \%$ of the developmental pipeline drugs molecules consist of poorly aqueous soluble molecules. Various methods and techniques have been research to enhance the solubility of drug such as particle size reduction, precipitation method, solid dispersion, Supercritical Fluid (SCF) Process, hydrotropy, solubilization of drug by drug-carrier (dendrimers, Carbon nanotubes). Solubilization and stability should be in balance manner, then only it lead to stable formulation and good pharmacological response, Different strategies required for the Solubility enhancement while maintaining its integrity and stability of drug.
\end{abstract}

Keywords:- Solubility, Hydrotropy, Particle Size Reduction, Dendrimers, Carbon Nanotubes 


\title{
IN - VITRO ANTI - CANCER STUDIES OF ETHANOLIC EXTRACT OF PEEL OF ALLIUM CEPA ON COLORECTAL CANCER CELL LINE (CACO-2)
}

\author{
SNEHIL JAISWAL, TARUNA PATHAK, NANDESH PATEL, HARI OM SHUKLA, GAURAV BANSAL, DV SURYA \\ PRAKASH*
}

Assistant Professor, Department of Biotechnology, Meerut Institute of Engineering and Technology, Meerut -250005 Uttar Pradesh Email: prakashsurya55@gmail.com

\begin{abstract}
Phenols comprise the largest group of plants secondary metabolite. The phenolic constituents are the main components of high antioxidant activity. These phenolic compounds are also inhibit the growth of the cancer cells. In the current research, Soxhlet Extraction process was used for enhancing the concentration of total phenolic content from ethanolic extract of peel of Allium cepa and found to be 8.8 mg/ml of total phenolic content. It was increased to $9.2 \mathrm{mg} / \mathrm{ml}$ from the column chromatography. The purity of total phenolic content was improved by column chromatography. The purified extract containing total phenolic content comprises of the medicinal composition and was used for anticancer activity studies. This plant extract induces a cell arrest to inhibit the growth of the colorectal cancer cell line (Caco-2) from 9.1\% to $72.6 \%$ by MTT assay method.
\end{abstract}

Key word: Allium cepa, Soxhlet extraction, Column chromatography, Total Phenolic Content, Caco-2 cell line 


\author{
NITOFURANTOIN RESISTANCE IN URINARY TRACT INFECTIONS \\ THOMSON SONI ${ }^{1}$, JEEVAN ${ }^{1}$, SUNIL K. GUPTA ${ }^{2}$, SAJID HUSAIN ${ }^{1}$ \\ ${ }^{1}$ Department of Microbiology, Guru Nanak Dev University, Amritsar \\ ${ }^{2}$ Health Center, Guru Nanak Dev University, Amritsar
}

\begin{abstract}
A Urinary tract infection is an infection which infect the one or several important parts of the urinary system such as urethra, bladder ureters and kidneys. In these days urinary tract infection is the most ordinary and recurrent infectious disease in India and it is the major cause of the mortility and morbidity in Indian women, which affects the all age groups across the life span. Escherichia coli, candida albicans, Klebsiella pneumonia and Pseudomonas aerogenosa are the pathogenic organism that cause urinary tract infections mostly. Sample of the patients who were undergoing treatment for the UTI in the Health Centre, Guru Nanak Dev University, Amritsar, were cultured for assessing the degree of resistance against nitrofurantoin (NFT). Nitrofurantoin is an antibiotic which is usually act against the urinary tract infection. It is basically used for the treatment of the cystitis but it is not sensitive for the pyelonephritis. It can be present mainly in two forms nitrofurantoin macrocrystals and nitrofurantoin monohydrate which are chemically known as 1-[[[5-nitro-2-furanyl] methylene] amino]-2,4-imidazoli-dinedione and 1-[[[5-nitro-2furanyl]methylene] amino]-2,4-imidazoli-dinedione monohydrate respectively. Flavoprotiens (nitrofuran reductase) activates the nitrofurantoin as a result it can alter and damage the bacterial ribosomal proteins and nuclic acids. Most of the samples were quite ineffective against nitrofurantoin, extending course of treatment and complications.
\end{abstract}

Key words: Nitofurantoin, Urinary tract infections, cystitis, antibiotic resistance 


\title{
POTENTIAL PRECLINICAL AND CLINICAL TOXICITY OF METALLIC NANOPARTICLES
}

CLARISSE AYINKAMIYE*, YOGITA KUMARI, GURMANDEEP KAUR, SACHIN KUMAR SINGH, ANKIT YADAV KUMAR, SURAJPAL VERMA, MONICA GULATI ${ }^{1}$, RAKESH NARANG, BIMLESH KUMAR, GOPAL LAL KHATIK

School of Pharmaceutical Sciences, Lovely Professional University, Phagwara-144411, Punjab, India Email: mulindaclarisse@gmail.com

\begin{abstract}
Toxicity is a major concern that affects NPs in preclinical phase as well as clinical phase. These NPs have several applications in diagnosis and treatment of diseases and they are used in targeted drug delivery due to their enormous properties such as small size, large surface to volume ratio and functionalized surface. NPs have various chemical, optical, structural and magnetic properties as well as possess different toxicity profiles. They may induce cytotoxicity, genotoxicity due to their exposures through the skin, respiratory tract, gastrointestinal tract and lymphatic system. Toxicity of NPs involves alteration of physiological, physicochemical and molecular conditions of the body. These may alter the physicochemical properties of xenobiotics which results in pharmaceutical changes in solubility, stability as well as pharmacokinetics disposition. This presentation summarizes the current progress in approaches assessing nanotoxicity in including hepatic, renal, gastrointestinal, pulmonary, cardiovascular, nervous, and immune systems.
\end{abstract}

Keywords: NPs, Toxicity, Cytotoxicity, Genotoxicity, preclinical. 


\author{
HISTORICAL PERSPECTIVE, PREVALENCE, RISK FACTORS AND SPECIAL REFERENCE ON \\ PATHOPHYSIOLOGY OF GESTATIONAL DIABETES MELLITUS \\ KAMALDEEP SINGH ${ }^{1 *}$, SAVITA DEVI ${ }^{2}$, MANISHA BASRA ${ }^{1}$, SHEIKH DANISH HAMID ${ }^{1}$ \\ 1* Department of Medical Laboratory Sciences \& Biotechnology, CT Group Of Institute, Shahpur, Jalandhar, Punjab, India. \\ ${ }^{2}$ Department of Medical Laboratory Sciences, Lovely Professional University, Punjab-144411 \\ Email: Kamaldeepbilkhu53@gmail.com
}

\begin{abstract}
Gestational diabetes mellitus (GDM) is a state which is firstly recognized during pregnancy that combating with the intolerance of glucose. GDM is one of the most common complication of pregnancy i.e. metabolic dysfunction and moreover mortality along with morbidity in fetal. Other possible cause of GDM are symbolic and probably fetal and maternal complications that are neonatal metabolic complications, perinatal death, preeclampsia, polyhydramnios, fetal macrosomia, birth trauma and perative delivery. As per historical panorama the diabetes accelerates pregnancy can have severe abnormal repercussion on neonate. In contemporary years the prevalence report has been impersonate that world wiedly the high number of GDM noted, particularly in developed nations due to advanced maternal age, obesity, migratory patterns and changes life style. There are plethora of risk factors for GDM that are history of macrosomia, strong family history of diabetes, and obesity. The keystone genesis of development GDM is related to modern lifestyle, first and formostly, a lack of exercise and an unhealthy diet, the environment and some degree of genetic profile. Similarly there are numerous path physiological reasons like genetically, hyperglycemias and oxygen stress, autoimmunity and ambience factors. In addition, due to involvement of feto placental unit and adipose tissue in GDM can also occur. The management of GDM have first line option with diet control and exercise, similarly insulin is also used primarily as a first line option in pharmaceutical.
\end{abstract}

Key Words: Gestational diabetes mellitus, neonatal metabolic complications, maternal age, obesity, hyperglycaemic 


\title{
PREVALENCE OF DYSLIPIDEMIA IN DIABETES MELLITUS TYPE2, OBESITY AND HYPERTENSION \\ INDU BALA
}

Chitkara School of Health Sciences, Chitkara University, Jhansla-140401, Punjab.Email: indu.bala@chitkara.edu.in

\begin{abstract}
Dyslipidemia is the major cause of mortality and morbidity worldwide. Mainly lipid alterations are occurred in dyslipidemia, it is most commonly defined as the impaired level of lipoproteins in blood like high levels of LDL(low density lipoproteins), VLDL(very low density lipoproteins), Total cholesterol, Triglycerides and low level of HDL(high density lipoproteins) which are responsible for the transportation of lipids in circulation. The most common causes for dyslipidemia are diabetes mellitus type2, obesity and hypertension. There are many other mechanism by which the Dyslipidemia is occurred like our eating habits, sedentary lifestyle. In this study the total 80 subjects were taken who had different types of complications like diabetes mellitus type 2, obesity and hypertension. Out of 80 subjects, there are 52 males and 28 females .Subjects were divided into 3 groups; diabetic group, obesity group and hypertensive group. After that the lipid profile and fasting blood sugar is done after 12 hrs overnight fasting. Other things are also noted down like BMI, height, weight and their eating habits. After the analyzing of lipid profile the results are following: - out of 80 patients there are 32[40\%] diabetic patients who have Dyslipidemia or altered lipid profile, 31[38.7\%] obese subjects who have Dyslipidemia and 17[21.3\%] hypertensive subjects who have Dyslipidemia. Conclusion of the study is that the diabetic's patients who have type 2 DM [Group1] and the obese peoples [Group2] are more prone to cardiovascular disease comparing to hypertensive subjects [Group3]. And also the study shows that the males are more prone than females for cardiovascular diseases.
\end{abstract}

Keywords: Dyslipidemia, DM2, hypertension, BMI, lipoproteins. 


\title{
ISOLATION AND CHARACTERIZATION OF MICROORGANISM FROM HAND AND UTENSIL SAMPLES OF FOOD VENDORS AND THEIR RESISTANCE TO COMMON USED ANTIMICROBIALS GURVINDER KAUR RANA
}

Chitkara School of Health Sciences, Chitkara University, Jhansla 140401, Punjab

\begin{abstract}
It is known that street foods are the major cause of food borne illness such as gastrointestinal infections caused by enteropathogen bacteria. Such as Staphylococcus, E. coli, Klebsiella, Salmonella. This study was conducted to examine the microbiological quality of hands and utensils of food vendors and their resistance to commonly used antimicrobial. For the isolation 20 hand swab and 20 utensil swab sampleswere collected from different food vendors from Chandigarh, Mohali and its periphery. These samples were identified morphologically and biochemically using standard procedures and their susceptibility to commonly used antimicrobials. The result of the study showed the presence of 11 Staphylococcus, 13 E. coli, 4 Klebsiella and 2 Salmonella. E.coli were the most prevalent food-borne pathogen isolate. Aspergillus niger was the fungal contaminant present in sample. Susceptibility of all isolate to a variety of antimicrobial agents was tested and the highest rates of resistance among microbial isolates for the antibiotic were methicillin and clindamycin. The entire organisms were sensitive to Amoxcylin and Ampicillin. Antibiotic resistance is recognized as a growing problem. The prevalence of antimicrobial resistance among food borne pathogens is a major threat which may pose difficulty in further treatment. This study highlights the need of awareness amongst the food vendors for hygiene practice. Thus lowering the incidence of antimicrobial resistance and gastrointestinal infection
\end{abstract}

Key words: microorganism, antibiotics, resistance, food vendors. 


\title{
SIGNIFICANCE OF CRYOPRESERVATION IN THE FIELD OF ASSISTED REPRODUCTIVE TECHNOLOGY
}

\author{
SAURABH, GEETA DIGRA
}

Janam Fertility Centre (Test Tube Baby Centre) Jalandhar City - 144001, Punjab

\begin{abstract}
Cryopreservation is the procedure which stabilizes the cells and its components at cryogenic temperature. The Significance of Cryopreservation of the Oocytes/ Embryos/ Sperms in the field of Assisted Reproductive Technology has increased now days. In 1866 an Italian physician Mantegazza introduced the concept to preserve the semen by cooling it at $-15^{*} \mathrm{C}$. Later on, the cryopreservation of the human Sperms introduced in 1960 . The first birth from cryopreserved human Oocytes was recorded in 1986. Cryopreservation of the Sperms is particularly important in case of nonmalignant diseases such as Diabetes mellitus, autoimmune disorders and chemotherapy or radiotherapy in testicular malignancy as it may lead to testicular damage. This technique involves cooling the cells at $-196^{*} \mathrm{C}$ and store them in liquid nitrogen where arresting of all type of metabolic activities/processes of the cells occurred. At the time of Cryopreservation the survival of the cells is depends upon the time, sterility, type and concentrations of the cryoprotectant used. The cells are dehydrated and permeated with the help of cryoprotectant and then preserved in liquid nitrogen. The cryoprotectant used for this technique (glycerol, ethylene glycol, dimethyl sulphoxide and 1,2- propanediol) having low molecular weight and highly permeable chemicals which protects the cellular wall and its components from freezing damage by ice crystallization. Today Cryopreservation of the Oocytes/Embryos/Sperms is the major and very useful part in ART for the treatment of the infertility.
\end{abstract}

Keywords: Cryogenic, Cryopreservation, Cryoprotectant, Liquid Nitrogen 


\title{
CO-CRYSTALS: ROLE IN DRUG DEVELOPMENT
}

SANANDA SOM*, JIVAN JOTI, SOVIK MOHANTA, SACHIN KUMAR SINGH, GOPAL LAL KATHIK, BHUPINDER KAPOOR

Department of Pharmaceutical Quality Assurance, Lovely Professional University, Phagwara Email: sanandasom92@gmail.com

\begin{abstract}
Over the last few years, design and synthesis of pharmaceutical co-crystals have acquired attention in pharmaceutical crystal engineering. Cocrystallization of drug substance provides a wonderful possibility to improve the physicochemical as well as pharmacokinetic properties such as solubility, bioavailability, adsorption, metabolisms, systematic elimination, stability, decomposition, and dissolution rate. It has linked both crystal engineering and supra-molecular chemistry. Hence, the physicochemical parameters can be varied. This can be done through shuffling and controlling various inter-molecular interaction including hydrogen bonding and noncovalent interaction such as halogen bond, $\pi-\pi$, and columbic interaction. These co-crystals provide the possibility of better alternatives to optimize drug physical characters and biopharmaceutical problems consisting of solubility, bioavailability, and stability. The prevalence of poorly soluble drugs in drug development provides a notable risk of new products demonstrating low and erratic bioavailability with consequence for safety and efficacy, particularly when delivered by oral route administration. Although numerous technologies exist for enhancing the bioavailability of drugs with low solubility, the success of these approaches is not yet guaranteed and is greatly dependent on the physical and chemical nature of the molecules being developed. Among studied compounds, polyphenols appear as one of the most promising groups. For example, the utility of curcumin is limited by its, lack of water solubility, and relatively low in vivo bioavailability. Crystal engineering offers a number of routes to improve the dissolution rate, which can be adopted through an in-depth knowledge of crystallization process and molecular properties of API.
\end{abstract}




\title{
PREDICTION OF ANTI-PARKINSON POTENTIAL OF PHYTOCONSTIUENTS USING PASS ONLINE PROGRAM
}

\author{
RAIAN KUMAR ${ }^{1}$, RAKESH KUMAR ${ }^{1}$, NEHA SHARMA ${ }^{1}$, SHELLY KHURANA ${ }^{2}$, NAVNEET KHURANA ${ }^{*}$
}

1Department of Pharmacology, School of Pharmaceutical Sciences,Lovely Professional University, Phagwara, Punjab, 144411

${ }^{2}$ Government Polytechnic College, Amritsar. Email: rajankumar2788@yahoo.com

\begin{abstract}
Neurodegenerative disorders are group of disorders in which there is loss of neuron cells in different brain regions leading to the debilitating condition of the patients. Parkinson's disease (PD) is one of the most common motor related neurodegenerative disorder. Dopaminergic neurons are the main targets in PD. Substantia nigra pars compacta is the area where degeneration of dopaminergic neurons takes place which further leads to deficiency of dopamine and appearance of symptoms like tremors, rigidity and postural instability. The available drug therapy is not able to cure the underline cause of PD but only provides the symptomatic relief. So, it is the main target of all scientists worldwide to search and develop a compound which can provide symptomatic relief as well as cure the underline pathological reason. Prediction of Activity Spectra of Substances (PASS) is a valuable software which can help to predict the different types of biological activities of compounds on the basis of their chemica structure. Canonical Simplified Molecular-Input Line-Entry System (SMILES) are used to predict the anti-parkinson activity on this software, which are obtained from PubChem website. The predicted activity have also been compared with marketed compound like levodopa. Present research work focused to predict and compile the information regarding the anti-parkinson activity of some pharmacologically important phytoconstiuents using PASS online program.
\end{abstract}

Keywords: Parkinson's disease, PASS, Levodopa, Phytoconstituents 


\title{
STRUCTURE ACTIVITY RELATIONSHIP STUDY OF SODIUM-DEPENDENT GLUCOSE CO- TRANSPORTER-2 (SGLT-2) INHIBITORS AS ANTIDIABETIC AGENT
}

\author{
LINDA ELIONA ITUWE*, RAKESH NARANG, SURENDRA KUMAR NAYAK, GOPAL L KHATIC, SACHIN KUMAR \\ SINGH
}

School of Pharmaceutical Sciences, Lovely Professional University, Phagwara (Punjab)

\begin{abstract}
Sodium-dependent glucose co-transporters (SGLT) are a family of glucose transporter found in the intestinal mucosa (SGLT-1) and the proximal tubule of the nephron (SGLT-2). They contribute to renal glucose reabsorption. Many SGLT-2 inhibitors approved by FDA for the treatment of type II diabetes mellitus (T2DM) and seen to be the best anti-hyperglycemic agents due to their high potency in inhibiting glucose reabsorption. Further research lead to C-arly glucoside SGLT-2 inhibitors dapagliflozin, canagliflozin and empagliflozin which are categorized as effective SGLT-2 inhibitors in vitro and gastrointestinal stability in vivo than 0-glucosides.SGLT-2 inhibitors tend to offer good bioavailability and single dose intake either in combination or alone. In view of above facts present report based on the study of mechanism of action, advantages and SAR of reported most active SGLT inhibitors as antidiabetic agent. SGLT are insulin-independent (allows to be used at various stages during the progression of T2DM), low risk of hypoglycemia, modest weight loss and $\mathrm{HbA}_{1 \mathrm{C}}$ reduction (i.e. ranging from $0.6 \%$ to nearly $1 \%$ ). SAR results indicated that introduction of alkoxy like methoxy group at ortho position of the phenyl ring adjacent to the glucose moiety resulted in good SGLT-2 inhibitory activity. In addition to that 0-spiroketal and macrocyclizing the glucose moiety improved SGLT-2 inhibitory activity. Furthermore, presence of alkyl and bulkier group at paraposition on the distal phenyl ring also increases the potency and selectivity of SGLT-2 inhibitory action. Present review will be helpful for the researchers, who are working in area of synthesis of SGLT inhibitors as antidiabetic agent.
\end{abstract}

Key Words: SGLT, Diabetes mellitus, Hypoglycemic agents, SAR 


\title{
STEM CELL THERAPY: A POTENTIAL BOON FOR METASTATIC BREAST CANCER ROHIT KUMAR*, REENA GUPTA
}

Lovely School of Pharmaceutical Sciences, Lovely Professional University, Phagwara, Punjab (INDIA)- 144411 Email: rohit.kumar88701@gmail.com

\begin{abstract}
Stem cell therapy is an intervention strategy that in order to treat disease tissue regeneration is probably the most important and possible application of stem cell research. Standard doses are utilized to kill cancer cells. So the approach of stem cell therapy can be applied with minimal side effects which results from the conventional therapies. Metastatic breast cancer (also called stage IV or Advanced) is a stage of breast cancer in which cancer cells break away from the tumour in the breast, spread to the other parts of body, and keep growing. Breast cancer in woman have recurred after treatment and metastasized to other parts of body and keep growing. Allogenic stem cell transporters have been used to cure the patients with haematological (such as blood or bone marrow cancer) and represents as an effective alternative treatment for some solid tumors including advanced metastatic breast cancer. In ACST peripheral blood stem cells and Tymphocytes especially CD34+ progenitors cells from the sibling donors are infused into the patient's blood stream after preparative chemotherapy. Stem cell therapy has the promising role and has the potential to change the face of metastatic breast cancer and alleviate suffering.
\end{abstract}

Keywords: Stem cell therapy, Metastatic breast cancer, progenitors cells 


\title{
INFECTION CONTROL: KNOWLEDGE AND PRACTICES AMONG STAFF NURSES AMANPREET KAUR 1 , RAMANPREET KAUR
}

1Professor, Khalsa College of Nursing, GT Road, Amritsar, Punjab-143001,Staff Nurse, Civil Hospital, Khadur Sahib, Tarn Taran, Punjab Email: amanpreet27@ymail.com

\begin{abstract}
Nurses play an important role in healthcare delivery system worldwide and play a critical role in prevention and control of infection spread. Negligence in infection control may thereby put the patients at risk of acquiring nosocomial infection. Hence they must have sound knowledge of infection control practices. A descriptive study was conducted using convenient sampling among 60 staff nurses serving at Government Hospital, Amritsar (Punjab). A structured questionnaire was divided into three parts including demographic profile and knowledge questionnaire and practices checklist on infection control. Demographic profile covers personal information of staff nurses such as age, area of practice, education, total clinical experience and family income per month. Knowledge questionnaire included areas pertaining to definition and factors responsible, hand washing, gowning, gloving, mask, sterilization, bio-medical waste and management of infection. Infection control practices checklist involved 14 items related to notifying higher authority, site of exposure, biomedical waste management, spill management, linen management, catheter related precautions and standard precautions. The study findings revealed that majority of staff nurses (88.33\%) had average knowledge regarding infection control. Mean percentage was highest in mask use (78\%) and lowest in the management of infection (52.6\%). Pertaining to infection control practices, about $36.67 \%$ inform the higher authorities about infection control practices if it has led to death of a client and nearly threefourths (71.67\%) of the staff nurses inform only if it has deteriorated the patient's condition. More than half (55.0\%) of the staff nurses do not wash the site of exposure with soap and water. Recapping or bending the needles was not done by $41.67 \%$ of the subjects whereas $41.67 \%$ of the staff nurses said 'yes' to discard disposable needles and other sharps into puncture resistant containers at the site of procedure. Out of total subjects, $25 \%$ of the staff nurses expressed not to cover spills of blood or body fluids with $1 \%$ of freshly prepared sodium hypochlorite for 10 minutes and then mop dry. It had been seen that $86.67 \%$ of the nurses get the area washed with detergent and water in case of a blood spill. But $28.33 \%$ ensured the second decontamination if required in case of a blood spill. Nearly three halves of the participants (73.33\%) made certain that the used linen is not shaken in order to prevent dissemination of micro-organisms into the environment. Most of the staff nurses certified that the urinary bag was placed below the level of the bed to prevent transmission of infection. Approximately 36.67\% denied regarding washing hands or using hand rub after removing gloves always. Only family income was found to be associated with knowledge among staff nurses except other demographic variables. In conclusion the staff nurses must receive infection control training within atleast 2 years.
\end{abstract}

Key words: Infection control; knowledge; practice; staff nurses 


\title{
MUSCULOSKELETAL DISORDERS AMONG UNIVERSITY STUDENT USING LONG -TERM AND SHORT-TERM PERSONAL COMPUTER

\author{
NAVREET KAUR ${ }^{*}$, IMMANUEL JEYASINGHRAJ, SURESH MANI
} \\ Department of physiotherapy, Lovely professional university, Phagwara-144411, Punjab (India) \\ Email: Immanuel.20855@lpu.co.in
}

\begin{abstract}
Expeditious penetration of laptop computers in the education system may result in various musculoskeletal pain disorders (MSPD) that need to be identified and managed at the earliest. The aim of the study was to determine the MSPD related to short term and long-term laptop users among the university college students. A total of 94 students aged between 18 and 28 years from the different departments of Lovely Professional University were participated in a survey using self-rated questionnaire comprises of carrying method of laptop, weekly and daily laptop usage and musculoskeletal pain. The participants were divided into short duration laptop usage (group A) and with long duration laptop usage (group B). Participants reported a higher frequency of laptop usage in sitting position with a laptop on the lap in both the groups followed by sitting with laptop on desk and lying supine. In this study, 20\% participants experienced MSPD during carrying a laptop in group A, whereas 30\% in group B. Laptop related MSPD was found higher among group B with the frequency of $41(88 \%)$, whereas $29(62 \%)$ among group A. The common location of prevalence of MSPD was reported at neck, upper back and right shoulder. In addition, around 45\% of participants reported less MSDP as they involved in recreational sports activities. Musculoskeletal disorders were reported more in group B with the frequency of 32 (68\%) as compared to group A with the frequency of 11(24\%). Early detection and management of MSPD is considered imperative in the management of MSPD through creating the awareness on computer ergonomics and promote regular physical activities.
\end{abstract}

Key words: Musculoskeletal disorders, ergonomics advice, recreational activities, expeditious, laptop, student. 
Abstract No. RTBS-P-38

\title{
CUBOSOME: AN HONEYCOMB STRUCTURE DRUG DELIVERY SYSTEM KARAN SINGH, SUDHAKAR CK
}

\author{
LIT (Pharmacy), School of Pharmaceutical Sciences, Lovely Professional University, Phagwara- 144411, Punjab (India)
} Email: Sudhakar.20477@lpu.co.in, Karansingh648@gmail.com

\begin{abstract}
Cubosomes are four-sided and round particles with inner cubic lattices visible. The discovery of cubosomes is a typical story and extents the fields of food science, disparity geometry, biological membranes and gastrointestinal processes. It action as active drug delivery systems; extremely accepted, has got reputation after invention and proposal. They are thermodynamically balanced and stable; they encircle a structure like to "Honeycomb" through continuous areas of water and lipid. The surfactant becomes stable and it is accumulated into bilayers and enfolded into a three dimension, periodic as well minimal surface, creating a strongly filled structure. They are bicontinuous cubic liquid crystalline phase through optically lucid, enormously viscous material and have special structure on the nanometer range. Preceding the whole, it concentrates high importance to popular nano drug preparations for topical treatment melanoma exceptional to their potential benefits, including heavy goods of drug since of enlarged surface area and cuboidal structures. They have very easy method of preparation; however biodegradability of lipids consume the capability of encapsulating hydrophobic, hydrophilic and amphiphilic constituents too for the meantime targeted and measured release of bioactive agents. When they dispersions it stays as bio adhesive and biocompatible. As of their properties, they are multipurpose systems, by variety of routes which can be administered by different means such as oral, percutaneous and parenteral also. They have wide-ranging vast applications in numerous areas and are categorized by numerous parameters. Therefore, they are in move forward of attentiveness by pharmaceutical formulation researcher.
\end{abstract}

Keywords: Cubosomes, Honeycomb, Drug payloads, Cubic liquid crystalline 


\title{
CURCUMIN NANOMEDICINE APPLICATIONS: AN ASSESSMENT DEEPAK NATH ${ }^{1}$, PRANAV KUMAR PRABHAKAR ${ }^{2}$, DILEEP SINGH BAGHEL ${ }^{1 *}$
}

1School of Pharmaceutical Sciences, Lovely Professional University, Phagwara, Punjab, India-144411 2Department of Medical Laboratory Sciences, Lovely Professional University, Phagwara, Punjab, India-144411 Email: deepak812nath@gmail.com

\begin{abstract}
Herbal medicines are used worldwide since ancient era and have been truly recognized by physician as well as patients for their therapeutic value, fewer adverse effects as compared with modern medicines. Phytotherapeutics need a scientific approach to deliver the components in a sustained manner to increase patient compliance and avoid repeated administration. This can be achieved by designing novel drug delivery systems (NDDS) for herbal constituents. Nano-sized drug delivery systems of herbal drugs have a potential future for enhancing the activity and overcoming problems associated with plant medicines. Nanotechnology is a multidisciplinary science where chemists, physicist, biologists and pharmaceutical scientist all have delivered a significant roles to develop novel treatment and diagnosing system. Nanoparticles enter into human body via three main route, direct injection, inhalation and oral intake. Nano-sizing of poorly water soluble curcumin (diferuloylmethane) increase their solubility and thereby the bioavailability. Curcumin is a bioactive and inexpensive polyphenol extracted compound of turmeric isolated from the rhizomes of curcuma longa linn. Due to its anti-oxidant and anti-inflammatory potency, it has been reported for its miracle therapeutic applications in various pathological conditions including cancer, cardiovascular disease, Alzheimer's disease, inflammatory disorders, neurological disorders and so on but the clinical implication of curcumin is obstruct due to its low solubility, physico-chemical instability, poor bioavailability, rapid metabolism, and poor pharmacokinetics.
\end{abstract}

Keywords: Curcumin, Drug delivery system, Nanoparticles, Bioavailability, Nanotechnology 


\title{
FORMULATION, CHARACTERIZATION AND IN VITRO ANTIOXIDANT EVALUATION OF POLYHERBAL BASED LOZENGES FOR TREATMENT OF STRESS
}

\section{AMARJOT KAUR, SAURABH SINGH*, SACHIN KUMAR SINGH, MONICA GULATI, BIMLESH KUMAR, DILEEP SINGH, NARINDER KUMAR PANDEY, BARINDER KAUR, MANPREET KAUR, ARUN KUMAR}

School of Pharmaceutical Sciences, Lovely Professional University, Punjab, India

Email: saurabh.singh2514@gmail.com, saurabh.singh@lpu.co.in

\begin{abstract}
The present work is aimed towards designing of the herbal lozenges for stress. The polyherbal formulation contains Ashwagandha, Brahmi, and Shankhpushpi as active ingredients with excipients and binders like starch, acacia, and gelatin. Dried aqueous extract of herbal drugs was used to formulate the lozenges, which is prepared by using soxhlet apparatus. Ten batches were prepared by Moulding method with different concentration of Sugar and liquid glucose for optimization. However, they were unstable and sticky in nature. Hence, five batches were prepared by adopting Compression method with different ratio of binders. The prepared lozenges have been evaluated for weight variation, hardness, thickness, friability, disintegration, microbial contamination and drug compatibility study. Along with in vitro dissolution study, which shown $70 \%$ to $80 \%$ drug released within 60 minutes. Hence it was taken as optimized batch and taken for further studies. Compressed lozenges were found to be stable at $37^{\circ} \mathrm{C} / 65 \% \mathrm{RH}$ and $40^{\circ} \mathrm{C} / 75 \% \mathrm{RH}$ for 30 days. Among five batches, the forth batch gave promising results. In vitro study was conducted for antioxidant potential with 2,2-diphenyl-1-picrylhydrazyl (DPPH). The results revealed promising antioxidant effect of the lozenges.
\end{abstract}

Keywords: Herbal Lozenges, Moulding, Compression, Dissolution study, Antioxidant potential 


\title{
DESIGN, FORMULATION, AND PHARMACOKINETIC EVALUATION OF BILAYER TABLET OF FEXOFENADINE HCL AND MONTELUKAST SODIUM
}

\section{SOURAV THAKUR* , BHUPENDRA SINGH, VIJAY MISHRA, BIMLESH KUMAR}

Lovely School of Pharmaceutical Sciences, Lovely Professional University, Phagwara Email: souravthakur1616@gmail.com

\begin{abstract}
Nocturnal asthma, a worst condition of asthma at night is a variable exacerbation of the underlying asthma condition associated with airway responsiveness, and/or worsening of lung function. The mechanism of nocturnal asthma is intimately related to circadian rhythm, which influences inflammatory cells, mediators, hormone levels and cholinergic tone. In night lung function decreases while bronchial hyper-reactivity increases. These changes have been related to the normally occurring circadian changes in cortisol levels at night. Decrease in cortisol level may lead to down regulation of the $\beta 2$ adrenergic receptors. Lower level of Epinephrine, an endogenous bronchodilator at night reflects a circadian variation and is unavailable at the time of need in nocturnal asthma. The present investigation aimed at formulation and development of bilayer tablet containing Fexofenadine $\mathrm{HCl}$ and Montelukast sodium in immediate release and slow release layer, respectively exhibiting a lag time of about 2 hours. The tablet is taken at bed time and expected to release the drug at midnight, when the asthma attacks are more likely and then give prolonged effect for 12 hours.
\end{abstract}




\title{
MICRONEEDLE: A NOVEL PLATFORM FOR TRANSDERMAL DRUG DELIVERY SYSTEM NAVNEET KUMAR, NARENDRA KUMAR PANDEY*, ABHISHEK THAKUR
}

School of Pharmaceutical Sciences, Lovely Professional University, Phagwara-144411, Punjab (India)

\author{
Email: raonavneetkumar99@gmail.com
}

\begin{abstract}
Advancements in novel drug delivery technologies has lead way towards achieving delivery of such drugs through the transdermal route, of which using of microneedlesfor the purpose is quite significant. Contrary to the conventional diffusion mechanism of drug release through skin this technique is based on the disruption of the skin \& placing the drug on the epidermal layer. Moreover it doesnot pass the stratum corneum so it does not reach the nerve endings making it a painless therapy. Thus, microneedle insertions are painless and improved patient compliance, reduction in dosing frequency. Microneedle is a novel carrier for transdermal drug delivery system where microgram quantity of drug can be achieved. The use of micron scale needles increases the permeability of the skin. The drug, in bimolecular form, is encapsulated within the microneedles in hollow, coated, dissolving and solid form by using of metals, polymers, silicon and glass. Thus it can be concluded, these painless systems would qualify to be one of the important devices for controlled drug release in future and represent to be an efficient and superior carriers as compared to other needle based formulation for transdermal delivery.
\end{abstract}

Keywords: Microneedle, Transdermal, Drug delivery, Permeability. 


\title{
INVESTIGATION AND OPTIMIZATION OF FORMULATION PARAMETERS FOR SELF- NANOEMULSIFYING DELIVERY SYSTEM OF CURCUMIN-DULOXETINE USING BOX-BENKEN DESIGN
}

\author{
BIMLESH KUMAR ${ }^{1}$, VARUN GARG ${ }^{1}$, AMARJEET SINGH ${ }^{2}$, NARENDRA KUMAR PANDEY ${ }^{1}$, SAURABH SINGH ${ }^{1}$, \\ SAKSHI PANCHAL ${ }^{1}$, INDU MELKANI ${ }^{1}$, SOUVIK MOHANTA ${ }^{1}$, JIVAN JYOTI ${ }^{1}$, SANANDA SOM${ }^{1}$, MONICA GULATI ${ }^{1}$, \\ AMIT BHATIA ${ }^{3}$, T PRAKASH ${ }^{4}$, SACHIN KUMAR SINGH*1
}

1School of Pharmaceutical Sciences, Lovely Professional University, Phagwara - 144411, Punjab, India. ${ }^{2}$ Pharmacovigilance Scientist, Paraxel International Services India Pvt Ltd, Chandigarh, India. ${ }^{3}$ Amity Institute of Pharmacy, Amity University, Noida, Uttar Pradesh, India. ${ }^{4}$ Department of Physiology and Pharmacology, Acharya and B.M. Reddy College of Pharmacy, Soladeuanahalli Hesargatta Road,

Chikkabanawara Post, Bangalore - 560 090, Karnataka, India.Email: singhsachin23@gmail.com; sachin_pharma06@yahoo.co.in

\begin{abstract}
Present research work aims towards co-delivery of two hydrophobic drugs, curcumin (CRM) and duloxetine hydrochloride (DXH) through selfnanoemulsifying drug delivery systems (SNEDDS). Initially binary mixture in the ratio of 1:1 was prepared and then loaded into SNEDDS. BoxBehnken Design (BBD) was adopted in order to develop SNEDDS. As per the optimal design, 13 SNEDDS prototypes were prepared. Castor oil, tween-80 and Transcutol ${ }^{\circledR}{ }^{\circledR}$ were used as oil, surfactant and co-surfactant, respectively. To $1 \mathrm{~mL}$ of SNEDDS, an amount equivalent to $30 \mathrm{mg}$ each of CRM and DXH was loaded (CRM-DXH- SNEDDS). The design revealed that for mean droplet size, polydispersity index (PDI) as well as \% drug loading, all the three factors i.e. ratio of oil (A), surfactant (B) and co-surfactant (C) were found to give significant effect. Factor B showed the most significant effect on mean droplet size ( $y 1$ ). In case of PDI ( $y 2$ ), factors B and C exerted maximum influence, whereas, factor A has showed nonsignificant effect. For \% drug loading of drugs ( $y 3$ and $y 4$ ), all the three factors were found to have the most significant effect. The optimized batch of CRM-DXH- SNEDDS having composition castor oil, tween-80, and Transcutol $\mathrm{P}^{\circledR}$ in the ratio: 2.17:5.22:2.61, revealed the mean drug loading (\%) of CRM and DXH in optimized batch of SNEDDS was found to be $87.22 \pm 1.87$ and $92.32 \pm 0.19 \%$ respectively. The mean droplet size, polydispersity index and zeta potential of formed SNEDDS was found to be $113.14 \pm 1.14 \mathrm{~nm}, 0.20 \pm 0.026$ and $-13.2 \mathrm{mV}$ respectively. BBD provided optimal formula composition for SNEDDS for obtaining desirable drug loading, emulsion droplet size and zeta potential.
\end{abstract}

Keywords: Curcumin; Duloxetine Hydrochloride; Binary mixture; CRM-DXH-SNEDDS; Box Behnken Design; Castor oil; Transcutol P ${ }^{\circledR}$; Tween-80 


\title{
STUDY OF ELECTROLYTES AND LIVER FUNCTION TESTS IN CHRONIC ALCOHOLISM GURPREET KAUR GILL ${ }^{*}$, JUHI KATARIA ${ }^{1}$, DALJEET KAUR ${ }^{2}$
}

${ }^{1}$ Khalsa College of Pharmacy \& Technology, Amritsar, Punjab, India, 143001

${ }^{2}$ BIS Institute of Sciences \& Technology, Gagra, Moga, Punjab, India

Email: gurpreet_pau25@yahoo.com

\begin{abstract}
Alcoholism and alcohol abuse is one of the most serious health problems in India, which has been seen in all the socio-economic and ethnic groups. Alcohol dependence refers to a disease that is characterized by abnormal alcohol seeking behavior that leads to impaired control over drinking that ultimately leads to the health consequences as well as social problems. Alcohol is central nervous system depressant and degree of depression produced is directly related to the amount consumed. Alcohol abuse may result in the electrolyte and acid base disorders. Alcohol impairs the metabolism of calcium and magnesium in the body. The present investigation was done to estimate the levels of calcium, magnesium and other biochemical parameters in the chronic alcoholic patients and their comparison with normal healthy controls. Fifty male alcoholics consuming variable amount of alcohol from more than last five years in the age frame of 30-70 years were taken. Equal number of age matched normal healthy individuals without the family history of any disease served as controls. Levels of magnesium, calcium and other biochemicals viz. urea, total protein, serum glutamate oxaloacetate transaminase (SGOT), serum glutamate pyruvic transaminase (SGPT) were estimated colorimetrically in all the subjects consuming variable amount of alcohol. Alcoholics were found to have lower magnesium, calcium and total protein levels as compared to non-alcoholics whereas transaminases were higher in alcoholics, predicting hepatocytes injury. Catalytic activity of alcohol dehydrogenase produced highly reactive acetaldehyde forming adducts with membrane proteins leading to organ damage. Alcohol disturbed the electrolytes balance produced hypomagnesia and hypocalcemia and severly affected liver function tests. Magnesium levels and other related parameters could be considered as diagnostic predictors of alcohol related toxicity. Age advances the alcohol related health consequences and this could be due to cumulative effect of reduced intestinal absorption, dietary deficiencies, alcohol toxicity.
\end{abstract}

Keywords : alcoholism, magnesium, transaminases, liver, calcium, total proteins 


\title{
IMMUNOTHERAPY: THE FUTURE OF CANCER TREATMENT KAMPALA MWAPE PHIRI*, SAZAL PATYAR
}

Department of Pharmacology, Lovely Professional University Jalandhar - Delhi G.T. Road, Phagwara, Punjab 144411. Email: beetlejuss@gmail.com

\begin{abstract}
Immunotherapy in cancer disease is tailored to restore, enhance, stimulate or suppress the body immune system giving it the ability to detect and destroy cancerous cells. The immune systems inability to detect cancer cells is caused by its propensity to express protein on their surfaces that induce immune cell activation. Reduce the expression of tumor antigens on their surface and induce cells microenvironment to release substances that suppress immune responses and promote tumor cell proliferation and survival. Immunotherapeutic agents can be subdivided into passive and active based on their interaction with cancerous cells. Available immunotherapeutic strategies include different approaches such as adaptive cell transfer, checkpoint inhibitors and cytokines (immune hormones). Furthermore, they provide better, effective alternative to other cancer treatments such as surgery, radiography, targeted therapy and chemotherapy. It is effective in cancer patients that have advanced cancer, cancer that has recurred and spread after primary treatment or first-time diagnosis at advance stage. Immunotherapy has proven to be very effective in the following cancers: leukemia, lung cancer and prostate cancer. Recently, treatments are being developed for rheumatoid arthritis. Many immunotherapeutic drugs have been approved by USA Food and Drug Administration and European medicine for cancer treatment. Most widely used drugs include lpilimab, nivolumab, pembrolizumab and avelumab.
\end{abstract}

KEYWORDS: immunotherapy, checkpoint inhibitors, cytokines, adaptive cell transfer 


\title{
A NOVEL MULTIPLEX PCR FOR SIMULTANEOUS DETECTION OF DENGUE AND CHIKUNGUNYA INFECTION
}

\author{
SWATI SINHA, MRITUNJAY SAXENA, RENUKA GAHTORI, PREETI KUMARI, DEEPALI SAVARGAONKAR, NEENA \\ VALECHA, ANUPKUMAR R ANVIKAR*
}

National Institute of Malaria Research- Indian Council of Medical Research, Dwarka Sector-8, New Delhi-110077

Email: swati.microbio04@gmail.com

\begin{abstract}
Dengue, a flavivirus and chikungunya an alphavirus are among the most ubiquitous human-infecting arboviral diseases across the globe transmitted by infected, day-biting Aedes mosquitoes (Aedes aegypti and Aedes albopictus). These diseases, present overlapping physical symptoms resulting misdiagnosis with each other. The incidence of co-infection of dengue and chikungunya is also reported mainly due to the common disease transmitting vector being highly adapted to human habitation, especially in Delhi, a hyper-endemic state of India. Co-infection of both the viral disease has been reported from different parts of the world including India. Several methods are available for the diagnosis of these two vector-borne diseases separately. The viruses can be diagnosed by virus culture method, antigen detection, immunohistochemistry; serological tests (based IgM and IgG). All methods of detection have its own limitations. To accurately diagnose potentially infected patients and to advise Health authorities on the presence of emerging pathogens, as well as for proper disease management a rapid and reliable test is needed that could differentiate between these two pathogens. The aim of this study was to assess experimental conditions for a multiplex single step RT-PCR assay allowing simultaneous detection of the two targets using two sets of 'in-house' designed primers in a single reaction. The present RT-PCR is novel in terms of sensitivity and specificity also the detection assay is prompt, robust, accurate (reliable) and a cost-effective. Higher sensitivity of this technique was shown with respect to other molecular techniques during the optimization using different viral dilution. This approach has enabled greater diagnostic capacity in our laboratory to confirm the co-existence of the disease easily.
\end{abstract}

Key words: Dengue, Chikungunya, Aedes, co-infection, vector borne disease, Multiplex, RT-PCR. 


\title{
PSYCHOBIOTICS: AN EMERGING TREND IN THE MANAGEMENT OF PSYCHOLOGICAL DISORDERS
}

\author{
DIKSHA*, SAZAL PATYAR
}

Lovely School for Pharmaceutical Sciences, Lovely Professional University Phagwara, Punjab (India) - 144411

Email: diksha306557@gmail.com

\begin{abstract}
Psychobiotics are defined as live beneficial bacteria that yield positive psychiatric effects in psychopathology when administered in appropriate quantities. Many CNS disorders are associated with dysbiosis in the gut microbiome resulting in gastrointestinal tract (GIT) disturbances. Alterations in the GIT activity induce changes in the brain functions through gut brain axis via three pathways such as immune (cytokines), neural (vagus nerve), neuroendocrine (HPA axis/ Corticosterone). In human body, a total number of 1500 bacteria species are present out of which $95 \%$ of bacteria are located in the gut that constitute the gut microbiome homeostasis. The psychophysiological effects of psychobiotics fall into the following three categories: (i) Psychological effects on emotional and cognitive processes. (ii) Systemic effects on the HPA axis by decreasing the corticotrophin releasing factor levels and inflammation which is often characterized by aberrant pro-inflammatory cytokine concentrations. (iii) Neural effects on $\gamma$-aminobutyric acid (GABA) and serotonin neurotransmitters as well as brain-derived neurotrophic factor (BDNF) proteins which plays a crucial role in learning and memory processes. Such disease-associated alterations in the microbiome are usually caused by genetic and environmental factors such as drugs, diet, toxins and pathogens. Therefore, the strong association between gut dysbiosis, intestinal permeability and neurological dysfunction suggests that modifying the gut microbiota may provide a promising therapeutic option in emotional and neurodegenerative ailments.
\end{abstract}

Keywords: Psychobiotics, microbiome, HPA (Hypothalamus pituitary adrenal gland) axis, brain-derived neurotrophic factor, neurodegenerative ailments. 


\title{
THERANOSTICS: MODERNISATION IN TREATMENT AMANDEEP SINGH, RUCHI SHARMA*, NARENDRA KUMAR PANDEY
}

Department of Pharmaceutical Sciences, Lovely Professional University, Phagwara- 144411, Punjab (India)

Email: passing.singh@gmail.com

\begin{abstract}
Medicines have been used since antiquity for improvement of health or the reduction of the morbidity state. The process of treatment involves two steps, Diagnosis, which involves the identification of the type of disease or the causative organism and, Therapy, involving the use of various medicinal agents or drugs for the eradication of the symptoms or the cause of the disease. The principle of "one medicine fits all" is now being replaced by the "Personalised medicine" due to inter-patient variability. Theranostics is a modern approach for achieving the mentioned task. The portmanteau of therapy and diagnostics, theranostics are agents which incorporate both the diagnostic agent as well the therapeutic agent in a single entity. It utilizes the advantages of nano-platforms having the capability of handling targeting agent, imaging agent and carrying the drug all in a single moiety. Theranostics have number of advantages over the conventional systems, which makes their research popular these days. These can be classified into targeted, non-targeted and leveraged theranostics based on the bonding between components. The techniques like MRI, CT, fluorescence, optical imaging, and Radiology are used in conjugation for efficient working of theranostics. Iron oxide nanoparticles (NP'S), gold NP'S, carbon nanotubes, dendrimers, quantum dots, silica NP'S and others have been researched for potential activity as a theranostic agent. Sufficient in-vivo data backup is unavailable for them, which serves as the possible disadvantage. Theranostics are emerging as a promising approach for the treatment of the heterogeneous diseases, involving cancer.
\end{abstract}

Key Words: Theranostics, Personalised Medicine, Nano-particles, Radio-imaging, Dendrimers, Targeted delivery. 


\title{
CHALLENGES IN DISSOLUTION TESTING OF ENTERIC COATED TABLETS
}

\section{RINKU ROZERA*, ANSHUL ATTRI, YOGITA KUMARI, GURMANDEEP KAUR, BHUPINDRA SINGH TOMAR, SACHIN KUMAR SINGH}

School of Pharmaceutical Sciences, Lovely Professional University, Phagwara-144411, Punjab India

Email: rinkurozera@gmail.com

\begin{abstract}
Enteric coated tablets are formulated to bypass the gastric $\mathrm{pH}$ of stomach and release the drug completely in the higher $\mathrm{pH}$ of intestine. This includes the utilization of various polymers such as cellulose acetate phthalate (CAP), cellulose acetate trimellitate (CAT), polyvinyl acetate phthalate (PVAP), hydroxy propyl methyl cellulose phthalate (HPMCP), fatty acid, waxes, shellac, plastic and plant fibres. All the above mentioned enteric polymers display different release profile of drug. Moreover, their composition as coating material and process used for their coating are the key governing factors for successful formulation of enteric coated tablets. Apart from the formulation and process parameter, intake of alcoholic beverages with these tablets alter the release rate controlling mechanism of drug which cause immediate or uncontrolled release drug this effect is known as alcohol induced dose dumping. The gastrointestinal (GI) physiology such as GI pH and gut microflora also control the release of drug. Hence, successful delivery of drug at intestinal site and correlation of its dissolution data with in-vivo pharmacokinetic profile is a consistent challenge for pharmaceutical industries and agencies that regulate them. The poor correlation of in-vitro and in-vivo profile is basically due to lack of proper selection of ratio of excipient for coating process. Further, in diseased state the pH of body and bacterial count changes. It drastically alters the release profile of drug from dosage form. The present study deciphers about various techniques that are used for enteric coating and challenges associated with their dissolution testing.
\end{abstract}

Keyword: Enteric coating; GI physiology; Challenges; Dose dumping 


\title{
$N$-SUBSTITUTED BENZYLIDENE-2-(1H-BENZOTRIAZOL-1-YL) ACETOHYDRAZIDE DERIVATIVES AS ANTIBACTERIAL AGENTS
}

\section{KIRTI RANI, PARDEEP KUMAR SHARMA, CHARANJIT KAUR, GURVINDER SINGH*}

Lovely School of Pharmaceutical Sciences, Lovely Professional University, Punjab

Email: gurvinder.21714@lpu.co.in

\begin{abstract}
Benzotriazole is an important class of heterocyclic compounds which shows good antibacterial activity with the advantage of having low toxicity and good oral bioavailability. Due to these properties of the related drugs has encouraged the medicinal chemist to synthesize a large number of novel chemotherapeutic agents. The reaction of $o$-phenylenediamine with glacial acetic acid yielded benzotriazole, which was further reacted with ethylchloroacetate and potassium carbonate in acetone to form ethyl-2-(1H-benzo[1,2,3]triazole-1-yl)acetate. Ethyl-2-(1H-benzo [1, 2, 3] triazole1-yl) acetate on further reaction with hydrazine hydrate and ethanol gives (Benzotriazol-1-yl)acetic acid hydrazide. Finally the resulted hydrazide is condensed with aromatic aldehydes in the presence of few drops of glacial acetic acid and ethanol under irradiation to give Schiff's bases (5a-5f). The purity of the compounds was determined by TLC and the structures of the compounds were confirmed by IR and ${ }^{1} \mathrm{HNMR}$. The compounds were screened for their antibacterial activity against E. coli, S. aureus and B. substilis, P. aeruginosa by cup and plate method. All the compounds exhibited activity against all the organisms employed. Compounds $5 \mathrm{~b}, 5 \mathrm{~d}, 5 \mathrm{e}$ were found to possess maximum antibacterial activity when compared to the standard vancomycin.
\end{abstract}

Keywords: Benzotriazole, Schiff's bases and Antibacterial agents. 


\title{
QUEST OF IMMUNOSUPPRESSIVE ANTI-CANCER DRUGS IN SOTR: A SYSTEMATIC REVIEW RISHI RAWAL, GURVINDER SINGH, CHARANJIT KAUR, PARDEEP KR. SHARMA*
}

Lovely school of Pharmaceutical Sciences, Lovely Professional University, Punjab Email: Pardeep.kumar1@lpu.co.in, Phone: 9988241014

\begin{abstract}
Organ transplantation is a well-established method for the therapy of end-stage organ failure. The emergence of novel immunosuppressive regimens has reduced the risk of rejection and extended the life expectancy of organ recipients. The long-term outcome of these patients is now challenged by life-threatening complications such as post-transplant infections, cardiovascular disease, and post-transplant malignancies. Evolving strategies aimed at effective immunosuppression could have differing effects on the likelihood of developing malignancy. Malignancy after organ transplantation has been described as the "price of immunotherapy." We have tried to analyse data from the transplant registries and historical sources from PubMed to ascertain which factors are associated and to understand currently available strategies to understand and minimize the risk of developing malignancy in the transplant population. By taking in account role of Immunoglobulins, Azathioprine, Corticosteroids, Calcineurin inhibitors (CNIs), mammalian target of rapamycin (mTOR) inhibitors, etc. To shift the focus of upcoming researches towards oncological research in immunosuppressive agents on cancer development and progression.
\end{abstract}

Key Words: Organ transplantation, immunosuppressive regimens, malignancy 


\title{
RHEUMATOID ARTHRITIS: AN AUTOIMMUNE DISEASE \\ CHARANIIT KAUR ${ }^{1}$, GURVINDER SINGH ${ }^{1}$, PARDEEP SHARMA ${ }^{1}$, RAJESH SACHDEVA $^{2}$, AMIT SHARMA ${ }^{2}$, CHANDERMOHAN LOTIA ${ }^{2}$
}

\author{
1Department of Pharmaceutical Sciences, Lovely Professional University, Phagwara- 144411, Punjab (India) \\ ${ }^{2}$ Rayat Bahra Institute of Pharmacy, Rayat Bahra Group of Institutes, Hoshiarpur-146104, Punjab (India) \\ Email: charanjit.22457@lpu.co.in
}

\begin{abstract}
Rheumatoid arthritis is prolonged, advancing, knock out autoimmune disease characterized by systemic inflammation of joints, damaging cartilage and bone around the joints. It is a systemic disease and it can affect the whole body and internal organs such as lungs, heart and eyes. Non-steroidal anti-inflammatory drugs, disease modifying anti rheumatic drugs and corticosteroid are the commercial drugs to reduce pain, swelling and suppressing several disease factors. Arthroscopy is useful method in case of severe degradation of joint tissues. Gene therapy is a major advancement in RA and to overcome the issues aroused from those therapies like side effects and expenses, phyto-constituents have been investigated and certain compounds are proved for their anti-arthritic potential. It is possible to use the herbs and plants in various forms in order to relieve the pain and inflammation in the joints along with modulation of intermediates in disease pathway with the possibility of disease cure. There are so many medicinal plants that have shown anti rheumatoid arthritis properties. So the plants and plant product with significant advantages are used for the treatment of rheumatoid arthritis. Furthermore certain complementary alternative therapies like yoga, acupuncture, massage therapy and tai chi have also been proved for their capability in RA treatment.
\end{abstract}

Key Words: Rheumatoid arthritis, autoimmune disease, phyto-constituents, systemic inflammation. 


\title{
PHARMACEUTICAL CO-CRYSTAL: AN EMERGING TREND IN PHARMACEUTICS
}

\section{PANKAJ KUMAR, SATTAR HAWARI, NARENDRA KUMAR PANDEY*, BIMLESH KUMAR, SACHIN KUMAR SINGH, MONICA GULATI, SAURABH SINGH}

\author{
School of Pharmaceutical Sciences, Lovely Professional University, Phagwara - 144411, Punjab (India)
}

*Email: narendra.pandey@lpu.co.in

\begin{abstract}
Out of $40 \%$ or more new chemical entities being generated, nearly $60 \%$ of them show low solubility. The drug solubility is an important parameter for drug absorption. Low soluble drugs can show poor drug absorption and causes mucosal toxicity. Therefore enhancing the aqueous solubility of poor water soluble drugs is a big challenge for pharmaceutical researchers. So, Pharmaceutical cocrystals (PCs) is one of the most emerging solid form which enhances the poor solubility of drugs or many other parameters like permeability, stability, tabletibility, compactibility, and dissolution profiles. This is the most useful and newest technique in the pharmaceutical field. Cocrystals are mainly composed of an API and coformers such as dicarboxylic acids, alcohols and amides, which are solid at room temperature. Sometimes APIs are also used as coformer and these cocrystals are known as drug- drug cocrystals or multidrug cocrystals. Cocrystals are mainly constructed through hydrogen bonding, $\pi$ - stacking, and weak vander Waal forces. The methods which are commonly used for the preparation of cocrystals are solvent evaporation technique, grinding technique, melting technique and slurry method. Other methods are also reported such as super critical technique etc. It can be characterize by different techniques like X-ray powder diffractometry, scanning electronic microscopy (SEM), transmission electronic microscopy (TEM), infrared spectroscopy etc. There are so many formulations of pharmaceutical cocrystals which are available in market namely Viagra, theophylline, fluoxetine $\mathrm{HCl}$, and melamine cocrystals.
\end{abstract}

Keywords: Solubility, Cocrystal, Coformer, Cocrystallization, Stabilizer, Permeability. 
Abstract No. RTBS-P-54

\title{
PRELIMINARY STUDIES ON GENERATION OF GLIMEPIRIDE COCRYSTALS
}

\section{Sattar Hawari, Pankaj Kumar, Narendra Kumar Pandey*, Bimlesh Kumar, Sachin Kumar Singh, Monica Gulati, Saurabh Singh}

School of Pharmaceutical Sciences, Lovely Professional University, Phagwara - 144411, Punjab (India)

Email: narendra.pandey@lpu.co.in

\begin{abstract}
Glimepiride primarily lowers blood glucose by stimulating the release of insulin from pancreatic beta cells. It belongs to BCS class -II drug, having low solubility and high permeability. Solubility improvement is the major challenge for formulating BCS class II drugs. Many approaches invented to tackle the problems associated with poor aqueous solubility as well as bioavilibity are clearly mention in scientific literature. It includes the use of salt forms, micronization, co-solvent approaches, complexation with cyclodextrins and micellar formation. The successes of these approaches are dependent at the time. Pharmaceutical cocrystal could be a promising approach for the enhancement of solubility, dissolution rate and bioavailability of poorly water soluble drugs. Present study attempted to screen out the coformenrs and method for the preparation of cocrystals of glimepiride. In this study cocrystal of glimepiride are prepared with number of coformers such as gallic acid, oxalic acid, stearic acid, malonic acid, salicylic acid, tartaric acid and 3-nitrobenzoic acid by using grinding and solvent evaporation techniques. Formations of cocrystals are ensured by melting point measurement and optical microscopy. Further, solubility of prepared cocrystals were compared with pure drug to identify the suitable conformers. Out of those seven conformers, cocrystals prepared by grinding technique using 3-nitrobenzoic acid gallic acid conformers showed 20-25 folds increase in solubility and cocrystals prepared by solvent evaporation technique using 3-nitrobenzoic acid and salicylic acid conformers showed 5-10 folds increase in solubility as compared to others. These results revealed that cocrystals prepared by grinding method indicated high increment in solubility of glimepiride than solventent evaporation method.
\end{abstract}

Keywords: Crystal form, bioavailability, drug solubility, dissolution, physicochemical property 


\title{
IDENTIFICATION OF POSSIBLE MOLECULAR TARGETS OF POTENTIAL ANTIPARKINSON DRUGS BY PREDICTING THEIR BINDING AFFINITIES USING MOLECULAR DOCKING TECHNIQUE
}

\author{
MAGUEMGA HOMSI CHANCELINE DORICE*, NAVNEET KHURANA, NEHA SHARMA, GOPAL LAL KHATIK
}

School of pharmaceutical sciences, Lovely Professional University, Phagwara-144411, Punjab, India.

Email: maguemgadorice4@gmail.com

\begin{abstract}
Parkinson's disease (PD) is a serious neurological disease which is progressive, age-related, and second most common neurodegenerative disorder after Alzheimer's disease. It results from a slow degeneration of dopaminergic neurons in the substantia nigra pars compacta (SNPC) region of the brain, leading to dopamine deficiency. This dopamine depletion is mainly responsible for the clinical features of PD. Dopamine replacement therapy is the mainstay of treatment for PD. Since, dopamine does not cross the blood brain barrier (BBB), when administered systemically, L-dopa (an immediate precursor of dopamine) has proven beneficial to treat this disorder. L-dopa has ability to penetrate into BBB and release dopamine inside the brain. However, it includes complications on long-term treatment like "dopa resistance" that results in aggravation of motor symptoms like, tremor, rigidity, bradykinesia (slow movement) postural instability, difficulty in walking and non-motor like mood disorder such as depression, anxiety and cognition. Till date various therapeutic approaches had been developed for the treatment of advanced PD, but all are associated with severe side effects. Therefore, the search for new drug for the treatment of PD is on going. The computational system makes the drug discovery process easier and less expensive by evaluating the early drug discovery process with the help of drug design software. With the aim of mechanistic study of newly reported antiparkinsonian agents, we used Autodock Vina which is a molecular docking software. Various molecular targets were selected (D2/D3, A2A, MAO-B) and studied for Pardoprunox, Istradefylline, Rasagiline and Bromocriptine. Pardoprunox, Istradefylline, and Bromocriptine had more affinity with their corresponding receptor with $7.2,-8.5,-9.4 \mathrm{kcal} / \mathrm{mol}$ binding affinity respectively, except rasagiline, who has less affinity with its corresponding receptor $(-6.4 \mathrm{kcal} / \mathrm{mol})$. Whereas, shown better affinity with 3 pbl receptor $(-6.7 \mathrm{kcal} / \mathrm{mol})$. The results help in prediction of mechanism and interaction to various PD targets.
\end{abstract}

Keywords: Parkinson's disease, Blood brain barrier, neurodegenerative, Autodock Vina 


\title{
ORODISPERSIBLE FILMS: AN OVERVIEW \\ IATIN KUMAR*, ASHUTOSH GUPTA, HARMANPREET SINGH
}

School of Pharmaceutical Sciences, Lovely Professional University, Phagwara, Punjab (India), Email: malikjettu95@gmail.com

\begin{abstract}
Orodispersible films (ODFs) are the most promising novel approach for drug delivery, as it has the potential to deliver the personalized therapies to the patients. They are being preferred over tablets or liquid dosage forms because of its advantages like fast onset of action, enhancement of bioavailability, bypassing of first pass metabolism, easy to handle etc. Main ingredients of any ODFs are water-soluble polymer (1-25\%), plasticizer $(0-20 \%)$, coloring agent, sweetener and filler (0-40\%) and active pharmaceutical ingredient (1-25\%). The basic mechanism involved in these film is that as soon as it come in contact with saliva it disintegrate in small particles and directly reaches to systemic circulation through mucous membrane. These are classified in three categories first mucoadhesive sustained release wafers, second flash release, and third mucoadhesive melt away wafers. Manufacturing of these does not require any special conditions. They are prepared by various methods like solvent casting method, hot melt extrusion method, semi- solid casting method, rolling method etc. There are some innovated technology used for the preparation of films are Soluleaves technology, 3D printing, Foamburst and Micap technology. The prepared films are evaluated for different parameters like thickness, drug content uniformity, tensile strength, in-vitro disintegration time, in-vitro dissolution etc. ODFs guarantees patient compliance particularly in pediatrics and geriatrics patients.
\end{abstract}

Keywords: Orodispersible films, plasticizer, mucoadhesive, solvent casting method, Soluleaves 


\title{
HERBAL SOAP FORMULATION USING PLANT EXTRACTS AND ESSENTIAL OILS SHARIB KHAN, MEGHNA SINGH*, AMREEN, FARAH, SONAM SINGH
}

1IMS Engineering College, Ghaziabad, Uttar Pradesh- 201009.2Department of Biotechnology, IMS Engineering College, Ghaziabad, Uttar Pradesh- 201009. Email: 009Sharibkhan@gmail.com

\begin{abstract}
According to University of Maryland, Herbal medicine, also called botanical medicine or phytomedicine, refers to using a plant's seeds, berries, roots, leaves, bark, or flowers for medicinal purposes. Scientists are not sure what specific ingredient in a particular herb works to treat a condition or illness. Whole herbs contain many ingredients, and they may work together to produce a beneficial effect. The most important factor riding in their favour is that herbal extracts do not have any side effects and can be taken orally or topically over a long period of time. One of the most commonly used cosmetic is soap. The aim of this study is to determine the various properties of Explants. In this study a total of 5 explants were collected from different plant sources and Extraction of Essential oils was performed by soxelation process, where determination of their properties like Anti-bacterial, Anti-fungal and virucidal elucidated. Soap is used every day by everyone for various purposes. Though the fact that most soaps have dangerous chemicals in them is not widely known to people. These chemicals can be drying and can cause many skin allergies. They also aid infection and exacerbate them. Above all, these chemical soaps block pores of the skin, thus inhibiting the skin from breathing. All this makes the skin age faster and hampers its renewal process. Then why do we continue using these chemical products. A safe alternative to these chemical based soaps are herbal soaps, a herbal soap is made from natural ingredients that may include both plant and animal products, including items such as: animal fat, such as tallow or vegetable oil, such as castor, olive, or coconut oil. In our study in IMSEC we optimize and performed Quality testing for the preparation of herbal soap and for their anti-infective action. The present preliminary study suggests that natural compounds have good efficacy to fight with skin infecting bacteria. The formulation containing essential oil and soluble compounds in the study suggest that herbal soap can provide a really good alternative to alkaline soaps in the market. Our herbal soaps show better efficacy that other standard soaps available in the herbal soap market.
\end{abstract}

Key words: Explant; ingredients; Essential oils; dangerous chemicals; good efficacy; skin infecting bacteria 


\title{
AN OVERVIEW OF SYSTEM DESIGNING OF LATEST INFUSION SYSTEM, SEALANT AND HEMOSTASIS USED FOR BIOMEDICAL APPLICATION
}

\author{
M. HIMAJA*, YOGITA KUMARI, GURMANDEEP KAUR, SACHIN KUMAR SINGH, ANKIT KUMAR YADAV
}

Department of Pharmaceutical Sciences, Lovely Professional University, Phagwara-144411, Punjab (India)

Email: mulehimajareddy08@gmail.com

\begin{abstract}
A medical device is an apparatus used in the diagnosis, mitigation, therapy, or prevention of disease, which does not attain its primary purpose through chemical action. The benefits of medical device domain include increased usability and reliability, decreased failure rate and recalls and reduced risks to patients and users. In the present study the description of latest FDA approved medical devices of "Implantable System for Remodulin" has been discussed, it is an infusion system that is fully implanted into a patient to deliver remodulin through a patient's veins. Another medical device is "Preveleak Surgical Sealant" it is used to help stop leaks that are formed in tissue, blood vessels or grafts (artificial blood vessels) during the surgical repair of the circulatory system. Other device is "Hemoblast bellows", this is a used to achieve hemostas is (control bleeding) during surgical procedures. A brief overview of designing, working conditions and medical applications in the patients has been discussed.
\end{abstract}

Key words: Medical device, Designing, Remodulin, Preveleak and Hemoblast. 


\title{
A REVIEW ON NOVEL TARGETS TO CURE CANCER MANMEET KAUR* ${ }^{*}$ ARSHVIR KAUR
}

\begin{abstract}
Cancer is the disease that causes the uncontrolled division of cells. Conventional drug therapy for treatment of cancer includes the use of monoclonal antibodies (mAbs), that has achieved considerable success in recent years. Antiproliferative drugs (mercaptopurine, methotrexate etc.), nitrogen mustards, Vinka alkaloids, antibody based treatments are also there to cure cancer. But, there is a need of more specific and safe therapies, also able to control or retard metastasis for successful treatment of cancer. This review is prepared using authentic search engines like, Google Scholar and Pubmed, thus retrieving the current information and approved therapies. Rec ently, FDA has approved an orally active selective Bcl-2 (B-Cell lymphoma-2) inhibitor, Venetoclax for treatment of specific chronic lymphocytic leukemia (CLL). Bcl-2 is a large family comprising of proteins that tend to regulate cell survival and cell death, thus controlling cell life and various death decisions. Discovery of such drugs, paved the way for better cure of certain cancer. Another agent like Bcl-2 Homology domain 2 (BH3) mimetic (ABT-737) is targeted to selective Bcl-2 proteins and is efficient in inducing apoptotic pathway via activating pro-apoptotic factors Bak/Bax. Since apoptosis, is seen to be impaired in malignant cells which shown over-expression of pro-survival Bcl-2 proteins, so drugs mimicking their natural antagonists, i.e. BH3-only proteins, might overcome chemoresistance. ABT-737 also triggered the pro-apoptotic proteins like Bax/Bak-thus, mediating apoptosis. It has also been seen that PTEN-Dependent Stabilization of MTSS1, inhibits the metastatic phenotype in pancreatic ductal adenocarcinoma (PDAC). PDAC presents at metastatic stage in over $50 \%$ of the patients. So, there is a need to have more extensive pre-clinical and clinical trials on novel therapies to treat cancer.
\end{abstract}

Keywords: Cancer, bcl-2, BH-3 mimetic, MTSS1, apoptosis. 


\title{
SUPERPARAMAGNETIC IRON OXIDE NANOPARTICLES (SPIONS) FOR HYPERTHERMIA TREATMENT
}

\author{
SARBJIT SINGH*, GURMEET SINGH LOTEY
}

Nano Research Lab, Department of Physics, DAV University, Punjab, India.Email: sarbjitphysics1989@gmail.com

\begin{abstract}
Magnetic hyperthermia is a promising method for non or low-invasive treatment of tumors, which is used by itself or as a help to chemotherapy, radiotherapy. Superparamagnetic iron oxide nanoparticles (SPIONs) are injected to the tumor and alternating magnetic field are applied to kill or destroy the tumor. Heating of SPIONs occur by two mechanisms Neel and Brownian relaxation. Superparamagnetic behaviour of iron oxide nanoparticles shows no hysteresis loss mechanism. Structural and magnetic properties of the samples were studied using powder X-ray diffraction (XRD), transmission electron microscopy (TEM) and a vibrating sample magnetometer (VSM). Biocompatibility, colloidal stability, conjugation with bioactive functional groups is the essential requirements for the nanoparticles to be used for hyperthermia. Due to high saturation magnetization, Zero coercivity, excellent chemical and thermal stability SPIONs possess a great potential for a wide application both in biomedical research and clinical practice.
\end{abstract}

Keywords: Hyperthermia, Superparamagnetic, hysteresis, Biocompatibility. 


\title{
ILEO-COLONIC TARGETED GRANULES OF BERBERINE FOR CHRONOTHERAPEUTIC TREATMENT OF RHEUMATOID ARTHRITIS
}

\author{
MAKHAN LAL ${ }^{*}$, HARMANPEET SINGH, SURAJPAL VERMA
}

Lovely School of Pharmaceutical Sciences, Lovely Professional University, Phagwara, Punjab, India Email: makhanmj02@gmail.com

\begin{abstract}
In this present research work, the aim was to develop ileo-colonic targeted granules of Berberine for chronotherapeutic treatment of Rheumatoid Arthritis. Berberine is found to be effective in the treatment of Rheumatoid arthritis when given at doses $75,150,200 \mathrm{mg} / \mathrm{kg}$ in rat. Ileo-colonic targeted granules of drug after administration at bed time will maintain high concentration of drug in the bloodstream during the early morning time on next day. This maintenance of high concentration will be useful in treatment of rheumatoid arthritis as joint pain and functional disability symptoms of rheumatoid arthritis usually occurs in the early morning hours. The compatibility of pure drug with various excipients used in preparation of granules was assessed using FT-IR studies. Berberine at doses $(75 \mathrm{mg} / \mathrm{kg}$ and $150 \mathrm{mg} / \mathrm{kg}) \mathrm{were}$ incorporated in pH sensitive polymers and ileo-colonic targeted granules were prepared by dry granulation method. The batch of optimized formulation of targeted granules was selected on basis of results obtained for flow properties (angle of repose, bulk density, tap density, Hausner ratio, and compressibility index) and dissolution profile in phosphate buffer pH 6.8 and 7.4. Before carrying out dissolution, the UV spectrophotometric method of Berberine in phosphate buffer pH 6.8 and 7.4 was developed and validated for linearity, precision, repeatability and reproducibility etc. The obtained results of validation proved that the method can be employed for the routine analysis of Berberine. The optimized batch of ileo-colonic targeted granules of Berberine will be further tested in specific animal model to proves its usefulness for treatment of Rheumatoid Arthritis.
\end{abstract}

Keywords: Ileo-colonic targeted granules, Berberine, Rheumatoid arthritis and joint pain 


\title{
ROLE OF DATA INTEGRITY IN QUALITY ASSURANCE: AN OVERVIEW \\ NITIN KUMAR BHATT*, RAVI KUMAR, BIJAY KUMAR YADAV, RINKU ROZERA, ANSHUL ATTRI, BHUPENDRA SINGH TOMAR, ANKIT KUMAR YADAV, SACHIN KUMAR SINGH, SURAJPAL VERMA
}

School of Pharmaceutical Sciences, Lovely Professional University, Phagwara - 144411, Punjab India Email: nitinbhatt3331@gmail.com

\begin{abstract}
Data integrity is one of the most important aspects followed in pharmaceutical industry to keep the track on the originality of the data being generated by the research scientists. The research data generated by the research scientists in Pharmaceutical industries is one of the most crucial document as it has to deal with the human health on later stages. It is about completeness, consistency and accuracy of data. It means the process that assures about attributability, legibility, contemporaneously recorded, original or a true copy, and accuracy of the data (ALCOA). Data integrity is important to maintain not only the originality of the data but to get the regulatory compliance also. The regulatory approval processes as well as their quality audit requires the report of the data generated and reported in the same condition as it is generated. An integrated data reveals true picture of the document and makes industry to achieve approval from regulatory bodies. The components of data integrity process include metadata analysis, audit trial, static v/s dynamic records, backup and system. These are the important systematic approaches that are used to demonstrate quality of product. Concept of data integrity is explained under 21 CFR Part 11 of ICH guidelines. During implementation of this processes the pharmaceutical company needs to comply with Title 21 of the Code of Federal Regulations (CFR) - Part 11 , commonly known as " 21 CFR 11". 21 CFR Part 11 establishes the criteria under which electronic records and signatures are stored and is considered trustworthy, reliable and equivalent to paper records by the US FDA. In the present study a systematic review of process flow of meta data analysis, audit trial, static $\mathrm{v} / \mathrm{s}$ dynamic records, backup, and system has been discussed along with their maintenance and advantages
\end{abstract}

Keywords:- AlCOA, CGMP, Data integrity, Meta data, Backup. 


\title{
CHARACTERISATION EVALUATION OF DENDRIMERS RAHUL THAKUR, VIVEK GUPTA*
}

School of Pharmaceutical Sciences, Lovely Professional University, Phagwara, Punjab, India-144411

\author{
Email: Thakurrahul214@gamil.com
}

\begin{abstract}
The dendrimer is the combination of the two Greek word dendron and meros. Dendron means tree and meros means part. The dendrimers are highly branched three-dimensional structure. Two strategies have been proposed for the preparation of dendrimers first one is divergent method and second one is convergent method. The size of dendrimer is in nanometers. The size of the dendrimer depends on how many steps are there in the building process. This criticism is an examine the techniques, which is used for evaluation of dendrimers, investigate the shape of dendrimer, reaction rate, morphology, structural defects, conjugation, synthesis, chemical composition, physical state, polydispersity, molecular weight, homogeneity and purity of dendrimer. It includes infra-red (IR), Raman spectroscopy, nuclear magnetic resonance, mass spectroscopy, fluorescence technique, x-ray photoelectron technique, atomic force microscopy, ultra-violet-visible (UV-vis), laser light scattering (LLS), small angle neutron scattering (SANS), small angle x-ray scattering (SAXS), scanning electron microscopy (SEM), transmission electron microscopy (TEM), electrophoresis, electrochemistry, electron paramagnetic resonance (EPR), size exclusion chromatography (SEC), dielectric spectroscopy, intrinsic viscosity, differential scanning calorimetry (DSC), titrimetry.
\end{abstract}




\title{
STEM CELL THERAPY: WORKING FOR JOINT PAIN, ALZHEIMER'S DISEASE, HEART DISEASE AND DIABETES
}

\section{AKSHAY KHANNA*, SAKSHI SHARMA}

Department of Pharmaceutical Sciences, Lovely Professional University, Phagwara- 144411, Punjab (India)

Email: akshaykhanna317@gmail.com. Contact: 7508509255

\begin{abstract}
The growing kind of biological concepts in the rebirth of oral tissues fixed with experiments on stem cells is possible to result in a paradigm shift in the therapeutic armamentarium of dental and oral diseases culminating in an strong search for "biological solution to biological problems." The rebirth of a lost tissue is known to mankind for certain years, it is only in the current former that research on regenerative medicine/dentistry has gained energy and escaped the dramatic yet scientific improvements in the field of molecular biology. Stem cells have the capability to distinguish into specific cell types. The two important features of stem cells are perpetual self - renewal and ability to distinguish into a specific adult cell type. There are two major classes of stem cells: pluripotent that can become any cell in the adult body, and multipotent that are limited to attractive a more incomplete population of cells. Cell sources, features, variation and therapeutic applications are discussed. Stem cells have great potential in tissue regeneration and repair but much still needs to be learned about their biology, manipulation and safety before their full therapeutic potential can be attained. The indication gathered so far has propelled many elegant studies travelling the role of stem cells. It also focuses on the various trails and walls that we have to surmount before translating laboratory results to fruitful clinical applications heralding the dawn of recreating dentistry.
\end{abstract}

Keywords: regenerative medicine, pluripotent, multipotent, therapeutic, tissue repair 


\title{
EXTRACTION METHODS OF NATURAL POLYMERS USED AS PHARMACEUTICAL SUPERDISINTEGRANTS
}

\section{SUBHAIIT GAIN*, SURAJPAL VERMA}

School of Pharmaceutical Sciences, Lovely Professional University, Phagwara, Punjab, India.Email: surajpal.15834@lpu.co.in

\begin{abstract}
Mother nature provided us a huge variety of components and materials to improve the health of living beings directly or indirectly. We, humans, enjoy the benefits from nature by isolating and extracting nature's valuable components as per our requirements. Most of the beneficial components are mainly collected from plant sources. These natural components are also precursors for several synthetic and semi-synthetic components, which has been widely used in pharmaceutical industries to produce pharmaceutical products. Gums and mucilages are the most useful natural substances. A vast variety of natural polymers are used as pharmaceutical excipients for improving the acceptability and efficacy of the drugs. Fast disintegrating tablets are one of the most popular dosage forms for providing quick action of active compounds. The superdisintegrants helps in inducing quick disintegration of these tablets. The natural superdisintegrants are bio-inert, non-toxic, less expensive, biodegradable and easily available as compare to synthetic superdisintegrants. Different extraction methods of natural superdisintegrants are available, but only some specific methods provide maximum yield with suitable quality. In this study, different extraction methods were performed for extraction of different natural superdisintegrants like Isabgol husk mucilage, Fenugreek seeds mucilage, Hibiscus rosasinensis leaf mucilage. The most suitable method was selected after studying the disintegration activity of these polymers.
\end{abstract}

Keywords: Natural polymers, Natural superdisintegrants, Polymer extraction, Isabgol husk mucilage, Fenugreek seeds mucilage, Hibiscus rosasinensis leaf mucilage 


\title{
SYNTHESIS OF COPPER NANOPARTICLES USING ASCORBIC ACID AND CETYL TRIMETHYL AMMONIUM BROMIDE
}

\author{
SAURABH SINGH ${ }^{1}$, BIMLESH KUMAR ${ }^{2}$, NARENDRA KUMAR PANDEY², DILEEP SINGH BAGHEL ${ }^{1}$, MALTI G. \\ CHAUHAN $^{3}$, SACHIN KUMAR SINGH ${ }^{2 *}$
}

1School of Ayurvedic Pharmaceutical Sciences, Lovely Professional University, Phagwara - 144411, Punjab, India

${ }^{2}$ School of Pharmaceutical Sciences, Lovely Professional University, Phagwara - 144411, Punjab, India

${ }^{3}$ Member Ayurvedic Pharmacopoeia Committee, Pharmacopoeia Commission for Indian Medicine \& Homoeopathy Ghaziabad Government of India, Uttar Pradesh, India

\begin{abstract}
Copper, popularly known as "Tamra", is well known for its use as Bhasma (incinerated powder) which is used in Ayurveda for treating various diseases like diabetes, arthritis and respiratory diseases etc. The present study highlights the development of a method to synthesize copper nanoparticles (CuNPs) by using $0.01 \mathrm{M}$ copper sulphate $\left(\mathrm{CuSO}_{4} .5 \mathrm{H}_{2} \mathrm{O}\right)$ and $0.11 \mathrm{M}$ of ascorbic acid and $0.03 \mathrm{M}$ of cetyl trimethyl ammonium bromide (CTAB) solution. The synthesized CuNPs were separated by filtration and washed with deionised water and ethanol. CuNPs were kept in dialysis bag $70 \mathrm{KD}$ (Kilo Dalton) in a $250 \mathrm{~mL}$ glass beaker with distilled water. The assembly was kept on a magnetic stirrer for $24 \mathrm{~h}$ at $500 \mathrm{rpm}$. Then the dialysis bag containing CuNPs solution was filtered by a filter assembly with $0.2 \mu$ m nylon filter. The filtered CuNPs was spray dried with the help of spray drier but the obtained spray dried. Further, the prepared CuNPs were characterized for micromeritic properties such as angle of repose, bulk density, tapped density, Carr's index and Hausner's ratio. The results revealed CuNPs with size of 400nm and higher values of micromeritic parameters.
\end{abstract}

Keywords: Copper nanoparticles; CTAB; Ascorbic acid; Spray drying; Micromeritics 


\title{
DEVELOPMENT AND EVALUATION OF EMULGELS FOR TREATMENT OF VIRAL BORN SKIN DISEASE WART
}

\author{
AANCHAL SAINI, NISHAT ANJUM, SHARAD VISHT
}

Smt. Tarawati Institute of Bio-Medical \& Allied Sciences, Roorkee.Contact: +91-8630073358 Email: rvaanchalsaini@gmail.com

\begin{abstract}
The purpose of study was to develop and evaluate an emulgel for treatment of viral born disease wart. The $2^{3}$ factorial design was used to prepare emulgel. Three factors were selected were concentration of turmeric oil, glycerol and tween-80. The Thuja oil was used as drug, carbopol-934P was used as gelling polymer, glycerol was used to improve hydration of dried wart mass, tween-80 was used as surfactant and turmeric oil were used as permeation enhancer. The drug and excipients were mixed in mortar pestle. The prepared emulgels were characterized for appearance, drug content uniformity, homogeneity, $\mathrm{pH}$, skin irritation, spreadability, in-vitro drug release, scanning electron microscopy and antiviral activity on humans. The BIT-soft 1.12 was used to determine the kinetics of drug release. The emulgels showed the white and cream colored, homogenous mixture with no aggregates. The FTIR studies shows drug excipient compatibility. The pH of emulgels were 6.1-6.7 and formulation showed no skin irritation. The spreadability was $3.5 \pm 0.11-4.3 \pm 0.12$ minutes. The drug content was found to be $98.95-99.85 \%$. The percentage drug release was found to be $57.65 \pm 0.15-68.65 \pm 0.62$ up to 150 minutes. Batch-F was selected best on the basis of maximum drug release. In-vivo study on human volunteers showed the $1 \mathrm{~mm}$ inhibition of wart after 2 weeks of application. The kinetics of drug release showed Korsmeyer-Peppas equation as a best fit model with $\mathrm{r}^{2}$ value 0.9971 and $\mathrm{k}$ value 1.4123 that indicate anomalous transport.It is concluded form results that prepared formulation is a promising candidate to treat wart.
\end{abstract}

Keywords: Thuja, turmeric, emulgel, wart, carbopol-934P, viral 


\title{
A REVIEW OF MEDICAL PLANTS WITH POTENTIAL ANTIDIABETIC ACTIVITY MANPREET KAUR ${ }^{1}$, PRANAV KUMAR PRABHAKAR ${ }^{2}$, DILEEP SINGH BAGHEL ${ }^{1 *}$
}

1School of Pharmaceutical Sciences, Lovely Professional University, Phagwara, Punjab, India-144411 ${ }^{2}$ Department of Medical Laboratory Sciences, Lovely Professional University, Phagwara, Punjab, India-144411 Email: manpreetvirdi386@gmail.com

\begin{abstract}
Diabetes mellitus is reaching potentially epidemic proportions in India, diabetes morbidity and mortality is a significant healthcare burdens on both families and society. Moreover, diabetes is now being shown to be associated with many complications and to be occurring at a relatively younger age within the country. Diabetes is a chronic disorder of metabolism caused by a relative or absolute lack of insulin in the body. Its primary characteristic is a high level of sugar in the body. Glucose is the main energy source for the body, and in the case of DM, management of glucose becomes irregular. There are three key defects in the onset of hyperglycaemia in DM, namely increased hepatic glucose production, diminished insulin secretion, and impaired insulin action. Conventional drugs treat diabetes by improving insulin sensitivity, increasing insulin production and/or decreasing the amount of glucose in blood. This review article provides a comprehensive review of the mode of action of most popular hypoglycemic herbs, such as ginseng, bitter melon, fenugreek, banaba, gymnema and Coptis chinensis. The efficacy of hypoglycemic herbs is achieved by increasing insulin secretion, enhancing glucose uptake by adipose and skeletal muscle tissues, inhibiting intestinal glucose absorption and inhibiting hepatic glucose production. Although evidence from animals and humans consistently supports the therapeutic activities of these phytomedicines, multi-center large-scale clinical trials have not been conducted to evaluate the safety and efficacy of these herbal medicines.
\end{abstract}

Keywords: Diabetes mellitus, antidiabetic, hypoglycemic, hyperglycemia, medicinal plants 


\title{
ASSESSMENT OF DENGUE FEVER: NATURAL AND HERBAL REMEDIES DAVINDER KUMAR, DILEEP SINGH BAGHEL*, SAURABH SINGH, BIMLESH KUMAR
}

School of Pharmaceutical Sciences, Lovely Professional University, Phagwara, Punjab, India-144411 Email: davinderkumar103320@gmail.com

\begin{abstract}
The word "Dengue" is derived from the Swahili phrase Ka-dinga pepo, meaning "cramp-like seizure. Dengue (break bone fever or dandy fever) is a vector-borne viral disease of humans that is transmitted by mosquitoes of the genus Aedes. The World Health Organization (WHO) regards dengue as a major international public health concern in tropical and subtropical regions in which it is endemic due to a combination of population growth, unplanned urbanisation, global warming, lack of efficient mosquito control, increased air travel and insufficient public healthcare facilities. Symptoms include fever, headache, muscle and joint pains, and a characteristic skin rash. In Ayurvedic system of medicine it is known as dandak jwara and comes under the category of Abhishangaja Jvara predominantly Pittaja in pathological ground. The complications represent Raktaja and Sannipataja Jvara. Dengue fever virus (DENV) is an RNA virus of the family Flaviviridae and exists in four serotypes, namely DENV 1, DENV2, DENV 3 , DENV 4 and DENV5. Infection with one type usually gives lifelong immunity to that type, but only short-term immunity to the others. Dengue is not transmitted directly from person-to-person. Aedes mosquitoes are the carrier of dengue viruses. This mosquito can be easily distinguished as it is larger in size and have black and white stripes on its body, so it is sometimes called tiger mosquitoes. There are several natural and herbal home remedies such as use of Ipecacuanha, Astragalus, Echinacea, Methi leaves, Tulsi, Laghu patha, Papaya, Guduchi, Neem, Grape and Orange juices etc to control the dengue virus and fever. As home remedies are easily available, inexpensive, valuable and highly effective, it is recommended to dengue patients to use these home remedies.
\end{abstract}




\title{
A SURVEY ON METABOLIC SYNDROME IN JAMMU \& KASHMIR NEHA RAJWAL ${ }^{1}$, DR. SHRUTI SETH ${ }^{2}$, SAVITA DEVI ${ }^{1}$, MUHAMMAD SHAFI BHAT ${ }^{1}$
}

1Department of Medical Laboratory Sciences, Shri Mata Vaishno Devi Narayana Superspeciality Hospital, Jammu - 182320, J \& K (India) *2Department of Medical Laboratory Sciences, Lovely Professional University, Phagwara - 144 411, Punjab, India. Email: savita.20526@lpu.co.in. Email: neharajwal39@gmail.com

\begin{abstract}
The metabolic syndrome (MetS) is described as the cluster of the several risk factors for cardiovascular disease such as hypertension, hyperglycaemia/ insulin resistance, abdominal obesity \& dyslipidaemia. Metabolic syndrome is highly prevalent among adults in developed countries and is an emerging health problem in developing countries. The criteria used for defining metabolic syndrome are those proposed by International Diabetes Federation (IDF), National Cholesterol Education Programme-Adult Treatment Panel-III (NCEP-ATP III). The aim of this study was to assess the prevalence of metabolic syndrome, its components, and its major risk factors among adults $\geq 20$ in Jammu \& Kashmir according to IDF and NCEP ATP III criteria. The purpose of these definitions is to find out the edge group in the population who are at increased risk of developing cardio-metabolic diseases (CVDs / CHDs). The study was conducted in the Department of Biochemistry, Laboratory Medicine, Shri Mata Vaishno Devi Narayana Superspeciality Hospital, Katra, and Jammu \& Kashmir in 100 subjects between the age groups $20-80$ years attending the OPD. The subjects were selected by simple random sampling method for the duration of 4 months from 2 January to 29 April 2017 . The overall prevalence of MetS in Jammu was estimated to be $57 \%$ and 55\% by IDF and NCEP ATP III criteria respectively. That show IDF criteria is better for early diagnosis of metabolic syndrome. On the basis of gender prevalence in all parameters in IDF females are at risk \& in NCEP ATP III males are more at risk. Central obesity is the only cause for IDF females are at risk.
\end{abstract}

Keywords: Metabolic syndrome, IDF (International Diabetes Federation), NCEP-ATP III (National Cholesterol Education Programme-Adult Treatment Panel-III), Prevalence. 


\title{
COMPARATIVE STUDY OF AN IMMUNOCHROMATOGRAPHIC ASSAY WITH ENZYME- LINKED IMMUNOSORBENT ASSAY FOR THE DETECTION OF HEPATITIS B SURFACE ANTIGEN IN NMCH BIHAR
}

\author{
RAVI RANJAN KUMAR ${ }^{*}$, KARAMJIT KAUR ${ }^{1}$, RANA PRATAP ${ }^{2}$
}

1Department of Paramedical Sciences, Lovely Professional University, Phagwara- 144411, Punjab (India) 2Department of Microbiology, Narayan Medical Collage and Hospital, jamuhar, Sasaram-821305, Bihar (India) Email: ranapratap1978@gmail.com

\begin{abstract}
Viral Hepatitis is a type of systematic disease with primarily inflammation in the liver. It can cause both type of disease acute and chronic. The Hepatitis B Virus (HBV) is transmitted through contact with blood or other body fluids which contaminated with HBV. According to World Health Organization (WHO) about 260 million people are living with HBV infection, known as hepatitis B surface antigen (HBsAg) and in 2015, about 887000 deaths accurse due to hepatitis B infection mostly from complications including hepatocellular carcinoma and cirrhosis. For routine screening of HBsAg infection in Indian laboratory frequently uses rapid card techniques such as immunochromatographic assay (ICA). This study aimed to compare an immunochromatographic technique with a more widely accepted technique enzyme-linked immunosorbent assay (ELISA). For detection of HBsAg in NMCH, Jamuhar (Bihar), the selection of participants for this study was done on sampling the IPD and OPD patients of NMCH, Jamuhar, BIHAR, from $1^{\text {st }}$ January to $31^{\text {th }}$ January 2018. Each patients was tested for Hepatitis B surface antigen (HBsAg) using both technique such as immunochromatographic assay (ICA) and enzyme-linked immunosorbent assay (ELISA).In this study total 206 patients serum samples are tested for HBsAg, by both technique in which $4.85 \%$ positive and $95.15 \%$ negative by (ICA) Technique and by ELISA technique $5.34 \%$ positive and $94.66 \%$ negative, about $0.48 \%$ are more positive by ELISA technique. So, that the ELISA technique are more sensitive then (ICA) rapid card technique, ELISA give more quality report then ICA.
\end{abstract}

Keywords: HBsAg, Hepatitis, ELISA, Hepatocellular, Cirrhosis, systematic disease. 


\title{
VITAMIN D DEFICIENCY - A RISK FACTOR FOR TYPE 2 DIABETES MELLITUS MOHAMMAD ZIA RASEKH, PRANAV KUMAR PRABHAKAR*
}

Department of Medical Laboratory Sciences, Lovely Professional University, Punjab-144411

Email: zia68.rasekh@gmail.com

\begin{abstract}
The prevalence of vitamin D deficiency is more common in $30 \%$ to $50 \%$ of general population. A growing studies suggested that the deficiency of vitamin D has been change the synthesis and secretion of insulin in both humans and animals. The studied reported that the vitamin D deficiency increase the glucose intolerance, change insulin secretion and increase the risk of type 2 diabetes mellitus. Another study reported that sever vitamin D deficiency increase the cardiovascular mortality in type 2 diabetic patients. Vitamin D supplementation regulate and improve the insulin secretion in type 2 diabetic patients. Vitamin D receptors (VDR) and vitamin D-binding proteins (DBP) are present in pancreatic tissues and the relationship between the different allelic variations in VDR and DBP genes with insulin secretion and glucose tolerance have supported these studies. Mostly vitamin D affect in type 2 diabetes with 2 mechanism, one of the mechanism is direct action of vitamin $D$ on pancreatic $\beta$-cell function and the other is to regulate the plasma calcium levels which calcium regulate the insulin synthesis and secretion. This review focus on the importance and relation of vitamin $\mathrm{D}$ deficiency on type 2 diabetes mellitus.
\end{abstract}

Keywords: Vitamin D deficiency, Type 2 diabetes mellitus, Vitamin D receptor, Vitamin D binding protein. 


\title{
CO-RELATION BETWEEN OBESITY AND HYPERTENSION ABDUR RAHIM ABIDI
}

Department of Medical Laboratory Sciences, Lovely Professional University, Punjab-144411

Email: rahim.abidi@yahoo.com

\begin{abstract}
Obesity is one of the global health concern and second leading cause of preventable death. It influences cardiovascular structure and function badly, and has negative effect on all cardiovascular risk factors. Overweight and obese patients as compared to the normal weight patients are more susceptible to the prevalence of cardiovascular diseases. Similarly, hypertension is an important contributor to global disea se burden. Both obesity and hypertension lead to cardiovascular, renal diseases and they are related with increased rate of morbidity and mortality. Visceral obesity is related with dyslipidemia and insulin resistance. It is more important determinant of hypertension as compared to subcutaneous obesity. Potential mechanisms of obesity-related hypertension involve increased activity of the sympathetic nervous system, activation of the renin-angiotensinaldosterone system, sodium retention, insulin resistance and impaired vascular endothelial dysfunction. Vascular fibrosis and lipid deposition can also enhance systemic vascular resistance in obese individual. Obesity is not only a marker of cardiovascular risk but it is regarded as an important and primary contributor to the pathophysiology of hypertension.
\end{abstract}

Key words: Obesity, Hypertension, insulin resistance 


\title{
BILAYER FLOATING TABLET TECHNOLOGY: AN OVERVIEW DIPANIOY GHOSH ${ }^{1}$, PANKAJ CHAKRAVORTY2 ${ }^{2}$, NARENDRA KUMAR PANDEY ${ }^{*}$
}

1Department of Pharmaceutical Sciences, Lovely Professional University, Phagwara- 144411, Punjab (India) ${ }^{2}$ Department of Quality Assurance, Delhi Institute of Pharmaceutical Science and Research, Pushp Vihar-110017 South Delhi, Delhi (India).Email: dipanjoyg@gmail.com

\begin{abstract}
In the recent past with the advent of technology bought an enormous advancement in the pharmaceutical sciences. The advances broke all narrow walls such as low bioavailability, poor solubility, toxicity and low efficacy. The introduction of novel drug delivery system made it possible to formulate dosage form which defeat physiological parameters of gastric retention by minimizing blood drug concentration, ramification of which leads to reduction of toxicity and poor efficacy. Numerous approaches have been introduced since last few decades to prolong gastric residence time. Bilayer floating is one of the best approaches of NDDS where the bilayer is amalgamated with floating mechanism. This aid in prolongs the gastric retention time and in addition decreases toxicity, enhances solubility of drug which is less soluble in alkaline pH. Bilayer floating system advantages out the conventional oral dosage forms as they can release drug immediately and in controlled manner too. Floatation possible because of lesser bulk density than gastric fluids and so, it remains buoyant in the stomach for a prolonged period of time. So the drug slowly starts to release at the desired rate from the system and increase the bioavailability of narrow absorption window drugs. The present article provides an outline to bi-layer tablet technology, challenges in bilayer tablet manufacturing, a number of tablet processes used, requirements \& quality for their manufacture a number of techniques used for bi-layer tablet and current developments in field of bilayer technology.
\end{abstract}

Keywords: gastroretentive, Bilayer tablet, Novel drug delivery system, floating drug delivery system 


\title{
POTENTIAL PRECLINICAL AND CLINICAL TOXICITY OF METALLIC NANOPARTICLES
}

CLARISSE AYINKAMIYE*, YOGITA KUMARI, GURMANDEEP KAUR, SACHIN KUMAR SINGH, ANKIT YADAV KUMAR, SURAJPAL VERMA, MONICA GULATI, RAKESH NARANG, BIMLESH KUMAR, GOPAL LAL KHATIK

School of Pharmaceutical Sciences, Lovely Professional University, Phagwara-144411, Punjab, India Email: mulindaclarisse@gmail.com

\begin{abstract}
Toxicity is a major concern that affects NPs in preclinical phase as well as clinical phase. These NPs have several applications in diagnosis and treatment of diseases and they are used in targeted drug delivery due to their enormous properties such as small size, large surface to volume ratio and functionalized surface. NPs have various chemical, optical, structural and magnetic properties as well as possess different toxicity profiles. They may induce cytotoxicity, genotoxicity due to their exposures through the skin, respiratory tract, gastrointestinal tract and lymphatic system. Toxicity of NPs involves alteration of physiological, physicochemical and molecular conditions of the body. These may alter the physicochemical properties of xenobiotics which results in pharmaceutical changes in solubility, stability as well as pharmacokinetics disposition. This presentation summarizes the current progress in approaches assessing nanotoxicity in including hepatic, renal, gastrointestinal, pulmonary, cardiovascular, nervous, and immune systems.
\end{abstract}

Keywords: NPs, Toxicity, Cytotoxicity, Genotoxicity, preclinical. 


\title{
AN OVER VIEW OF PHARMACEUTICAL USES OF ALLICIN AND ITS METHOD OF ISOLATION BIJAY KUMAR YADAV*, NITIN KUMAR BHATT, RAVI KUMAR, RINKU ROZERA, ANSHUL ATTRI, ANKIT KUMAR YADAV, SACHIN KUMAR SINGH, BHUPENDRA SINGH TOMAR, BIMLESH KUMAR
}

School of pharmaceutical science, Lovely professional university, Phagwara -144411, Punjab, India. Email: bkydev456@gmail.com

\begin{abstract}
Garlic (Allium sativum) is one of the most important constituent of food and it is utilized worldwide form the ancient times. It is mainly utilized in the food to increase the taste, odor and other properties. Apart from its uses as food ingredients garlic has a long history as a remedy for reducing fatigue, improving stamina and strength, boosting immunity and for prevention and treatment of many gastrointestinal disorders. Garlic contains large number of chemical constituents which are diallyldisulphide, amino acids, minerals and proteins. Out of which Allicin is one of the major chemical constitutes present in the garlic. It is reported for a wide range of pharmacological activities such as scurvy, diabetes, hypertension, atherosclerosis, hyperlipidemia, cancer, stroke and heart related problems like congestive heart failure by the different researchers. Pharmacological activity of Allicin is reported on different diseases by the different researchers on the varying dose ranges. As per the various researchers Allicin can be successfully extracted from raw garlic (Allium sativum) by using aqueous and alcoholic extraction in the laboratory. In the present study an overview of various pharmacological uses of Allicin, its method of extraction and isolation is carried out and reported.
\end{abstract}

Keywords: Garlic (Allium sativum), Allin, Allicin, Diallyldisulphide, Hypertension, vasodilation 


\title{
TRANSFORMATION OF HERBAL REMEDIES TO NOVEL THERAPEUTICS FORMULATIONS FOR TARGETED TREATMENT OF RHEUMATOID ARTHRITIS: A REVIEW
}

\author{
BIKRAM SINGH*, MANINDER SINGH, ARSHVIR KAUR
}

Department of pharmaceutical sciences, Lovely Professional University, Phagwara-144411, Punjab (India)

Email: bikramsingh2864@gmail.com

\begin{abstract}
Rheumatoid arthritis (RA) is a chronic, inflammatory autoimmune disease that leads to a synovial inflammation, destruction of articular cartilage, bone erosion, deformities, accompanied by pain, swelling and stiffness, most commonly in limbs. The pathophysiology elaborates the role of $\mathrm{T}_{\mathrm{H}} 1$ ( $\mathrm{T}$ helper) cells secreted in response to IL-1 (Interleukin-1) and 12, thus producing pro-inflammatory Interleukins (IL-6 and IL-2) whereas T 2 cells activated by IL-4 secretes anti- inflammatory cytokines (IL-4, 5, 10 \& 13). Neutralization of endogenous anti-inflammatory cytokines mainly IL-10 by production of anti-IL-10 monoclonal antibodies (mAbs) which results in down regulation of anti-inflammatory cytokines which lead to more severe collagen induced arthritis. Conventional treatment for RA includes Non-steroidal anti-inflammatory drugs (NSAIDs), glucocorticoids, nonbiologics and biological disease-modifying anti-rheumatic drugs (DMARDs), conjugate of humanized monoclonal antibody, dendritic cells etc. Although, conventional therapy and newer treatments are effective but suffers from several limitations like serious adverse effects, high cost and invasive intervention. Novel herbal therapies using phytochemicals of Curcuma longa, Zingiber officinale, Glycerrhiza glabra, Withania somnifera, Tripterygium wilfordii, Boswellia serrate, Camellia sinensis, Tanacetum parthenium, Commifora, mukul, Plumbago zeylanica through their promising novel drug delivery systems like microspheres, transdermal patches, ethosomes, liposomes and phytosomes etc. have shown promising response and efficacy via well-defined immune mechanism along with their easy accessibility, mild or negligible adverse effects, thus gaining the edge over conventional and invasive therapies for RA. So, there is a need to study these novel formulations, extensively on preclinical and clinical levels and develop these herbal therapies as a promising alternative to conventional therapies for treatment of rheumatoid arthritis.
\end{abstract}

Keywords: Rheumatoid arthritis, interleukins, cytokines, herbal, novel therapeutic formulations, autoimmune. 
Abstract No. RTBS-P-78

\title{
EXPLORING POTENTIAL OF FUNGUS IN BIOETHANOL PRODUCTION AND POLLUTION CONTROL
}

\section{GAGANDEEP SINGH}

Department of Medical Laboratory Sciences, Lovely Professional University, Phagwara- 144411, Punjab (India)

Email: gagandeep.22675@lpu.co.in.

\begin{abstract}
Burning of the agricultural residue (such as rice straw, wheat bran and sugarcane bagasse) is one of the major cause of pollution and global warming. This is because of the reason that the crop residue which is leftover is of no use for the farmer. But this residue is to be used as renewable source of energy by the production of biofuel from it by using various microbial technologies. This will help in reducing the pollution level and will also lead to development of alternate energy source. Mesophilic fungus (such as Aspergillus fumigatus and Trichoderma reesei) has the property of undergoing saccharification of crop residues and convert it into valuable product such as ethanol. This fungus has ability to produce various enzymes such as endoglucanases, lignocellulases and xylanases, which help in the bioconversion of lignocellulosics present in plant cell wall into second generation biofuel. In addition to cellulolytic activity, some basidiomycetes (such as Phanerochaete chrysosporium) also have oxidative system, which in combination with cellulase system accelerates the process of saccharification. Moreover, some molecular techniques such as induced mutagenesis and heterologous gene expression are also being used to obtain robust strains of fungus, capable of producing more efficient enzymes. So this conversion of biomass can help in meeting dual motive of decreasing pollution and providing alternative to conventional energy
\end{abstract} source.

Key words: Crop residue; fungus; bioethanol; cellulase system. 


\title{
TREATMENT OF NEUROLOGICAL DISEASE BY GENE EDITING TOOL (CRISPER-CAS9) PARTIKSHIT THAKUR, THOMSON SONI*
}

Department of Medical Laboratory Sciences, Lovely Professional University, Phagwara- 144411, Punjab (India) Email: patial86229@gmail.com

\begin{abstract}
Increased accumulation of transcribed protein from the damaged DNA repair capability contributes to numerous neurological diseases for which effective treatment are lacking. Gene editing techniques provide new hope for replacing defective genes and DNA associated with neurological disorders or disease. The advancement is using such editing tools as zinc finger nucleases (ZFN) or mega nucleases and transcription activator like effector nucleases (TALENS); the scientists are able to design DNA-binding proteins, which can make precise double standard breaks (DSBs) at the carrier DNA. The recent development with the CRISPR-Cas9 gene editing technology has proven to be more precise and efficient when it compared to most other gene editing techniques. In this, two methods Non-Homologous end joining (NHEJ) and Homology direct pair (HDR) are used in CRISPR-Cas9 system which can easily excise the defective gene. In this poster, we provide an overview of the CRISPR-Cas 9 methodology, with a focus on how in this gene editing tool can be used to counteract certain genetic defects associated with neurological diseases.
\end{abstract}

Key words: CRISPER Cas9, Neurologic disease, Gene editing, Homology direct pair, Zinc finger nucleases 


\title{
SUBDERMAL BUPRENORPHINE IMPLANT: SUITABLE ALTERNATIVE IN THE MANAGEMENT OF OPIOID ADDICTION
}

\author{
MONIKA SHARMA, VANDANA KALSI, BARINDERJIT KAUR
}

Department of Pharmaceutical Sciences, Lovely Professional University, Phagwara- 144411, Punjab (India)

Email: barinderjit.12062@lpu.co.in

\begin{abstract}
Drug addiction is a relapsing brain disorder that leads to continuous drug seeking and repeated use. Symptoms of addiction include glazed or blood shot eyes, abrupt weight changes, constricted or dilated pupils, lethargy and depression. Drugs belonging to the category of opioids are attributed to the addiction and abuse. Buprenorphine is one of the successful medications for opioid dependence. It is a semi-synthetic compound derived from thebaine and a partial agonist of $\mu$ opioid receptors. Buprenorphine is available as different formulations. For decades, oral or intravenous buprenorphine along with other opioid agonists (methadone, oxycodone), antagonists (naltrexone, naloxone), and combinations of the two (buprenorphine/naloxone) have helped the patients in their recovery. The combinations of buprenorphine/naloxone blocks opiate receptors, reduces cravings and is non-addictive. However, oral and intravenous forms of treatment come with certain constraints and challenges. Furthermore, buprenorphine when used sublingually as tablets, the fluctuations in blood concentrations were reported. All of these challenges led to the development of Probuphine, buprenorphine in the form of implants which are implanted subdermally and deliver the active drug over 6 months. The release of buprenorphine from such implants is fairly constant, avoiding plasma fluctuations, and the implant is also reported to be safe. The major advantage of using this implantable formulation is that the effect of buprenorphine can be terminated rapidly by removal of Probuphine. Therefore, among all the formulations of buprenorphine, subplants are most preffered as it eliminate the need for daily supervision and minimizing fluctuations in plasma concentrations.
\end{abstract}

Key words: Buprenorphone; Opiod addiction; Probuphine; Subdermal implants; 


\title{
COMPARATIVE EVALUATION OF MARKETING APPROVAL PROCESS FOR THE PHARMACEUTICAL PRODUCTS IN REGULATED AND SEMI REGULATED COUNTRIES
}

\author{
ABDUL AZEEZ MAIYAKI*, GIRI PRAVEEN NARENDRA, JANE MULENGA, ANKIT KUMAR YADAV, DIKSHA SACHIN \\ KUMAR SINGH, AMIT MITTAL
}

School of Pharmaceutical Sciences, Lovely Professional University, Phagwara, Punjab- 144411. Email : amaiyaki@yahoo.com

\begin{abstract}
Development of a new drug product requires great amount of research and efforts in chemistry, manufacturing, preclinical and clinical testing and later marketing authorization application is a necessary part of the drug life-cycle. Marketing authorization application is one of the most important parameters in the life span of a pharmaceutical product which is required to be approved by the regulatory agencies. Pharmaceutical market for the drugs is divided into regulated, semi regulated and no regulated market. Countries that lie under the categories of regulated and semi regulated have their own set of guidelines which governs the marketing authorization of pharmaceuticals. Every country has its own regulatory authority, which is responsible to enforce the rules and regulations and issue the guidelines to regulate the marketing of drugs. United States Food and Drug Administration (USFDA) govern the marketing authorization in USA, European Medical Agency (EMA) in Europe, Central Drug Standard Control Organization (CDSCO) in India, Health Canada in Canada, Therapeutic Goods and Administration (TGA) in Australia, Ministry of Health Labour and Welfare (MHLW) for Japan, China Food and Drug Administration (CFDA) in China, Medicinal Control Council (MCC) for South Africa and Saudi Food and Drug Authority (SFDA) in Saudi Arabia. Drug reviewers in regulatory agencies around the world bear the responsibility of evaluating whether the research data supports the safety, effectiveness and quality control of a new product to serve the public health. In the present study a detailed comparison of drug approval process in regulated, semi regulated and non-regulated countries has been conducted and summarised.
\end{abstract}

Keywords: Regulatory agency, drug approval, marketing authorization 


\title{
Artificial Intelligence: Machine Intelligence Contrast to Natural Intelligence and Future in Pharmacy
}

\author{
LUQMAN IBNI YASEEN*, IQBALJIT KAUR
}

School of Pharmaceutical Sciences, Lovely Professional University, Phagwara, Punjab- 144411

\begin{abstract}
A defining feature of the time is progressive advances in computing. As far as computing world is concerned, the introduction of Artificial Intelligence (A.I) has changed the dynamics of the world and has evolved it very fastly. When it comes to pharmacy, it has completely changed the outlook of pharma field. In the era of precision medicine, Physician or Pharma person is able to keep up with the speed of in formation to some extent. In an exponential age where every person wants to get true precision, personalized medicine and get the right drug, right treatment, right preventions and right diagnosis; the challenge is really hard for humans to connect all those credentials simultaneously, thereby better health outcomes at lower cost is a still huge challenge. However, A.I has brought consequent changes in the healthcare system. It is a smart mimicry of human brain display by machines. Sometimes, humans eye is unable to detect the small changes in the body. Therefore, these hidden patterns can be decoded with the help of computer. A.I allows us to reveal the invisible changes in the human body that in turns helps to diagnose a disea se even before it develops. Moreover, it has made the life of scientists and researchers, particularly in R \& D relatively easy because QSAR of drugs is more reliably examined and studied by A.I without wasting so much of time. It can be effectively used in clinical trials where companies usually spend millions and billions of rupees and are not sure for the final result. It is a lifeline to the company owners. In diagnosis, it holds key to the industry particularly when it comes to life-saving drugs and somehow incurable diseases like AIDS.
\end{abstract}

Keywords: Artificial Intelligence; QSAR; Human brain; Healthcare; R\&D; Diagnosis 


\title{
CIRCADIAN RHYTHM: ENDOGENOUS AND ZEITGEBERS ARVINDER KAUR $^{*}{ }^{*}$ IQBALJIT KAUR $^{1}$ YASH GUPTA $^{2}$ PAVAS $^{2}$
}

School of Pharmaceutical Sciences, Lovely Professional University, Phagwara, Punjab- 144411

\begin{abstract}
Circadian rhythm is a major mark in biological research. The term circadian is derived from the Latin word circa, which means "about" and diemeans "day". Therefore, Circadian rhythm is a biological rhythm that repeats about 24 hours. The suprachiasmatic nucleus (SCN) act as a master circadian clock that is located in a middle of the brain known as the hypothalamus. SCN acts as a circadian pacemaker and contains a group of thousand number of tiny nerve cells. In turn, this internal clock is responsible to control the timing of various physiological body rhythms like body temperature, sleepness and the production of growth hormone, sex hormones, etc. Moreover, humans generate its own circadian rhythms internally. SCN helps to maintain the synchronisation of itself with the environmental cycle. Light shows a direct effect on the circadian rhythm via SCN. As light stimulates the cone cells of the eye that leads to turn on the SCN. Sleep disorders are the fallouts of misalignment of the biological clock with the external time. When circadian pacemaker alters then it exhibits different types of sleep disorders such as delayed or advanced sleep phase syndrome due to abnormal sleep-wake cycle, non-24-hour sleep-wake syndrome and sleep disturbances in blind individuals just because of disturbance in circadian cycle that causes periodic insomnia and jet lag and shift-work sleep disorder occurs due to impermanent sleeplessness due to social conditions. Melatonin is a neurohormone secreted from the gland known as pineal gland and SCN stimulates its release. The primary function of melatonin to elevate sleep level. It's production level sharply elevates in the night. Although, light and melatonin have opposite effects i.e. bright light suppress the melatonin secretion. The better understanding of human circadian rhythm helps to manipulate the internal biological clock to treat sleep disorders via light and melatonin.
\end{abstract}

Keywords: Suprachiasmatic nucleus (SCN); Light; Melatonin; Circadian rhythm; Pineal gland; Insomnia; Circadian pacemaker 


\title{
E-PSYCHIATRY: STRATEGIES FOR CONNECTING MEDICAL PROFESSIONALS WITH PSYCHIATRIC PATIENTS \\ DIVYANI VERMA $^{1 *}$, IQBALJIT KAUR ${ }^{1}$
}

School of Pharmaceutical Sciences, Lovely Professional University, Phagwara, Punjab- 144411

\begin{abstract}
Human mental health crisis is enhancing day by day across the world. So, the need for mental health is increasing at a faster pace than the resources available to provide health care. In most of the developing countries like India, a majority of the health workforce is concentrated in urban areas. However, technology has so developed that it becomes much easier and less expensive to create a good patient care quality video link in the form of e-psychiatry. Consumers are much keener as they are using technology in many aspects of their life to seek out and therefore comfortable with patient care via technology. Telepsychiatry is a form of telemedicine. It is the delivery of behavioral health services over interactive video conferencing and the kind of services that can be done in psychiatric services assessment diagnosis medication, choice medication management and also the delivery of psychotherapeutic or counseling services over interactive video. There is a slender difference between the traditional natural setting for psychiatry and e-psychiatry. It helps to reach the clients who are not able to receive the preliminary medical services to a distance specialist and thereby provide support towards the psychological health. It is a great opportunity to a doctor who is not willing to maintain a full office and office staff or wants to practice in a semi-retirement kind of mode. It enables such doctors to deliver care to the patients via technology and thereby increasing the acceptability of using psychiatric workforce gradually.
\end{abstract}

Keywords: Telepsychiatry; Telemedicine; Technology; Video conferencing; Teletherapy 


\author{
IONTOPHORESIS: CURRENT AND NOVEL APPROACH TO SKIN PENETRATION \\ Rakshit Kestwal*, Narendra Kumar Pandey, Swati Tyagi, Nishika Yadav \\ Lovely School of Pharmaceutical Sciences, Lovely Professional University,Phagwara- 144411, Punjab (India) \\ Email: rakshitkestwal2000@gmail.com
}

\begin{abstract}
From many decades, skin has been the major site of delivery of therapeutics for local and systemic action. The structure of stratum corneum was always a road blocker in transporting of therapeutic agents. But as the passage of time and advancement of technology some novel approaches came into existence like iontophoresis, sonophoresis, electroporation, microporation, radiofrequency and microneedles. There are very few drugs available to transport transdermally due to their physicochemical restrictions. For oral and hypodermic injections, transdermal delivery seems to be a remarkable substitute. Iontophoresis is a technique of physically facilitated transport system which is highly effective in transporting of drug molecules through the skin for local and systemic effect at a pre-determined rate. It is a technique where local transmission of medication in the body is achieved non-invasively. Drug delivery iontophoretically has become, the most committed delivery system between thousands of clinicians and patients for over 3 decades. This review aims on some present and new physical approaches giving access to skin penetration of drug via iontophoresis.
\end{abstract}

Keywords: Iontophoresis; Drug-delivery; Transcutaneous; Non-invasive; Stratum corneum; electrically assisted delivery; Permeation enhancer. 


\title{
DEVELOPMENT AND APPLICATION OF RECOMBINANT DNA TECHNOLOGY IN PHARMACEUTICALS
}

\section{KHUSHBOO SINGH ${ }^{1}$, SUJIT BOSE*}

Lovely School of Pharmaceutical Sciences, Lovely Professional University, Phagwara, Punjab Email: sujit.19571@lpu.co.in

\begin{abstract}
Recombinant DNA innovation, consolidating of DNA atoms from two unique species that are embedded into a host life form to deliver new hereditary mixes that are of incentive to science, medication, horticulture, and industry. Since the concentration of all hereditary qualities is the quality, the essential objective of lab geneticists is to disengage, describe, and control qualities. In spite of the fact that it is moderately simple to confine a specimen of DNA from an accumulation of cells, finding a particular quality inside this DNA test can be contrasted with finding a needle in a bundle. Consider the way that every human cell contains around 2 meters ( 6 feet) of DNA. In this manner, a little tissue test will contain numerous kilometers of DNA. In any case, recombinant DNA innovation has made it conceivable to disconnect one quality or some other section of DNA, empowering scientists to decide its nucleotide arrangement, think about its transcripts, transform it in profoundly particular ways, and reinsert the altered grouping into a living being. With the progression of hereditary building, it is currently conceivable to exchange qualities between indirectly related species. The obstructions of quality exchange between species or even genera have been overcome. The attractive qualities can be exchanged even from bring down life forms to higher living beings through recombinant DNA innovation. Keeping in mind the end goal to comprehend the headway of organically dynamic succession from the decent variety display in a creature quality pool, in this way, it is so essential to comprehend what calculation are best and adequate. Recombinant DNA innovation is effectively assuming an essential part in endeavor to enhance plants and creatures stock. Biotechnological documented is in this way a quick growing field demonstrating the likelihood of successful treatment for that ailment which is serious. Insulin, human growth hormone, erythropoietin, activase etc. are utilized as helpful proteins which have currently developed by utilizing recombinant DNA innovation.
\end{abstract}

Keywords: Recombinant technology, DNA innovation, Insulin, Erythropoietin. 


\title{
IMPLICATIONS OF SIGMA RECEPTORS LIGANDS IN CARDIOVASCULAR DISEASES
}

\section{BARINDERIIT KAUR ${ }^{1}$, NAVPREET KAUR ${ }^{1}$, VANDNA KALSI ${ }^{1}$, ASHISH SUTTEE ${ }^{1}$, ARUNACHALAM MUTHURAMAN ${ }^{2}$}

${ }^{1}$ Department of Pharmaceutical Sciences, Lovely Professional University, Phagwara- 144411, Punjab (India)

2 Department of Pharmacology and Toxicology, Akal College of Pharmacy \& Technical Education, Mastuana Sahib, Sangrur-147001, Punjab, (India).Email: barinderjit.12062@lpu.co.in

\begin{abstract}
Ischemic heart disease (IHD) as a part of cardiovascular diseases (CVDs) is primary reason of mortality and morbidity worldwide. Angina pectoris (AP), myocardial infarction (MI), silent myocardial ischemia and sudden cardiac death are ischemic heart diseases which occur due to blockage in the coronary artery by atherosclerotic clot. Atherosclerotic clot is a systemic inflammatory process characterised by the accumulation and subsequent thickening of the wall by low-density lipoproteins within the intima of arteries and formation of plaque susceptible to rupture or erosion. Plaque rupture initiates both platelet adhesion and aggregation on the exposed vascular surface as well as the activation of the clotting cascade leading to coronary artery blockade. Coronary artery blockage interrupts the coronary blood supply leading to damage of myocardium. Furthermore, certain sigma receptor ligands have been reported to show protective action against coronary artery diseases. Sigma receptor, a transmembrane protein, is expressed in many tissues including cardiovascular, liver and central nervous system. Sigma ligands significantly prevented the deviated biochemical parameters such as cardiac marker enzymes, lipid profile and antioxidant parameters to near normal status. Therefore, sigma receptor stimulation represents a new therapeutic strategy to prevent heart from ischemic and hypertrophic dysfunction in case of cardiovascular disorders. This review summarises the sigma receptors and cardioprotective potential of sigma receptor ligands.
\end{abstract}

Key words: Coronary artery diseases; Ischemic heart disease; Sigma ligands; Sigma receptors. 


\title{
GENE THERAPY: NEW POSSIBILITIES AND FUTURE EXPECTATIONS \\ RUPINDER KAUR*, JAYPRAKASH GUPTA, SAUMYA DARSHNA SHIKHA, GEETANJALI MEHRA, ANUPRIYA, SHUBHAM SINGH, MAYUKH BANERJEE, ANKIT KUMAR YADAV, SACHIN KUMAR SINGH, AMIT MITTAL
}

School of Pharmaceutical Sciences, Lovely Professional University, Phagwara, Punjab, India.Email: kaur04103@gmail.com

\begin{abstract}
Gene therapy is the therapeutic delivery of nucleic acid into a patient's cells as a drug to treat disease. The basic principle of gene therapy is to fix the genetic complication or, the disease at its root cause level by using polymer molecules which are translated into proteins and interferes with a target gene expression or it may also rectify genetic mutations. The polymer molecule is enclosed within a 'vector' which transports it inside the target cells. With millions of dollars being invested for this therapy several novel approaches are being discovered. Gendicide, the first commercially available product for gene therapy was approved by the Chinese State Food and Drug Administration. Gene therapy for hemoglobi nopathies is currently based on transplantation of autologous hematopoietic stem cells genetically modified with an integrating lentiviral vector expressing a globin gene under the control of globin transcriptional regulatory elements. Studies have demonstrated the potential therapeutic efficacy and safety of this approach. Recently gene editing strategies based on the use of nucleases offered a novel approach to increase globin expression in a quasiphysiological way which is independent from the addition of transgenes and viral sequences to the human genome. It has also been proposed for treatment of cardiac arrhythmias. Replacement of cardiac pacemakers has also been possible by combination gene therapy using the Hyperpolarization activated cyclic nucleotide gated potassium and sodium channel 2 (HCN2) gene with the gene for adenylate cyclase, the skeletal muscle isoform of the sodium channel or a dominant negative mutant of the potassium channel responsible for resting membrane potential. Gene therapy is also considered to be a novel strategy for growing population of heart failure patients. A new frontier in gene editing is T-cell therapy. The adoptive transfer of engineered T-cells for the treatment of cancer, autoimmunity, and infectious disease is a rapidly growing field that has shown great promise. Gene editing holds tremendous potential or further improvements of T-cell therapy. In the present study, the potential applications of gene therapy are reviewed and compiled.
\end{abstract}

Keywords: Gene therapy, gene expression, T-cell therapy 


\title{
SCREENING OF IN-VITRO ANTIOXIDANT AND ANTI-INFLAMMATORY ACTIVITIES OF HINGULESHWARA RASA
}

\section{ABHISHEK CHATTERJEE ${ }^{1}$, DILEEP SINGH BAGHEL*1, BIMLESH KUMAR ${ }^{1}$, SAURABH SINGH ${ }^{1}$, NARENDRA KUMAR PANDEY $^{1}$, SACHIN KUMAR SINGH ${ }^{1}$, S. TAMILVANAN ${ }^{1}$, SHRUTI CHOPRA ${ }^{2}$, AMIT BHATIA ${ }^{2}$, ANAND KUMAR CHAUDHARY 3}

\author{
1School of Pharmaceutical Science, Lovely Professional University, Punjab, India \\ ${ }^{2}$ Amity Institute of Pharmacy, Amity University, Uttar Pradesh, India, \\ ${ }^{3}$ Department of Rasa Shastra \& Bhaishjya Kalpana, (Ayurvedic Pharmaceutics), Faculty of Ayurveda, Institute of Medical Sciences, \\ Banaras Hindu University, Uttar Pradesh, India
}

\begin{abstract}
The present study was designed to prepare and evaluate the invitro anti-oxidant and anti-inflammatory activities of hinguleshwara rasa Hinguleshwara rasa (HR1) was prepared as methodology mentioned in classical text i.e. Rasatarangini using suddha hingula (10 g), suddha vatsanbha (10 g) and Pippali (10 g). Modified versions of Hinguleshwara rasa were prepared by replacing suddha hingula with kajjali where kajjali made from hingulotha parada and sodhita parada constitutes two varieties of Hinguleshwara rasa i.e. HR2 \& HR3 respectively. In vitro anti-oxidant activity was studied using DPPH (2, 2-diphenyl-1-picrylhydrazyl) and absorbance is recorded at $517 \mathrm{~nm}$ and in vitro anti-inflammatory studies was studied by using inhibition of albumin denaturation technique. In all the formulation of hinguleshwara rasa dose dependent activity was observed. $100 \mu \mathrm{g}$ conc. of HR1, HR2 and HR3 showed 36.11, 17. 22 and $16.11 \%$ radical scavenging activity. The test drug also exhibited significant antiproteinase activity at different concentrations. The present study revealed the invitro anti-oxidant and anti-inflammatory activity of hinguleshwara rasa.
\end{abstract}

Keywords: DPPH, Hinguleshwara rasa, anti-inflammatory 


\title{
PREVALENCE OF PSYCHOLOGICAL DISTRESS AND ITS ASSOCIATED FACTORS IN HYPERTENSIVE PATIENTS: A SURVEY AT SPS HOSPITALS, LUDHIANA
}

\author{
MANINDER SINGH*, BIKRAM SINGH, ARSHVIR KAUR
}

Department of pharmaceutical sciences, Lovely Professional University, Phagwara-144411, Punjab (India)

Email: manindersingh009988@gmail.com

\begin{abstract}
Elevations in blood pressure is an important risk factor of cardiovascular disease and several factors can contribute to hypertension induced psychological distress like socio demographic characteristics, use of herbal supplements, lifestyle and substance use disorders in patients. Therefore, this study aimed to estimate these factors in hypertensive patients leading to psychological distress. The study was conducted among 275 hypertensive patients on follow-up at SPS (Satguru Pratap Singh) Hospitals, Ludhiana. During the face to face interview with patients at OPD, an unstructured questionnaires were used to assess general awareness regarding disease, substance abuse and use of herbal drugs. Psychological distress was assessed using the Kessler-10 scale. Standard descriptive measures were used to characterize the study samples and responses to the questionnaire.The prevalence of psychological distress among hypertensive patients was $46.9 \%$. Out of the total participants ( $\mathrm{n}=214$ ), $15.42 \%$ $(n=33)$ of them had alcohol use disorders and $8.88 \%(n=19)$ of them were addicted to smoking habits, $16.8 \%$ ( $n=36)$. K10 scale results in patients $(\mathrm{n}=213)$, showed 46.5\% (100) patients were suffering from psychological distress out of which $26 \%(\mathrm{n}=56)$ were having mild, $16.7 \%(\mathrm{n}=36)$ moderate and $3.7 \%(n=8)$ patients were having severe psychological distress. Highest percentage (33.80\%) of patients with psychological distress were from age group 31-60 years of age. $18 \%$ of psychologically distressed hypertensive patient $(\mathrm{n}=100)$ were found to use herbal formulations from several manufactures, $19 \%$ of which were seen to associated with consumption of Health Aid formulations, many were consuming the herbal supplements out of which $92 \%$ of patients consuming grapes were found to have physiological distress. The results of the study indicated the high prevalence of psychological distress in hypertensive patients belonging to age group of 31-60 years of ages and patient involved in consumption of grapes.
\end{abstract}

Keywords: Hypertension, herbal formulations, Psychological distress, Kessler-10 


\title{
RECENT ADVANCES DRUG DELIVERY IN LYMPHATIC SYSTEM SWADHIN S BISWAL, SUDHAKAR CK
}

LIT-Pharmacy, School of Pharmaceutical Sciences, Lovely Professional University, Phagwara- 144411, Punjab (India) Email: Sudhakar.20477@lpu.co.in, sekharbiswalswadhin9@gmail.com

\begin{abstract}
The lymphatic system has an important defensive role in the human body. Various types of diseases occur in lymph like lymphadenitis, lymphangitis, lymphocytosis etc. Lymph related diseases problem are not treated properly, it may leads to further spreading in the body which can leads to death. Lymphatic routes plays an important role in transporting extracellular fluid to maintain homeostasis. It helps in transferring immune cells to injury sites and avoids first pass metabolism. Various types of formulation are used in lymphatic drug delivery like lipid based formulations, prodrug approach, cationic charge based formulation. Lipid based nano-formulation like solid lipid nanoparticles and nanostructured lipid carriers have unique characteristics which helps them in drug delivery. Different way to enhance lymphatic drug transport like gastrointestinal administration, intramuscular administration, parenteral administration, subcutaneous administration, intrapulmonary administration. Different types of models are used to study lymphatic drug delivery system like in vivo model, in vitro model. Different factors which affect the transport of lipid based nanoparticles into the lymphatic system such as charge, size and shape of carriers. Prodrug approach is also used to increase the lipophilicity of drug through covalent coupling of drugs to lipid moieties including diglyceride and fatty acids. Transport of lipophilic compounds through intestinal lymphatic primarily occurs in association with chylomicron of intestinal lipoproteins. Currently there is no specific formulation for lymphatic drug delivery system in the market but in near future formulation will be discovered for this system which is a promising route of delivery system for curing the disease.
\end{abstract}

Keywords: Lymphatic system, lipid based formulations, homeostatis, nanoparticles, nanostructured lipid, prodrug fatty acids, lipophillic compounds. 


\title{
ANTIBIOTIC SENSITIVITY PATTERN OF EXTENDED SPECTRUM BETA-LACTAMASE DEEPIKA KAPOOR ${ }^{1}$, SANJIV KALIA ${ }^{1}$, ANANIA ARJUNA ${ }^{2}$
}

${ }^{1}$ Department of Microbiology, RIMT University, Mandi Gobindgarh, Punjab, India, 2Department of Medical Laboratory Sciences, Lovely Professional University, Phagwara, Punjab, India.

Email: riyaldeepika@gmail.com, sanjeevkalia@rimt.ac.in, anania.arjuna@lpu.co.in

\begin{abstract}
Antibiotic resistance is one of the highest threats to the global health. Antibiotic resistance can affect anyone, in any age and even in any area worldwide. Antibiotic-resistant bacteria are those bacteria which are not controlled or even not killed by an antibiotic. Antibiotic resistance occurs naturally but prolonged use of antibiotics or misuse of antibiotics in human or animals can be accelerating this process. Extended-spectrum betalactamase (ESBLs) is an enzyme which is made by some bacteria that are to able to the hydrolyzed extended spectrum of Cephalo sporins and also inhibited Clavulanic acid. Extended-spectrum beta-lactamase was first reported in 1983. Extended-spectrum beta-lactamase is those enzymes which are responsible for the cause of hospital-acquired infection. Beta-lactam antibiotic is used to treat the Gram-positive and Gram-negative bacteria, but beta-lactamases produced by Gram-negative organisms. GIT plays an important role in the development of antibiotic-resistant microorganisms in humans and animals. Extended-spectrum beta-lactamase infection may spread through in the environment through contaminated feces in which E.coli or other bacteria are present. About 630 samples were collected and after proceeding they all were analyzed by standard microbiological techniques. The result showed that 158 samples were given positive and rest of 472 samples had no growth.
\end{abstract}




\title{
NOVEL MEDIUM DESIGNING FOR THE CULTIVATION OF SOME ECONOMICALLY IMPORTANT FUNGAL SPECIES
}

\author{
RAMAN DHIMAN ${ }^{1}$, SANJIV KALIA ${ }^{1}$, ANANIA ARJUNA ${ }^{2 *}$ \\ 1Department of Microbiology, RIMT University, Mandi Gobindgarh, Punjab, India, \\ ${ }^{2}$ Department of Medical Laboratory Sciences, Lovely Professional University, Phagwara, Punjab, India. \\ Email: ramandhiman5252@gmail.com,Sanjeevkalia@rimt.ac.in, anania.arjuna@lpu.co.in
}

\begin{abstract}
Fungi kingdom has so many species which is used in numerous industries for many commercial, research and medicinal activities. In this scenario the present study is based on Trichoderma viridae, Aspergillus niger, Aspergillus fumigatus, Fusarium and Saccharomyces cerevisiae species which are mostly used in industries. These species are grown on conventional fungal culture media such as Potato Dextrose Agar (PDA), Sabouraud Dextrose Agar (SDA) and Corn Meal Agar (CMA). These media are more expensive and even some time not easily available in developing countries. The present study is aimed to evaluate the scope of developing agricultural and kitchen waste such as sugarcane bagasse, orange, peas peels and tomato waste as a culture media. In the present study all these waste material were dried and make fine powder in steel grinder individually. All the ingredients were filtered two time with cotton cloth and mixed each in $150 \mathrm{ml}$ distilled water. After mixing, flasks were placed in BOD incubator at 37 degree for 6 days with $150 \mathrm{rpm}$. These all constituents were filtered with Whatman filter paper number 1 . The pH of these material adjusted at 5.6 after adding $2 \%$ agar. These formulated media were autoclaved and then Trichoderma viridae, Aspergillus niger, Aspergillus fumigatus, Fusarium and Saccharomyces cerevisiae species were grown on these newly prepared media at 25 degree for seven days. It was also compared with the growth on conventional fungal culture media such as SDA, PDA and CMA. These formulated new media also showed some very good results. Hence, this study has found a new alternative media to an exorbitantly priced conventional fungal culture media but this may be needed further to investigate to be grown on commercial level.
\end{abstract}




\title{
CANCER: AN INSIGHT INTO THE DETECTION, ASSESSMENT AND TREATMENT DEEPIKA MOHIL*, MAYUKH BANERJEE, DIKSHA MANKOTIA, JAYPRAKSASH GUPTA, ANKIT KUMAR YADAV, SACHIN KUMAR SINGH, AMIT MITTAL
}

School of Pharmaceutical Sciences, Lovely Professional University, Phagwara, Punjab 144411. Email : deepikamohil8@gmail.com

\begin{abstract}
Cancer is generally considered as uncontrolled growth and alteration in the death cycle of cells of the body. It's one of the most severe disease as it causes around 8.8 million deaths every year around the globe. Cancer can be classified as carcinoma, sarcoma, melanoma, lymphoma, and leukemia. Carcinoma is the most commonly diagnosed cancers which originate in the skin, lungs, breasts, pancreas, other organs and glands. Similarly lymphomas are cancers of lymphocytes, leukemia of blood, melanoma of pigment in the skin and sarcomas arise in bone, muscle, fat, blood vessels, cartilage and other connective tissue of the body. The survival rate of localized sarcoma is $83 \%$ and for regional is $54 \%$. Melanoma accounts for only $1 \%$ of skin cancers but causes a large number of deaths per year. As per latest reports, carcinoma is responsible for 171.2 , lymphoma for 5.8 and leukemia for 6.8 deaths per year out of 100,000 people. The most severe cases of deaths per year are observed due to lung and bronchial cancer $(7,92,495)$ followed by colon and rectal cancer $(2,69,783)$ followed by breast cancer $(2,06,983)$. As per the report of American Cancer Society, economic burden of cancer accounts for $\$ 1.4$ trillion per year worldwide. Diagnosis of cancer can be done at early stages before they have had a chance to grow and spread in the body. If detected early, about 30-50\% of total cancers can be prevented. Cancer can be easily detected by the physical examination, medical examination, laboratory test of tissue, blood, urine and other substances in the body. Imaging procedures and genetic tests are also utilized for detection. Lung cancer is detected using low-dose computed tomography (LDCT), cervical cancer using Pap test while breast cancers by mammograms. For the treatment of cancer a variety of techniques are utilized which are surgery, chemotherapy, radiation therapy, stem cell transplant, precision therapy and immunotherapy. In the present study a systematic review about the detection, assessment and treatment of the cancer is done and the summary of the results has been compiled.
\end{abstract}

Keywords: Cancer, Imaging, Biological sample testing, Chemotherapy 


\title{
CRITICAL PARAMETERS IN FORMULATING A MUCOADHESIVE FILM ROHAN MUKHOPADHYAY*, SURAJPAL VERMA
}

Pharmaceutical Quality Assurance, Lovely Professional University, Phagwara.Email: surajpal.15834@lpu.co.in

\begin{abstract}
Mucoadhesive films were prepared by solvent casting technique using hydroxypropyl methylcellulose (HPMC) as basic polymer and Carbopol 934, Eudragit RL 100, Polyvinyl pyrrolidone (PVP K90), Polyvinyl alcohol and Ethyl cellulose were taken in various ratios and 6 different formulations were made. The films were found to be smooth in appearance, uniform in thickness, weight uniformity, drug content, swelling behaviour, and surface pH. Various studies were done on polymers and their role in drug release. Sustained release films were formulated, and their drug release pattern were studied. Certain parameters like drying temperature and rate of stirring of the casting solvent were also considered in the study. Each polymer and their effect on various characteristics of the films like folding endurance, in-vitro residence was examined. This present study focuses on developing sustained release mucoadhesive buccal films to treat diseases like nocturnal asthma where this dosage form will increase patient compliance.
\end{abstract}




\title{
GENE THERAPY \\ DALIP KUMAR
}

Lovely School of Pharmaceutical Science; Lovely Professional University, Phagwara, Punjab (India) - 144411 Email : dk345s32@gmail.com.

\begin{abstract}
Gene therapy is defined as a technique to introduce the normal gene into the cell to replace abnormal or defective gene in or der to treat the disease. It was first developed in 1972 by Martin Cline. It involves a novel method for treatment of diseases by utilizing gene or oligonucleotides as therapeutic agents instead of use of conventional drugs. Gene therapy is of mainly two types i.e. somatic gene therapy, gemline gene therapy but can also incorporate gene augmentation, target killing and gene inhibition. Gene insertion can be achieved with various vectors like virus, bacterium and plasmid. All of these have certain advantages and disadvantages one over the other. Gene therapy has been successfully used for treatment of number of life threatening diseases such as cancer, HIV. Gene therapy has many advantages such as cure from genetic diseases, efficient transfer, and control of gene expression, cost effective for long term use. Although there are many advantages of gene therapy treatment but still is associated with few limitations which includes immune system disturbance, short lived therapy, use of viral vectors, multigeneic disorders, mutagenesis and ethical issues. A lot of researches are going to make it much better and convenient in treatment of other disease s like skin problems, muscle dystrophy and liver disease. Gene therapy is uprising in field of medicines and has been believed that after 20 years all genetic disorders can be overlooked by this technique. However further research has to be carried out to know causes and role of faulty gene in diseases and it will play Copernican part and will change our lives forever.
\end{abstract}

Keywords: Gene therapy, disease, cancer, immune 


\title{
DEVELOPMENT AND EVALUATION OF LEVOCETRIZINE DIHYDROCHLORIDE MICROSPHERE SAHBAN AHMED*, MOHD. VASEEM, MOHD. MUSTKEEM, SHARAD VISHT
}

Smt. Tarawati Institute of Bio-Medical \& Allied Sciences, Roorkee.*Contact: +91- 7300936288.Email: sahbanahmed3@gmail.com

\begin{abstract}
The purpose of study was to develop and evaluate of levocetrizine dihydrochloride microsphere using ethylcellulose to find the effect of drug polymer ratio on drug entrapment, particle size, surface properties of microspheres and drug release. The solvent evaporation method was used to prepare microsphere using different ratios of drug and polymer. The prepared microspheres were characterized for particle size, surface characterization, drug content uniformity and in-vitro drug release. The BIT-soft 1.12 was used to determine the kinetics of drug release. The equation of line for levocetrizine dihydrochloride was found to be $\mathrm{y}=0.0355 \mathrm{x}+0.0078$ and $\mathrm{R}^{2}$ value was 0.9978 . The FTIR studies showed drug excipient compatibility. The microspheres showed the particle size ranged between $45.56 \pm 0.24-137 \pm 0.21 \mu$ m. The SEM analysis chowed irregular rough surface. The drug entrapment efficiency varied between $20.29 \pm 0.45-65.21 \pm 0.31$ percent. The drug entrapment efficiency varied between $39.53 \pm 0.23-78.75 \pm 0.63$ percent. The drug content uniformity varied between $95.63 \pm 0.65-98.74 \pm 0.11$ percent. The in-vitro drug release showed drug release between $58.63 \pm 0.21-89.65 \pm 0.32$ percent. The kinetics of drug release showed Korsmeyer-Peppas equation as a best fit model with $\mathrm{r}^{2}$ value 0.9889 and $\mathrm{k}$ value 3.1926 that indicate anomalous transport. Microspheres are the promising carrier for sustained and prolong drug delivery.
\end{abstract}

Keywords: Levocetrizine, microsphere, ethylcellulose, entrapment, release 


\title{
ORODISPERSIBLE TABLETS: A NEW TREND IN FAST DISSOLVING TABLET SYSTEM DIKSHA SHARMA, KALVATALA SUDHAKAR*
}

LIT (Pharmacy), School of Pharmaceutical Sciences, LPU, Jalandhar, Punjab 144411.Email: sudhakar.20477@lpu.co.in

\begin{abstract}
Fast dissolving tablets emerge as a prominent dosage form in the field of dosage form design. Since the oral route is still widely accepted route but having a common drawback of difficulty in swallowing of tablets and capsule. It reduced the cost and ease administration especially in case of pediatrics and geriatrics. Many orally administered drugs experience a hostile environment in the gastrointestinal tract, where most drugs are degraded in variable $\mathrm{pH}$ conditions, or face solubility issues, and first-pass metabolism. This route is also preferable for quick absorption and for rapid onset of action. Also, there are some types of diseases which are so acute that they require immediate relief for which orodispersible formulation is best option. There are various techniques for preparation which are conventional as well as patented also. Some patented techniques are Wowtab , Orasolv, Durasolv etc. Orodispersible Tablets (ODTs) are developed by the addition of super disintegrants which may be of any type i.e synthetic, natural or semisynthetic like cross-linked cellulose derivative; carboxymethyl cellulose, sodium starch glycolate, polyvinylpyrrolidone, guar gum, gum karaya which gives burst disintegration when gets in contact with water or salivary secretions. Bioavailability of drugs may enhanced due to oral and pregastric absorption, reducing the first-pass metabolism in the gastrointestinal tract. In future perspective it would be a great option for immediate release formulation.
\end{abstract}

Keywords:- Orodispersible Tablets, Orasolv, Durasolv, Fast dissolving tablets 


\title{
FORMULATION DEVELOPMENT AND EVALUATION OF ANTIHYPERTENSIVE DRUG LOADED MULTI-WALLED CARBON NANOTUBES
}

${ }^{*}$ AMANJOT KAUR, ${ }^{2}$ DR VIJAY MISHRA

${ }^{1}$ Lovely Institute of Technology, Lovely Professional University, Phagwara, Punjab, 144411

${ }^{2}$ Associate Professor, School of Pharmceutical Science, Lovely Professional University, Phagwara, Punjab, 144411

Email: kauraman.bph@gmail.com

\begin{abstract}
Hypertension contributes to one of the most prevailing cardiovascular disorder characterized by systolic blood pressure (BP) $\geq 140 \mathrm{~mm}$ of Hg and diastolic blood BP $\geq 90 \mathrm{~mm}$ of Hg. Multiwalled carbon nanotubes (MWCNTs), which are formed from graphene sheets possess contino us and empty cavity that represents the bulk of the nanotube's volume, meaning that the drug can be included in high yield.The present study involved the functionalized multiwalled carbon nanotubes (MWCNTs) to be used for the incorporation of antihypertensive drug, Ramipril, an angiotensin converting enzyme (ACE) inhibitor. Further, the study involves the characterization as well as evaluation of the resultant drug loaded MWCNTs. MWCNTs were synthesized using graphite powder at $70^{\circ} \mathrm{C}$ by reacting with sulphuric acid, nitric acid and potassium chlorate. Further, MWCNTs were funtionalized to obtain acyl chloride funtional group and loaded with ramipril. The resultant formulations were examined for entrapment efficiency, drug release as well as particle size. Also, the synthesized and funtionalized MWCNTs were examined for surface morphology by scanning electron microscopy (SEM) and transmission electron microscopy (TEM). The FTIR spectroscopy was also performed for the synthesized MWCNTs, funtionalized MWCNTs ( $f$-MWCNTs), and formulation. The entrapment efficiency was found to be $91.62 \pm 1.34 \%$. The in vitro durg release was performed in phosphate buffer pH 7.4 for 24 hours. The release data depicted the sustained release of ramipril, which was found to be $85 \pm 2.12 \%$ for 24 hours. From the results obtained, it can be concluded that the MWCNTs based formulation expected to possess blood pressure lowering effects for prolonged period of time.
\end{abstract}




\title{
SNEDDS: AN APPROACH TO ENHANCE BIOAVAILABILITY ABHISHEK THAKUR ${ }^{1}$, NARENDRA KUMAR PANDEY ${ }^{1}{ }^{*}$
}

School of Pharmaceutical Sciences, Lovely Professional University, Phagwara-144411, Punjab (India)

Email: abhi.atif.at@gmail.com

\begin{abstract}
Nano emulsions are the emulsions having nano sized globules in the range of 20-200nm which are under investigation as drug delivery system for poorly water soluble drugs. The Self-nano Emulsifying Drug Delivery System (SNEDDS)is formulated by mixing oil phase with surfactants, cosurfactant and sometimes co-solvents are also added under the conditions of gentle agitation to form a common phase with suitable globule size. The isotropic system thus formulated is kinetically and thermodynamically stable. Self-nano emulsifying drug delivery systemswere formulated to enhance the oral bioavailability of Biopharmaceutical class II drugs as oral route is easiest and convenient way of administering drug.SNEDDS works by avoiding drug dissolution before absorption site in the gastro intestinal track and increase the concentration of dissolved drug in the gastric fluid or intestinal fluids and results in better drug absorption. It leads to decrease in dose to be administered and selective drug release at particular site in absorption window in gastro intestinal track(GIT). Beside the enhancement in bioavailability these offers several other advantages such as better drug stability, better targeting towards site of drug release, minimize gastric irritation. It is a novel approach can be applicable for parenteral, ophthalmic, intranasal drug delivery systems.In the formulation of solid SNEDDS selection of carrier (Hydrophilic/hydrophobic) is considered as important aspect as it affects properties of drug like crystalline behavior and dissolution and oral bioavailability of drug.
\end{abstract}

Keywords: Nanoemulsion, Isotropic, Bioavailability, Surfactant, Absorption window. 


\title{
BIOMARKERS FOR ALZHEIMER'S DISEASE SHABNAM BANGA*, MUKTA GUPTA, EKENE CHARLES OBELE
}

\begin{abstract}
Biological markers known as biomarkers may be a gene, gene mutation, protein, or other molecule and has characteristics of measuring and evaluating indicator of normal biological and pathogenic processes and hence provide a dynamic and powerful approach for understanding spectrum of neurological processes. Number of diseases has their biomarkers such as Wilson, celiac, Alzheimer, Parkinson, hypertension, diabetes. However, identifying a possible biomarker in neurological diseases such as Alzheimer disease is more challenging in comparison to other diseases due o a variety of factors like poor clinical diagnosis, complexity of brain, models for validation etc. Alzheimer's disease(AD), is a chronic neurodegenrative disease which is form of dementia, characterized by an accumulation of $\beta$-amyloid plaques, neuritic extracellular amyloid plaques in brain that are frequently surrounded by dystrophic neurites and intraneuronal neurofibrillary tangles. Identification treatment available for AD such as neuroimaging, magnetic resonance imaging (MRI), computerized tomography (CT), neuropsychological testing, advanced imaging, and cerebrospinal fluid measures etc. Magnetic resonance imaging (MRI) extended the ability of researchers to assess the microscopic changes that accompany progressive brain atrophy. However, these all methods are having various drawbacks associated with the cross-sectional nature of this analysis (inter individual variability, laborious manual outlining and subjectivity in defining structural boundaries) has limited the precision, and thus efficacy, of the procedure. Biomarkers for AD includes biomarkers in CSF ( $\beta$-amyloid(1-42) [A $\beta(1-42)]$, total and phospho-tau-181), blood proteins, Inflammatory markers. Use of biomarkers in increasing day by day due to large number of applications such as objective assessment, precision, reliability, validity, less biasness. Although numbers of advantages have been identified regarding safe use of biomarkers still few limitations like critical time analysis, cost, time consuming, laboratory errors and ethical responsibility has limited its use. Further intensive research is required to incorporate safe use of biomarkers in clinical practice.
\end{abstract}

Key words: Biomarker, disease, biological, Alzheimer's disease 


\title{
ROLE OF VEIN FINDER DEVICE IN MEDICAL SCIENCES AS WELL AS IN FORENSIC SCIENCES SANDEEP BASRA
}

Research Scholar, Department of Anthropology, Panjab University, Chandigarh. Email: sandeepbasra144@gmail.com

\begin{abstract}
The forensic science is not a separate part of medical science, but by combining these two sciences we can get better results in both fields and can be known as forensic medicine. Basically the vein finder device is used to see the proper image of human veins. In forensics, the pattern of veins consider as a biometric. The term 'Biometrics' refer to the measurements of biological data. A person carries so many documented identity proofs such as PIN (personal identity number) card, ATM card, voter card, etc, but whenever question arises on person's security, everyone trust in computer systems. These days biometrics mostly used for the authentication of personal identification because these are unique for each and every person. In this paper, we survey many studies conducted on the vein pattern which shows each and every person have a unique vein pattern of fingers and palm. The matching or comparison of blood vessel patterns which are visible from the surface of skin, known as Vein matching or vascular technology. Although this technique still not adopted by the criminal labs and in hospitals in India, but this can be fruitful for D octors, in criminal cases and to prove authentication of individual in this modern era. This technology can also be useful for the security purpose to prevent our important things from burglary. During fingerprint scanner, some people feel uncomfortable and as unhygienic because many people touching the same fingerprint scanner. The advantages of vein pattern as a security purpose in banks, office, ATM because it is contactless, hygienic and leaves no harmful effect on the human body. This vein pattern can be used for the authentication of a person because these are difficult to forge.
\end{abstract}

Keywords; Biometrics. Vein finder, finger vein verification, palm vein authentication. 


\title{
LEDEBOURIA OVATIFOLIA (BAKER) JESSOP USED IN THE HEALING OF PEPTIC ULCER SHUBHAM KUMAR
}

School of Pharmaceutical Sciences, Lovely Professional University, Jalandhar, Punjab, India Email: shubu380@gmail.com

\begin{abstract}
Ledeboria Ovatifolia (Baker) Jessop is a perennial herb found in African rural, belonging to family Asparagaceae. It is also used in the treatment of Diarrhoea \& Stomach acne. The main purpose of this study is to determine the healing effect of L. ovatifolia (Baker) Jessop in peptic ulcer. Peptic ulcer is induced by using Aspirin (50mg/kg,po) ,ethanol( $4 \mathrm{ml} / \mathrm{rat}$,po) \& stress(cold stress) were used. Naturally obtained L. ovatifolia (Baker) Jessop $100 \mathrm{gm}$ bulb was collected dried and crushed \& powdered drug is used. Ledebouria ovatifolia (Baker) Jessop used in the Healing of Gastric Ulcer. The oral administration of drug is compare with other group and activity of drug is checked. The result of extract of drug show's that it has effect in treatment of ulcer when it is compared with the aspirin induced group and ethanol group. The dose $100 \mathrm{mg} / \mathrm{kg}$ and $200 \mathrm{mg} / \mathrm{kg}$, po, is effective in ulcer. These result show that the drug have Anti-ulcerogenic properties.
\end{abstract}

Keyword: Gastric ulcer, Ledebouria Ovatifolia(Baker) Jessop, Aspirin induced ulcer, Ethanol Induced ulcer, Stress 


\title{
NANOSUSPENSION: - A LOOM FOR THE IMPROVING THE BIOAVAILABILITY OF DRUGS VIKRANT GAHLYAN, SUDHAKAR C
}

LIT-Pharmacy, School of Pharmaceutical Sciences, Lovely Professional University, Jalandhar, Punjab.*Email: Sudhakar.20477@lpu.co.in

\begin{abstract}
Nanotechnology has emerged as a vast field in the medicine Nanosuspensions is formulation of drugs and is the part of nanotechnology in sciences and pharmaceutical field. One of the predominant troubles related to poorly soluble drugs is very low bioavailability. Recently, nanoscale systems for drug delivery have gained much interest as a way to improve the solubility problems Nanosuspensions are biphasic structures, which along with pure drug particles dispersed in an aqueous vehicle and stabilized by using surfactants. Nanosuspension technology solved the problem of drugs, which are poorly aqueous soluble and less bioavailability. The reduction of drug particles into the sub-micron range leads to a significant increase in the dissolution rate and therefore enhances bioavailability. Nano suspension are simple to prepare and are more advantageous than the other approaches. Techniques such as milling (Nanocrystal), highpressure homogenization (Nanopure, Dissocubes and Nanoedge) supercritical fluid and emulsification-solvent evaporation have been used in the preparation of nanosuspensions. Solubility enhancement increase the bioavailability of drugs. Nanosuspension enhances the solubility of drugs and which indirectly helps in the better pharmacokinetics and pharmacodynamics and shows better bioavailability of drugs.
\end{abstract}

Keyword: Nanopure, Dissocubes, Nanosuspensions, Nanocrystal, Nanoedge. 


\title{
STEM CELL THERAPY: ADVANCED APPROACHES IN MEDICAL TREATMENT Rajat Kumar Thakur*, Lipika, Ruchi Sharma
}

School of Pharmaceutical Sciences, Faculty of Applied Medical Sciences, Lovely Professional University- Jalandhar G.T. Road, Phagwara, Punjab-144401. Email: sarkarrajat527@gmail.com, chandwanilipika@gmail.com, ruchi.19260@lpu.co.in

\begin{abstract}
The emergence of advanced medical techniques and their implementation for the diagnosis, prevention and treatment of various disorders have always been a thrust area for research in healthcare. Many considerable approaches and discoveries have empowered this field by identifying various competent therapies. One out of which includes the utilization of stem cell therapy to conquer certain diseases or conditions like Alzheimer, parkinsonism, cirrhosis, spinal cord injury, HIV, cardiac disorders etc. The stem cells are pluripotent which are undifferentiated and possesses immense potential to convert into differentiated specialized cells. Therefore, this unique potential serves as the base for utilization of these cells for repairing and replenishment of the damaged cells, tissues and organs. Additionally, in the field of transplantation certain assessments have been made about difficulty in finding donors for organ transplants and immunological rejection of the organ by patient's body. Resultingly, development of artificial organs like limbs, heart from the stem cells in the lab and the successful transplantation reported by research reportings can be of practical importance. Furthermore, studies have also provided possibilities of overcoming the harmful effects of chemotherapy and radiation therapy in patients suffering from cancer by replacing the diseased cells with the stem cells. Although, this holds prospective to be employed as a reasonable effective therapy but, there are some ethical issues, challenges associated related to identification, extraction of the stem cells and arificial organ development. For instance, in the adults, the cells can be derived from certain tissues which can differentiate into neural, cardiomyocytes, and liver cells. But, extraction of stem cells from human embryo from the blastocyst is controversial due to destruction of human embryo. Therefore, the presented work represents the scope and shortcomings of the stem cell therapy for disease management.
\end{abstract}


Abstract No. RTBS-P-106

\title{
RELATION BETWEEN AIR POLLUTION AND CARDIOVASCULAR DISEASE
}

\section{PARVEEN}

Department of Paramedical Sciences, Shekhawati Ayurvedic Medical College, Bahal - Pilani Road, Pilani, Rajasthan 333031

\begin{abstract}
Air pollution is a revealing environmental and health hazard, this is exhaust from vehicles, and industry contain gases: nitric oxide, nitrogen dioxide, and carbon monoxide, sulphur dioxide, PM (both solid and liquid) like carbon black, organic black. Short- term exposure to elevated PM significantly involvement to increase acute cardiovascular mortality. Long term exposure to elevated PM cause acute myocardial infraction, enhanced coagulation/thrombosis, acute arterial vasoconstriction and the chronic promotion of arthrosclerosis. Particulate matter (PM) classified as $\mathrm{PM}_{10}, \mathrm{PM}_{2.5}$ and ultra-fine Particulate. $\mathrm{PM}_{10}$ comes from road and agriculture dust construction ,PM $\mathrm{PM}_{2.5}$ has comes from the traffic and industry includes fuel combustion from power plant and oil refinery, ultra-fine particles those particles diameter less than $0.1 \mu \mathrm{m}$. Increased oxidative stress and activated inflammatory pathway in pulmonary due to exposure to $\mathrm{PM}_{2.5}$ with long term and PM 10 with short term . Exposure to PM increased circulating level of pro- inflammatory cytokines that are related to increased blood coagulability and endothelial dysfunction can cause myocardial ischemia.
\end{abstract}

Keyword: Particulate matter, cytokines, cardiovascular mortality 


\title{
COSMETOVIGILENCE IN AYURVEDA
}

\section{KALPANA THAKUR, SUKRITI BISWAS, SAURABH SINGH*, SACHIN KUMAR SINGH, BIMLESH KUMAR, NARENDRA PANDEY, DILEEP SINGH}

School of Pharmaceutical sciences, Lovely Professional University, Phagwara, Punjab.Email:Saurabh.singh@lpu.co.in

\begin{abstract}
The term cosmeceutical was coined by dermatologist "Albert kligman" in 1980, FD and C Act does not recognize any such category as cosmeceuticals hence there is no meaning of cosmeceuticals under Law basically it is a combination of word drug and cosmetic. Now a days various Ayurvedic, Allopathic and FMCG companies are manufactured such kind of products and sale under the category of cosmeceutical, cosmetics and evaluated in house. The major stake holders of cosmeceutical and cosmetics are Himalya, Dabur, Baidyanath, Unilever, Lotus, Loreal, Garnier and Patanjali in Indian as well as Global Market. In India, cosmetics are regulated under Drug and Cosmetic act 1940 and rules 1945 for sale distribution and storage, but there is a lack of vigilance system as parallel to drugs. In case of Allopathic and Ayurvedic drugs various pharmacovigilance centers are working in India, however, there is absence of Cosmetovigilence centers in India as well Asian countries for safety of customers. European union (EU) have already regulations like (EC) No. 1223/2009 and strong vigilance systems for sale and distribution of cosmetics as parallel to drugs. The present paper highlights the opportunities and needs to open cosmetovigilance centers for Ayurvedic and Herbal cosmetics in order to ensure the safety of customers.
\end{abstract}

Keywords: Cosmetovigilance, Ayurveda 


\title{
BIOSENSORS: EFFECTIVE TOOL IN DIAGNOSTIC EVALUATION IN HEALTH SCIENCES KARAMDEEP SINGH ${ }^{*}$, RUCHI SHARMA ${ }^{1}$
}

*School of Pharmaceutical Sciences, Lovely Professional University- Jalandhar G.T. Road,Phagwara, Punjab-144401

Email: karamdeep000@gmail.com,ruchi.19260@lpu.co.in

\begin{abstract}
In light of the expansion for identification of pathogenesis and physiologically important precursors in the body with high resolution, the requisite of efficient diagnostic techniques are considerable. Although, enormous efforts are made regularly in the detection and treatment of diseases but the effectiveness and safety always remain as the major concern. Hence, the need to grow productive, dependable and safer methods for detection and treatment of ailments is desirable. With the discovery and advancement in utilization of new entities, many frameworks in biosensing laboratory techniques have been studied and employed with the capability of providing enviable results. Biosensors are the devices which utilizes biochemical responses interceded by separated catalysts, immunocytes, tissues, organelles or entire cells. Basically, the system works upon three basic units namely, the detector, transducer and signal processing system.This helps to identify mixed substances more often in the form of electrical, thermal or optical signs as a response. The strategy is based upon the fundaments of immobilization which involves the interaction of transducer with the analyte, eventually delivers the electronic reaction that can be estimated. Depending upon the form of response collection, biosensors with specifications like electrochemical, amperometric, potentiometric, and blood glucose sensing are available. The objective of exploring the technique is to insight the sensitivity, effectiveness and selectivity with respect to diagnostic purposes in diversified fields of research and technology. Therefore, the future perspectives related to improved targeting, cost effectiveness and enhanced efficiency offered by the technique can bring enormous changes in the field of health sciences. Futhermore, it holds a great market potential to be accepted for the empowerment of conventional diagnostic approaches.
\end{abstract}

Keywords: Biosensor, Immobilization, Detector, Transducer. 


\title{
RECENT ADVANCEMENTS IN THE DETECTION OF TYPE 2 DIABETES MELLITUS: A REVIEW SAUMYA DARSHNA SHIKHA*, RUPINDER KAUR, JAYPRAKASH GUPTA, GEETANJALI MEHRA, MAYUKH
BANERJEE, ANKIT KUMAR YADAV, SACHIN KUMAR SINGH
}

School of Pharmaceutical Sciences, Lovely Professional University, Jalandhar-Delhi G.T. Road, Phagwara, Punjab- 144411

\begin{abstract}
Type 2 diabetes mellitus (T2DM) is a complex disease caused by high blood sugar levels in the body for a prolonged period of time affecting most tissues and organ systems leading to metabolic complications. There is no known cure for T2DM till now. However, early diagnosis and interventions are a key to prevent or postpone the serious complications associated with the disease. For the detection of T2DM there are many techniques available worldwide and biosensors are one of the most significant tool out of them. Biosensors and their applications have acquired utmost importance in the field of healthcare system dealing with T2DM. Recent advances in biological techniques and instrumentation has paved a new path for the development and configuration of biosensors. Application of Surface Plasmon Resonance, nanomaterials and aptasensors have developed innovative biosensors over conventional methods. These innovative approaches provides a better perspective for developing specific and sensitive biosensors with wide potential applications. Another approach for early detection of diabetes mellitus is by the help of computer intelligence software like 'Fuzzy Hierarchical Model' and the 'Michigan Model' or by data mining of medical databases using multiple classifier systems. Studies have also been carried out regarding the accuracy of fasting plasma glucose and hemoglobin A1c (hbA1c) testing for the early detection of diabetes. For the future perspectives and development in the healthcare system, it is necessary to develop novel and non-invasive technologies including blood and tissue based biomarkers, which will help out in the detection, prevention and treatment of diabetes and its complications long before the disease can progress and manifest.
\end{abstract}

Keywords: Biosensors, biomarkers, diabetes mellitus 


\title{
COMBINATION THERAPY: SYNERGISTIC EFFECT OF SYNTHETIC DRUG AND NATURAL PHYTOCHEMICALS FOR THE TREATMENT OF DIABETES MELLITUS
}

\author{
MAYUKH BANERJEE*, SHUBHAM KUMAR SINHA, ANKIT KUMAR YADAV, SACHIN KUMAR SINGH, BIMLESH \\ KUMAR, AMIT MITTAL
}

School of Pharmaceutical Sciences, Lovely Professional University, Phagwara, Punjab-144411.

Email: mayukh.banerjee93@gmail.com

\begin{abstract}
According to the World Health Organization, diabetes mellitus will be the 7th leading cause of death globally by the year 2030 . Of all the deaths caused by the disease about $90 \%$ are caused by type II diabetes mellitus. International Diabetes Federation released a statement recently that the current cost of combating diabetes worldwide is 726.7 billion USD and the worldwide death toll due to diabetes in 2017 was 424.9 million. International Diabetes Federation also predicted that the total diabetic population will rise to be about 628.6 million by the year 2045 . As the current pharmaceutical market is saturated by multiple synthetic drugs like Sulfonylureas, Metformin, Thiozolidinediones and their combination therapies, it is high time to rethink on release of a new set of combinations which will not only be novel but also therapeutically efficient. It is believed that the combinations of phytochemicals which are readily and quite easily available in the market along with established synthetic drugs should be the future in treating the ever increasing rise of diabetes throughout the globe. Phytochemicals which have been proven safe and have been known to treat diabetes as per ancient texts from India, China and other South Asian countries, popularly known as home remedies, if incorporated in a dosage form along with a lower dose of a popular synthetic drug will be beneficial. Recent studies concluded that the combination of synthetic and phytochemicals have shown promising results on a laboratory scale. These combinations can be incorporated into not only conventional drug delivery techniques but also novel techniques like salt formation, co-crystal formation, nanocrystal formation or selfemulsification. Further research has to be carried out on the dosing and effectiveness on all possible combinations so that scale up can be done and finally the targeted combination can be marketed successfully. This study contains everything about the disease diabetes mellitus, its conventional therapies which are available in market including their limitations and how combination therapy between synthetic drugs and phytochemicals will play a significant role in the coming years in order to control diabetes mellitus.
\end{abstract}

Keywords: Diabetes, Combination therapy, Synergism, Phytochemicals 


\title{
COMPARISON OF REMOVAL OF CRYSTAL VIOLET ON PROCESSED AND UNPROCESSED, COST EFFECTIVE AGRO-WASTE, WHEAT BRAN
}

\section{PRAMA RANI, SUJATA DAS, SHALINI SINGH}

Department of Microbiology, School of Bioengineering and Biosciences, Lovely Professional University, Phagwara 144402, Punjab, India Email: sujata.dass@lpu.co.in

\begin{abstract}
In the present times the effluents released from the textile as well as pharmaceutical industries have been implicated to carry certain dyes which have been widely reported to cause carcinogenesis in the surrounding inhabitation. The present study was carried out with an ideology to suggest a physically effective, cheap, viable and above all, an eco friendly method capable of removal of such malicious dyes for the maintenance of the natural flora and fauna of the water bodies. The work was done taking into account, crystal violet (a commonly used dye in textile industry) and a readily available adsorbent falling in the category of agricultural waste such as wheat bran. The latter was used for the employment of a physical treatment methodology for removal of crystal violet from the artificial sample. The decolourization of crystal violet (dissolved in agricultural waste wheat bran) was studied regularly under various parameters as adsorption dosage, contact time, $\mathrm{pH}$, temperature etc on both treated and untreated wheat bran. It was seen that about $81 \%$ of decolourization of crystal violet was achieved at a concentration of $100 \mathrm{mg} / \mathrm{l}$ by the usage of minimal concentration of $2.5 \% \mathrm{w} / \mathrm{v}$ of processed wheat bran in comparison to an unprocessed one. The outcomes clearly fall in the Freundlich adsorption isotherm pattern indicating that the utilized adsorbent under study can be efficiently used as a preliminary treatment for effluent produced by the pharmaceutical or textile industries which can lead to an immense degree sludge reduction usually produced because of the chemical treatment methods employed.
\end{abstract}

Keywords: Effluents; Carcinogenesis; Adsorbent; Decolourization; Freundlich isotherm 


\title{
FOOD PACKAGING FORMULATION USING CHITOSAN IN CONJUGATION WITH A BIOLOGICAL ANTIMICROBIAL AGENT
}

\author{
ROHAN SACHAN, SUJATA DAS, SHALINI SINGH
}

School of Bioengineering and Biosciences, Lovely Professional University, Punjab, India-144411

Email: sujata.dass@lpu.co.in

\begin{abstract}
The carbohydrates, proteins, vitamins, minerals, as well as amino acids provide high biological values for human consumption. Food products of biological values provide home for many pathogenic as well as spoilage microorganisms, sometimes, the material used for food packaging also get contaminated by microorganisms which may lead to a physical and or a chemical spoilage of the food product. The environmental pollution issue has invoked the concept of utilization of biopolymers as a packaging material that can be isolated from various sources like plants, animals or microorganisms. Microorganisms, serve a better option for the purpose as can be easily manipulated for its production most importantly can be grown in mass. These bio-polymers can be of wide variety like chitosan, chitin, alginates, collagens, etc. Such bio-polymers, used as packaging materials, have also reported to exhibit antimicrobial property or can also be used in conjugation with an antimicrobial agent. Chitosan has proven to fall under such a category obtained from microbial cell wall mainly fungi in the form of chitin. Among the various groups of fungi Basidiomycetes has shown a appreciable zone of study for such a production. Chitin obtained from them can be deacetylated to chitosan and can be conjugates with any antimicrobial agent such as a bacteriocin produce by Lactobacillus genera such as to inhibit the growth of related food related contaminants. In this review the current status of the usage of chitosan alone or in conjugation with other antimicrobial agents for a safe, affordable and eco-friendly biological food packaging system are elaborated.
\end{abstract}

Keywords: Chitosan, Antimicrobial agents, Bacteriocins, Bio-polymers, Lactobacillus. 


\title{
A REVIEW: GENETIC ENGINEERING AND ITS MEDICAL APPLICATIONS
} IAYPRAKASH GUPTA*, GEETANJALI MEHRA, SAUMYA DARSHNA SHIKHA, RUPINDER KAUR, ANUPRIYA,
SHUBHAM SINGH, PARTIKSHIT THAKUR, ANKIT KUMAR YADAV, SACHIN KUMAR SINGH, AMIT MITTAL

School of Pharmaceutical Sciences, Lovely Professional University, Phagwara, Punjab- 144411, India. Email: jayprakashgupta261@gmail.com

\begin{abstract}
Genetic engineering is the science of manipulation of genes in the living organisms by the aid of biotechnology. It is mainly utilized to identify, alter and separate the genetic material of living organisms. Genes are the most important unit of any living organism which are responsible for their shape and size, physical and biological activities, behavior, reproduction, production of primary and secondary metabolites, intake and processing of nutrition and almost everything inside a living cells. To alter any of these activities, change in the gene sequence of a cells is the key and to bring genetic changes in an organism recombinant DNA technology is utilised. Genetic engineering has produced a wide range of medical application including recombinant DNA vaccines, drugs, transgenic plants and animals. Genetically engineered animals, microorganisms and plants can produce medically useful proteins, antibiotics and large amount of useful drugs for the treatment of life threatening diseases like cancer. Vaccines for hepatitis, herpes simplex virus, enzymes and hormones are also the products of genetic engineering. It also plays a major important role in the diagnosis of the disease and gene therapy to introduce functional genes for the replacement of defective genes. This technique can also be useful for the production of lymphokines (to regulate the immune system), somatostatin (drug used for certain growth abnormalities) and to increase blood clotting factor. Erythropoietin is an example of a genetically engineered hormone, which is used to stimulate the production of red blood cells in the patients of severe anemia. Genetically engineered interleukin-2, a substance that stimulate multiplication of lymphocytes, is useful for the AIDS patients and being currently used for the treatment. Genetic engineering has provided a tool to change many aspects of nature and could result in a techniques for treatment of life-threatening diseases. In future it can be further developed for the diagnosis and treatment of the diseases and to live a better \& a disease free life.
\end{abstract}

Keywords: Recombinant DNA technology, Vaccines, transgenic species, Erythropoietin 


\title{
COLON SPECIFIC DRUG DELIVERY SYSTEM (CSDDS) FOR THE TREATMENT OF RHEUMATOID ARTHRITIS (RA)
}

\author{
SHUBHAM KUMAR SINHA*, MAYUKH BANERJEE, ANKIT KUMAR YADAV, SACHIN KUMAR SINGH, AMIT MITTAL, BIMLESH KUMAR
}

School of Pharmaceutical Sciences, Lovely Professional University, Phagwara, Punjab-144411

Email: shubhamsinha03@gmail.com

\begin{abstract}
Rheumatoid arthritis (RA) is an autoimmune inflammatory disorder primarily associated with bones (synovial joint) but also affect many tissues and organs. This disorder is characterized by a proliferative synovitis leading to cartilage destruction and synovial hypertrophy, resulting in joint deformities and increasing functional limitations. According to the WHO arthritis report, more than $1 \%$ people globally suffer from rheumatoid arthritis. The incident rate is gradually increasing due to obesity, anxiety, fatigue, changes in lifestyle and aging. In past 20 -year of about 146,377 deaths were recorded globally due to arthritis. In India, about seven million people are affected by arthritis. Globally treatment of RA costs $\$ 5720$ per person every year. There are several treatments available for rheumatoid arthritis like Non-steroidal anti-inflammatory drugs (NSAIDs) which reduce the pain by reducing inflammation but do not affect the progression of rheumatoid arthritis. Disease-modifying antirheumatic drugs (DMARDs) is also recommended for those patients who have failed the use of single or combination of conventional DMARDs therapy. Colon specific drug delivery system (CSDDS) is a systemic way to deliver the drug into the specific part of the body so that the desired drug concentration can be achieved in time. Targeted drug delivery systems are preferred in drugs having instability, low solubility, low specificity, and low therapeutic index. In this, the drug is coated with the enteric coating material to resist the $\mathrm{pH}$ of the stomach and easily reaches the colon where it releases its drug during the rise of flair in the body at the middle of the night. It is a suitable way to deliver the drug by reducing side effect to release the drug into the body immediately during the flair of the pain in the middle of the night and stop the disturbance or inconvenience condition by the patients to their family.
\end{abstract}

Keywords: colon specific targeted drug delivery (CSDDS), rheumatoid arthritis (RA), drug modifying antirheumatic drugs (DMARDs), non-steroidal anti-inflammatory (NSAIDs). 


\title{
ADVANCEMENT IN NANOTECHNOLOGY AND ITS ROLE IN DRUG DELIVERY: A REVIEW GEETANIALI MEHRA*, JAYPRAKASH GUPTA, SAUMYA DARSHANA SHIKHA, RUPINDER KAUR, MAYUKH BANERJEE, ANKIT KUMAR YADAV, SACHIN KUMAR SINGH, AMIT MITTAL
}

School of Pharmaceutical Sciences, Lovely Professional University, Phagwara, Punjab-144411. Email: geetkashyap481@gmail.com

\begin{abstract}
Nanotechnology is the science of designing, characterization, production and application of materials, devices, systems at nanoscale within the range of 1-100 $\mathrm{nm}$. The science of designing of nano objects have multiple applications in various fields like communications, engineering, chemistry, physics, robotics, biology, and medicines. It has also been utilized in the analytical field known as Analytical Nanoscience and Nanotechnology (AN \& N). The size and configuration of nanomaterial makes them suitable for their use in drug delivery where targeted delivery of the therapeutics can be successfully achieved by functionalizing them. The most promising applications of nanotechnology is in the field of therapeutic drug delivery includes the development of nanoparticles of and drug loaded nanoparticles. The drug loaded nanoparticles can be designed in the form of micelles, dendrimers, quantum dots, carbon nanotubes, liposomes and other nano structures of natural and synthetic polymers. In the past few years various advanced drug delivery systems have been developed based on inorganic nanoparticles like metal nanoparticles and mesoporous silica systems, polymeric nanostructures like polymeric micelles and polymeric nanoparticles. The development of nano carriers for improved delivery of different oral hypoglycemic agents has shown greater efficacy over the increased blood glucose and enzymatic levels in a recent study. Although nanotechnology holds great promise for applications in medical sciences, it does have many inadequacies that result in a variety of risks and challenges. The potential hazards to the human body and environment associated with some nano carriers and their underlying mechanisms requires in-depth study. In the present study a systematic review of advanced nano carriers and their application in drug delivery has been conducted and concluded.
\end{abstract}

Keywords: Nanotechnology, nanocarriers, targeted drug delivery. 


\title{
ALLIED HEALTH PROFESSIONALS IN HEALTH SECTOR: AN OVERVIEW WITH EMPHASIS ON NEED OF REDEFINING INDIA'S HEALTH SERVICE PARADIGM
}

\section{VIKASH GAUR}

${ }^{1}$ Maulana Azad Medical College, New Delhi.Email: vikashgaur07@gmail.com

\begin{abstract}
Introduction- Health is defined by the World Health Organization (WHO) as a state of complete well-being, i.e. physical, mental and social wellbeing, and not merely the absence of disease. The US Department of Health and Human Services defines AHPs as 'experts in a multitude of therapeutic, diagnostic and preventive intervention. These professionals are leaders in the degree and blend of clinical and technical expertise. According to this definition, AHPs would include dental hygienists, diagnostic medical sonographers, dieticians, medical technologists, occupational therapists, physical therapists, radiographers, respiratory therapists, and speech language pathologists.

Indian Scenario- India's human resources for health are diverse and multi-faceted. They range from rigorously trained biomedical specialists and super-specialists to an assortment of community- and household-based healers. The wide variation in the understanding of the concept of allied health professional, better known as 'paramedic', the nomenclature, and functions has led to the poor image of allied health sciences. Despite a huge demand for services from this sector, the allied health sciences domain is highly fragmented. Currently, due to the absence of a central regulatory authority for AHPs and courses, they are divided into smaller groups, appearing to be 'regulated' by independent professional bodies at the national and state levels

Recommendations- For the allied health cadre to grow in the healthcare system, these professional associations need to be bound by a common authority that will help AHPs to flourish as a family rather than different classes within the community of the healthcare system. It is thus imperative to structure a taskforce which would play an important role in generating awareness and thereby improving the perception and image of allied health sciences. This taskforce should advocate for the important role played by AHPs and also highlight the advantages of all non-invasive and preparatory work done by them. Each level of education in the field should comply with University Grants Commission (UGC) norms. This is essential to promote a uniform level of education imparted across all institutes throughout the country. Therefore, it is recommended that a standard duration for each level of education.
\end{abstract}

Keywords- Health, Paramedic, Allied Health Professional, Health Care System 


\title{
CIRCULATION OF CONTAMINATED CURRENCY NOTES: A BIG THREAT AND PUBLIC HEALTH HAZARD
}

\section{ARMAAN KAUR BHAGTANA, ANANIA ARJUNA*}

Department of Medical Laboratory Sciences, Lovely Professional University, Phagwara, Punjab

Email: anania.arjuna@lpu.co.in

\begin{abstract}
Most exchangeable thing nowadays is paper currency. It is regularly subjected to contamination. The contaminated hands after using toilets, handling of infectious samples in hospitals, counting notes using saliva, placement of notes on dirty surfaces, leads to contamination. Microorganisms get attached on notes. These microbes can be pathogenic and non-pathogenic as well. Many studies have been done in different countries with different methods. The studies were done to check the micro-organisms load on the notes. The objective of study is to check the microbes on the currency notes found in hospital premises. The material and method I followed for this is: All the new and older currency notes were collected and the total number of notes collected were 40 . The persons handling the notes were asked to hold notes tightly from the edges. In the sterile conditions, the swabbing was done on both the sides of notes. These swabs were inoculated in the tryptic soy broth for 4 hours. The subculturing was done from the broth on to the tryptic soy agar plates and were incubated for 24 hours. The colonies were isolated and were checked by gram staining and other microbiological techniques. The result of my study shows there are all gram positive and gram negative bacteria with cocci, bacilli, coccobacilli shapes. The commonest microorganism found is Bacillus subtilis, Staphylococcus aureus, Escherichia coli etc. These all are pathogenic microbes and cause various kinds of infections. The result represents the risks and public health hazards. So, the currency notes must be handled with caution.
\end{abstract}

Keywords: Indian currency notes, pathogenic, non-pathogenic micro-organisms, contamination, health hazards 


\title{
INFLUENCE OF FORMULATION PARAMETERS ON DISSOLUTION RATE ENHANCEMENT OF ACYCLOVIR USING LIQUISOLID FORMULATION
}

\author{
KUBOTA MWAKA HAZEMBA*, SACHIN KUMAR SINGH, JIVAN JYOTI, RAKESH NARANG, BIMLESH KUMAR
}

School of Pharmaceutical Sciences, Lovely Professional University, Phagwara (Punjab)

Email: kubohazemba@gmail.com

\begin{abstract}
Liquisolid technique also called as powder solution technology involves improvement of solubility of poorly soluble drugs. Nowadays, many drugs with poor solubility tend to also have poor dissolution and bioavailability, are available in the market. Liquisolid technique is the most suitable and discussed technique in dealing with this problem. Drug, non volatile solvent, carrier material, coating material and disintegrant are the things involved in this technique. In liquisolid technique the final powder product is filled into capsules or compressed into tablets after drug, carrier and coating material are mixed with the non volatile solvent followed by addition of disintegrant. Liquisolid helps in transformation of liquid systems into solid drug delivery systems. Liquisolid technique also helps in formulating both immediate and sustained release types of drugs. In present study, a liquisolid system loaded with acyclovir was formulated and their solubility studies were carried out in various non-volatile liquids. It included pre formulation studies, characterisation, pre compression studies, and formulation of tablet, post compression studies, advantages, disadvantages and applications of liquisolid technique.
\end{abstract}

Keywords: Liquisolid, Acyclovir, bioavailability, dissolution, sustained release. 


\title{
POTENTIAL OF PLANT GROWTH-PROMOTING RHIZOBACTERIA (PGPR): AS ANTAGONISTS AND BIOCONTROL AGENTS
}

\author{
SIMRANIEET KAUR, JYOTI HANDA*, AND PALKI SAHIB KAUR
}

Department of Biotechnology, Chandigarh Group of Colleges, Landran Mohali.Email: jyoti.3722@cgc.edu.in

\begin{abstract}
With the increase in world population an immense pressure is created on the existing land area for food, fiber, fuel and raw materials. In order to meet the demands of the growing population in the country, utilization of improved plant varieties is necessary. Due to the adoption of agrochemicals and fertilizers along with the reduced availability of water for irrigation, the quality of the soil is depleting and the soil is becoming saline. This non-availability of good soil for agriculture affects the production of the crops (or food) worldwide. Therefore, there is requirement of different approaches that can ensure good yield of crop and protection while maintain long term ecology balance in agro-ecosystem. An important role is played by microorganisms to promoting the circulation of plant nutrients and reducing the need for chemical fertilizers as much as possible. PGPR strain inoculation at an early stages of development in crop plants expands biomass production with direct effects on roots and shoots growth leading to a more efficient use for biocontrol strategies to improve cropping systems. Also, Rhizobacteria belonging to the genera Pseudomonas and Bacillus are well known for their antagonistic effects.
\end{abstract}

Keywords: Plant growth promoting rhizobacteria; biomass; PGPR. 


\title{
EVALUATION OF ANTAGONISTIC POTENTIAL OF SOIL BACTERIA AGAINST PATHOGENIC FUNGUS: CANDIDA ALBICANS \\ SIMRANIEET KAUR, JYOTI HANDA*, AND PALKI SAHIB KAUR
}

Department of Biotechnology, Chandigarh Group of Colleges, Landran Mohali. Email : jyoti.3722@cgc.edu.in

\begin{abstract}
Bacteria are able to synthesize a wide range of metabolites with fungicidal capabilities. The antagonistic potential of soil bacterial species was assessed by the agar well diffusion assay against pathogenic fungus, i.e. Candida albicans causing candidiasis. The result indicated that bacterial strains exhibited varying degree of biocontrol potential against tested fungi. Among different bacterial cultures, a potent bacterial isolate isolated from soil sample was effective in inhibiting Candida albicans, with zone of inhibition of 18mm. Physiological, biochemical and $16 \mathrm{~S}$ rDNA gene sequence analysis strongly suggested that the isolate belonged to Bacillus sp.. Chloroform was the best extraction solvent for the isolation of the antimicrobial metabolite and MIC value of the antifungal metabolite was $1 \mathrm{mg} / \mathrm{ml}$. The experimental results exhibit the antifungal activity of bacterial species and indicate the possibility of using these bacterial species as mode of production of antifungal agents against the fungal species.
\end{abstract}

Key words: Soil bacteria, Biocontrol, Antagonistic Activity, MIC. 


\title{
DESIGN OF MICROPARTICULATED SALBUTAMOL SULPHATE PH SENSITIVE PULSATILE DELIVERY SYSTEM FOR CHRONOTHERAPY OF NOCTURNAL ASTHMA
}

\author{
SURESH PUROHIT ${ }^{2}$, BHUPENDRA SINGH ${ }^{1 *}$, GEETANJALI SAINI $^{1}{ }^{1}$, SURAJPAL VERMA $^{1}$, MANISH VYAS $^{1}$
}

${ }^{1}$ School pf pharmaceutical sciences, Lovely Professional University, Phagwara. ${ }^{2}$ IMS, Banaras Hindu University, Varanasi, Uttar Pradesh, India.Email: bhupendratomar81@gmail.com

\begin{abstract}
The purpose of this study was to prepare and evaluate $\mathrm{pH}$ dependent chronotherapeutic drug delivery of salbutamol using chitosan \& eudragit polymers. Chronotherapeutic microparticles were prepared in two steps, firstly core chitosan microparticles were prepared by using gluteraldehyde cross linking and entrapped within Eudragit S 100 and Eudragit L 100. The microparticles were spherical with size ranging from 50$100 \mu \mathrm{m}$. Core and coated microparticles were monodisperse (UI $<1.2$ ) and had wide size distribution (UI > 1.2). The Eudragit S-100 coated microparticle did not release the drug in acidic $\mathrm{pH}$ of the stomach, and the eudragit S-100 and L-100 coated microparticles showed burst release at pH 7.4 and at pH 5.8, indicating perfect pH sensitive pulsatile drug delivery.
\end{abstract}

Keywords: Chronotherapeutic, Chitosan, Eudragit, Uniformity Index, pH dependent, release kinetic. 